\title{
Performance and Evaluation of Gas-Engine- Driven Split-System Cooling Equipment at the Willow Grove Naval Air Station
}

\author{
P. R. Armstrong \\ J. R. Schmelzer
}

January 1997

Prepared for

the U.S. Department of Energy

Federal Energy Management Program

under Contract DE-AC06-76RLO 1830

Pacific Northwest National Laboratory

Richland, Washington 99352

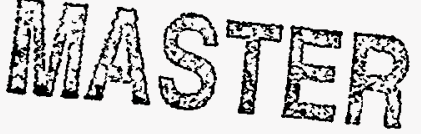




\section{DISCLAIMER}

Portions of this document may be illegible in electronic image products. Images are produced from the best available original document. 


\section{DISCLAIMER}

This report was prepared as an account of work sponsored by an agency of the United States Government. Neither the United States Government nor any agency thereof, nor any of their employees, make any warranty, express or implied, or assumes any legal liability or responsibility for the accuracy, completeness, or usefulness of any information, apparatus, product, or process disclosed, or represents that its use would not infringe privately owned rights. Reference herein to any specific commercial product, process, or service by trade name, trademark, manufacturer, or otherwise does not necessarily constitute or imply its endorsement, recommendation, or favoring by the United States Government or any agency thereof. The views and opinions of authors expressed herein do not necessarily state or reflect those of the United States Government or any agency thereof. 


\section{Preface}

The federal government is the largest single energy consumer in the United States with consumption of nearly 1.5 quads/yr $\left(1\right.$ quad $\left.=10^{15} \mathrm{Btu}\right)$ and cost valued at nearly $\$ 10$ billion annually. The U.S. Department of Energy's (DOE) Federal Energy Management Program (FEMP) supports efforts to reduce energy use and associated expenditures within the federal sector. One such effort, the New Technology Demonstration Program (formerly the Test Bed Demonstration Program), seeks to evaluate new energy saving U.S. technologies and secure their more timely adoption by the federal government.

Through the results of the New Technology Demonstration Program (NTDP), a federal energy manager can receive unbiased guidance and performance data with which to evaluate the applicability of a new technology to a particular facility. Energy saving technologies regularly emerge in the marketplace. This program seeks to identify those technologies, determine which have the broadest application for the federal sector, and then shorten the deployment time for those that prove beneficial to the federal market. NTDP evaluations are conducted by DOE laboratories with support from FEMP and the U.S. Department of Defense (DoD) Strategic Environmental Research and Development Program (SERDP), but other essential program elements-tech transfer, demonstration site support, utility-type metering, and the new equipment itself-are paid for by other interested parties under Cooperative Research and Development Agreements (CRADAs). Pacific Northwest National Laboratory $^{(a)}$ is one of four DOE national multiprogram laboratories ${ }^{(b)}$ that manage and participate in the NTDP by providing technical expertise and intrumentation to evaluate new, energy saving technologies being evaluated under the program.

One of the first NTDP CRADAs was signed in 1992 to evaluate two gas-engine-driven rooftop cooling units at the Naval Air Station in Willow Grove, Pennsylvania. An interim report describing the performance and reliable operation of the technology was distributed in May 1993 and reported at the 1994 ACEEE Summer Study. In September 1996, a final report was issued on the technology. The CRADA was extended to demonstrate a more flexible implementation of the technology-a 15-ton gas-engine-driven condensing unit-shortly after it was introduced by Thermo King and Trico Energy in 1993.

This report describes a field evaluation that PNNL conducted to examine the performance of a new energy-saving technology-a 15-ton natural-gas-engine-driven, split-system, air-conditioning unit. The unit was installed at a multiple-use building at Willow Grove Naval Air Station (NASWG), a regular

(a) Pacific Northwest National Laboratory is operated for the U.S. Department of Energy by Battelle under Contract DE-AC06-76RLO 1830.

(b) The others being Lawrence Berkeley National Laboratory (LBNL), National Renewable Energy Laboratory (NREL), and Oak Ridge National Laboratory (ORNL). 
and reserve training facility located north of Philadelphia, Pennsylvania, and its performance was monitored under the NTDP. Participating in this effort under a CRADA were Thermo King Corporation, the manufacturer; PECO Energy, the local utility; NASWG; the American Gas Cooling Center (AGCC); and PNNL.

During the 2-year period in which this gas-cooling technology was being evaluated at Willow Grove, Thermo King decided to sell its stationary air-conditioning assets to Trico Energy in order to focus on its primary markets in mobile air conditioning. As of November 1996, Trico Energy continues to produce equipment using Thermo King compressors and Hercules engines, as well as to develop new gas-cooling designs. 


\section{Executive Summary}

Through a Cooperative Research and Development Agreement (CRADA), the U.S. Department of Energy Federal Energy Management Program (FEMP), Pacific Northwest National Laboratory (PNNL), the American Gas Cooling Center, PECO Energy, Thermo King Corporation (TK), and the Naval Air Station at Willow Grove (NASWG) have evaluated the performance of a new U.S. cooling technology that has been installed for the first time at a federal facility.

The cooling technology selected for study by the New Technology Demonstration Program is a 15ton natural-gas-engine-driven condenser unit manufactured by Thermo King Corporation. The equipment consists of a 31-hp natural-gas-fired engine coupled to a four cylinder refrigeration compressor and a 42-inch condenser fan which draws air through condenser, subcooler and radiator coils with respective net face areas of $24.4,4.2$, and 4.2 square feet. The unit is factory assembled, and charged with R-22 (an HCFC refrigerant), and requires single point connections of electrical power (for controls and starting battery), natural gas, and refrigerant liquid and vapor lines. The unit's cooling capacity is 182,000 Btuh at ARI Standard 360 rating conditions. Variable engine speed allows for cooling operation in four stages to match a range of load conditions.

The Thermo King unit serves an 8,000-square-foot portion of a multi-use building at NASWG that includes offices, a library, and class rooms. To evaluate the new technology, the building, the fan-coil unit, and the new gas-engine-driven condenser unit were instrumented and monitored.

Data collected during the demonstration included outdoor temperature, wind, and solar radiation, indoor temperature and humidity, gas and electric consumption of the equipment, refrigerant pressures and temperatures, and operating times associated with each of the four capacity stages of the unit. The measurements, averaged over and recorded at the end of each 15-minute scan interval, were used to evaluate performance and energy use and to diagnose operational problems.

The relation between cooling load and ambient temperature and the relation between coefficient of performance (COP = cooling effect/input energy) and load were characterized based on the recorded data. A number of problems associated with the operation of the equipment, and possible solutions, were also identified.

The cooling capacity of the unit is varied to meet load by changing engine/compressor shaft speed to operate in one of four cooling stages designated $\mathrm{C1}$ through $\mathrm{C4}$. The nominal (ARI conditions) capacities are 99,000 Btuh in C1, 124,000 Btuh in C2, 149,000 Btuh in C3, and 182,000 Btuh in C4. Deviations of capacity measured under actual operating conditions from nominal capacity were typical of field-monitored, air-cooled DX equipment, ranging from $+29 \%$ in $\mathrm{C} 1$ to $-4 \%$ in $\mathrm{C} 4$.

The COP was computed from air-side sensible and latent loads and gas input energy rate. COP was relatively constant in each cooling stage, averaging 0.66 in $\mathrm{C} 1$ and $\mathrm{C} 2,0.62$ in $\mathrm{C} 3$, and 0.54 in C4. 
The measured COPs were compared to the COPs quoted by Thermo King (TK 1993, p. 21). The C1 COP was $19 \%$ lower than the quoted value, and the $C 2$ through $C 4$ COPs were within $2 \%$ of the quoted values.

The seasonal COP is, in simplest terms, the sum of the part-load COP and part-load operating time products divided by the total operating time. The seasonal COP was almost $20 \%$ less than the integrated part-load value (IPLV) quoted, due to poorer than expected performance in $\mathrm{C} 1$ and excessive cycling to higher cooling stages. The unit consumed $43 \mathrm{MBtu}$ (HHV) of natural gas and provided $26 \mathrm{MBtu}$ of cooling effect during the 20-day monitoring/analysis period. It is expected to consume 370 MBtu of gas and provide $225 \mathrm{MBtu}$ of cooling in a normal cooling season. The unit will use about the same amount of source energy ${ }^{(a)}$ for cooling as a comparable electric-powered unit.

The new and unique nature of the equipment required extra care and support from experienced local service people. However, the added cost, in terms of lost performance, was relatively minor. There was only one equipment failure-the result of an engine oil leak. The refrigeration leak that was reported and repaired in June occurred at the connection to a pressure transducer used for monitoring, which is not a normal part of the condensing unit. Service for this installation will probably not be a problem in future years because the local service people are now familiar with the new technology. The growing market penetration that is currently underway nationally should ensure the availability of qualified local service in the future.

The annual energy cost for cooling, based on the loads and performance measured during the 20day monitoring period and weather normalized to the full cooling season in a normal year, is $\$ 1,225$. The annual energy costs to operate the compressor and condenser fan in a comparable electric-powered unit would be $\$ 520$ in energy charges and $\$ 7,190$ in demand and ratchet charges. Maintenance of the TK unit is expected to cost about $\$ 200 / y r$ more than the maintenance of a comparable electric-powered unit. The net savings for the gas-engine-driven unit is the difference between the present value of savings, $\$ 76,791$, and the increased total investment of $\$ 12,090$. This gives a net LCC savings, expressed as a present value, of $\$ 61,921$. The savings-to-investment ratio is 5.12 .

Analysis of 240 federal sites indicates that the new technology is life-cycle cost-effective at sites representing about $6 \%$ of the installed federal-sector cooling capacity and over 5\% of the aggregate annual cooling load. Assuming that gas-engine-driven cooling equipment with performance and price characteristics similar to the 15-ton condenser unit is made available in a range of sizes (2 to 2,000 tons) and configurations (chillers, split systems, package units), the aggregate potential NPV is over $\$ 100$ million. Full federal-sector penetration of the technology would result in about $396,000 \mathrm{MWh} / \mathrm{yr}$ of electric energy use being displaced by $5,628,000 \mathrm{MBtu} / \mathrm{yr}$ of natural gas consumption. These

(a) Source energy is defined here as the energy input to the power plant in the case of electricity, or the energy input to the regional gas transmission system in the case of natural gas, to provide a given amount of energy at the customer's meter. By this definition, source energy includes transmission and distribution losses and generation losses, but does not include energy input required for fuel extraction, processing, and transportation to get the fuel to the region. 
numbers can be extrapolated to the entire stock of federally owned buildings if it is assumed that the distributions of building type, installed cooling capacity, climate, and utility rates for the entire federal sector are well represented by the 240 military sites. For the entire federally owned building stock, the potential NPV and energy savings are about twice as large.

The analysis shows the technology to be generally cost-effective with respect to electric-powered cooling equipment only in areas where gas is cheap and.electric rates and cooling loads result in present-value operating costs for the electric alternative that are at least twice the first cost of conventional electric cooling equipment. This present-value breakeven point will be reduced by the amount of any utility rebate that is given.

For preliminary feasibility assessment in a typical hot climate (2,000 full-load-equivalent (FLE) $\mathrm{hr} / \mathrm{yr}$ of cooling plant operation), the marginal electric cooling cost (per MBtu at the meter) must exceed the gas cost (per MBtu at the meter) by a factor of four plus an adder of $\$ 13 / \mathrm{MBtu}$. For year around cooling (3,000 FLE $\mathrm{hr} / \mathrm{yr})$, the adder is $\$ 8.5 / \mathrm{MBtu}$, and for a milder climate $(1,500 \mathrm{FLE} \mathrm{hr} / \mathrm{yr})$ it is $\$ 17 / \mathrm{MBtu}$. In this type of analysis, the adder is reduced by the electric fuel price equivalent of any utility incentive that is given. In assessing cooling technologies, it is important to remember that estimates of FLE are based on gross simplifying assumptions about building balance point and peak load; a model that accounts for building and occupancy-specific characteristics, such as the ASEAM or FEDS computer programs, is preferred for building-specific feasibility assessment. 


\section{Acknowledgments}

The authors wish to acknowledge the participation, review, comments, and support provided to this project by the CRADA participants and others associated with the project. These include $\mathrm{K}$. Dean DeVine (now retired), Federal Energy Management Program; Commander Mike Strand and Jim Edmond, NASWG; Bob Ellis, Trico Energy; Chuck Karr, Thermo King; Terry Falvey, Northern Division, NAVFAC; Jack Flanigan, Greg Byrd, Robert McNulty, and Jim Verna, PECO Energy; and Rich Sweetser, AGCC. 


\section{Contents}

Preface $\ldots \ldots \ldots \ldots \ldots \ldots \ldots \ldots \ldots \ldots \ldots \ldots \ldots \ldots \ldots \ldots \ldots \ldots \ldots \ldots$

Executive Summary $\ldots \ldots \ldots \ldots \ldots \ldots \ldots \ldots \ldots \ldots \ldots \ldots \ldots$

Acknowledgments $\ldots \ldots \ldots \ldots \ldots \ldots \ldots \ldots \ldots \ldots \ldots \ldots \ldots \ldots \ldots$ ix

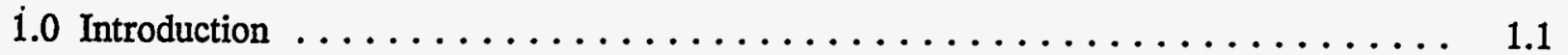

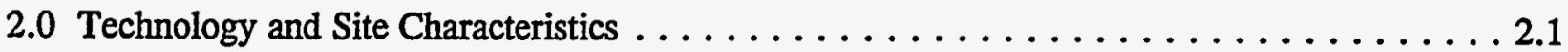

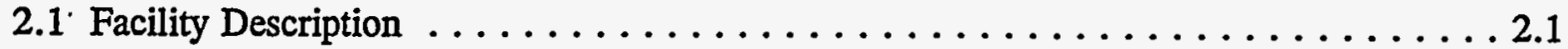

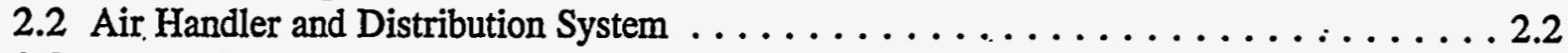

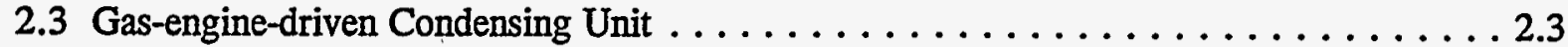

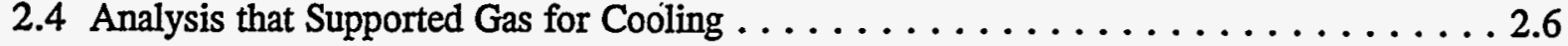

2.5 Technology Assessment Methodology $\ldots \ldots \ldots \ldots \ldots \ldots \ldots \ldots \ldots \ldots$

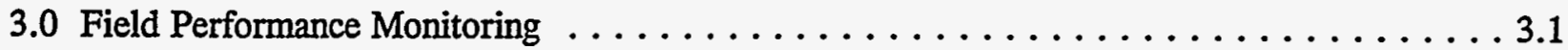

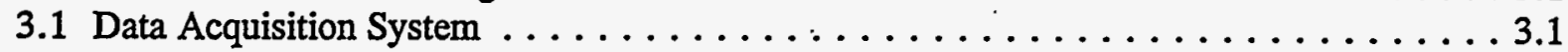

3.2 Measurements for Field Performance Evaluation $\ldots \ldots \ldots \ldots \ldots \ldots \ldots \ldots$

4.0 Observed Performance and Operation $\ldots \ldots \ldots \ldots \ldots \ldots \ldots \ldots \ldots \ldots \ldots \ldots \ldots$

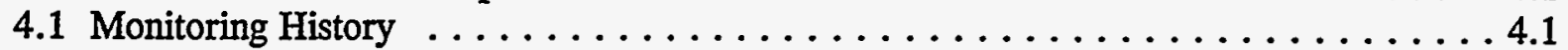

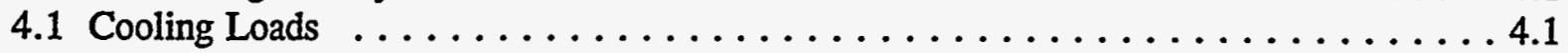

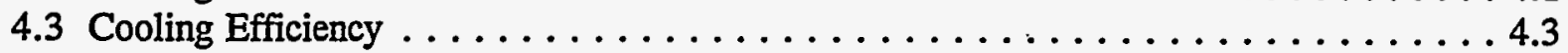

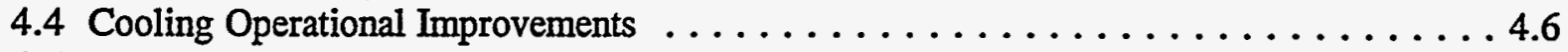

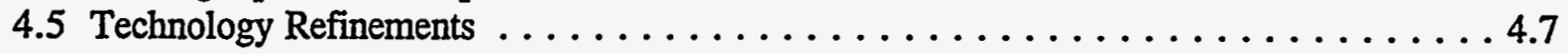

5.0 Annual Performance and Life-Cycle Cost $\ldots \ldots \ldots \ldots \ldots \ldots \ldots \ldots \ldots \ldots \ldots$

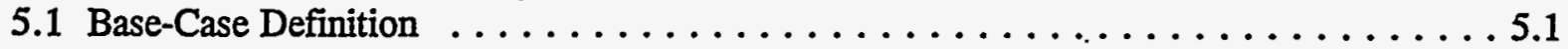

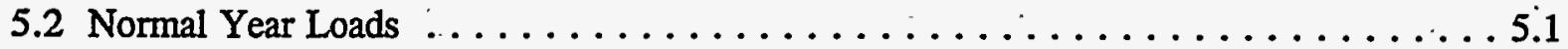

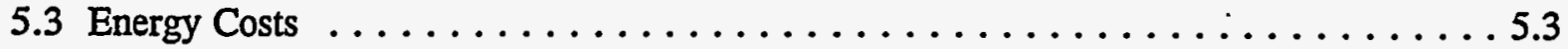

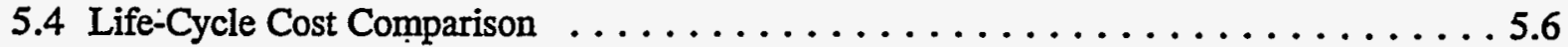

6.0 Conclusions and Recommendations $\ldots \ldots \ldots \ldots \ldots \ldots \ldots \ldots \ldots \ldots \ldots \ldots \ldots \ldots \ldots$

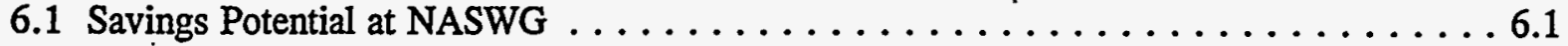

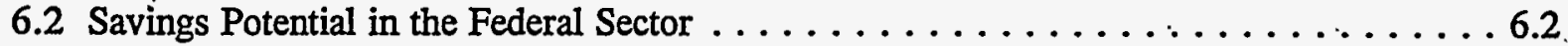

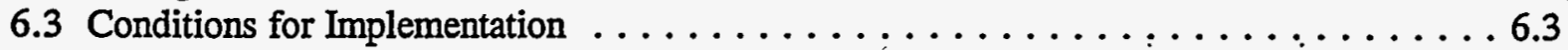

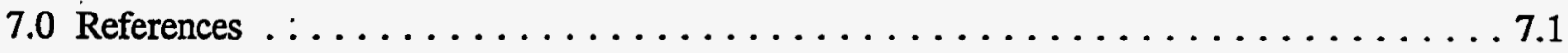

Appendix A - Summary of Activity Leading to the Cooperative R\&D Agreement and the

Joint Statement of Work . . . . . . . . . . . . . . . . A.1

Appendix B - Glossary of Terms and Abbreviations $\ldots \ldots \ldots \ldots \ldots \ldots \ldots \ldots \ldots \ldots$

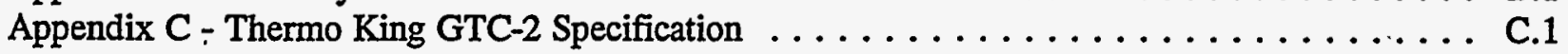




\section{Figures}

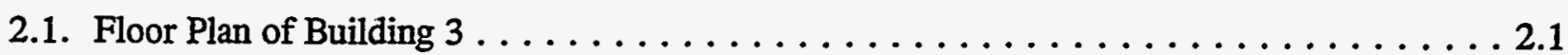

2.2. Condensing Unit and the Middle Wing of Building 3 from the South $\ldots \ldots \ldots \ldots . . \ldots 2$

2.3. Cut-Away View of the Thermo King Condensing Unit $\ldots \ldots \ldots \ldots \ldots$

2.4. Thermo King Condensing Unit: View from the South $\ldots \ldots \ldots \ldots \ldots$

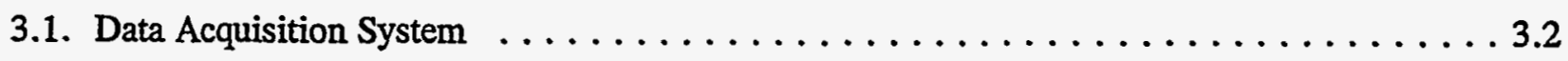

3.2. Location of Thermostat Controls in Relation to TK Unit and Air Distribution Systems . . . . 3.4

3.3. Sensor Locations in Zone and Air-Side Loop $\ldots \ldots \ldots \ldots \ldots \ldots$

3.4. Sensor Locations in Refrigerant Loop $\ldots \ldots \ldots \ldots \ldots \ldots \ldots \ldots \ldots \ldots \ldots \ldots \ldots$

4.1. Cooling Stage as a Function of Time $\ldots \ldots \ldots \ldots \ldots \ldots \ldots \ldots \ldots \ldots \ldots \ldots$

4.2. Daily Average Fuel Input and Temperature as a Function of Time $\ldots \ldots \ldots \ldots . \ldots . \ldots 4$

4.3. Relation Between Daily Gas Loads and Ambient Temperature . . . . . . . . . . 4.3

4.4. Daily Gas Loads for the Navy Exchange and Building $3 \ldots \ldots \ldots \ldots$

4.5. AHU-Temperature-Normalized COPs for All Observed Conditions . . . . . . . . . 4.4

5.1. Comparison of Normal-Year and 1994 Ambient Temperature Distributions . . . . . . . . 5.3

5.2. Energy Requirements for Electric and Natural Gas Alternatives $\ldots \ldots \ldots \ldots$

5.3. Monthly Energy Costs for Electric and Natural Gas Alternatives . . . . . . . . . 5.5

5.4. Distribution of Monthly Energy Costs for the Electric Alternative $\ldots \ldots \ldots \ldots$

6.1. LCC-Effectiveness Thresholds for the Gas-Cooling Technology Based on the REEP Data for 240 Military Sites 


\section{Tables}

2.1. Capacity and Related Operating Parameters $\ldots \ldots \ldots \ldots \ldots \ldots \ldots$

2.2. Life-Cycle Cost Comparison of Gas and Electric-Powered Cooling of the Navy Exchange . 2.6

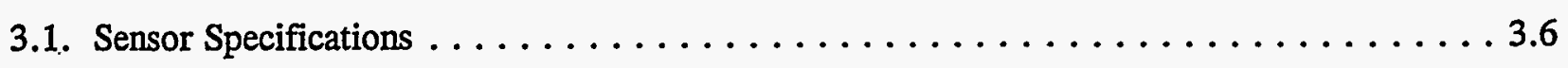

4.1. Measured Versus Rated COPs $\ldots \ldots \ldots \ldots \ldots \ldots \ldots \ldots \ldots \ldots \ldots \ldots \ldots \ldots \ldots \ldots \ldots$

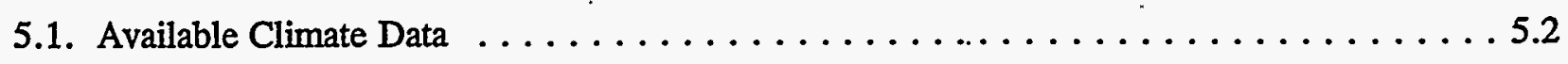

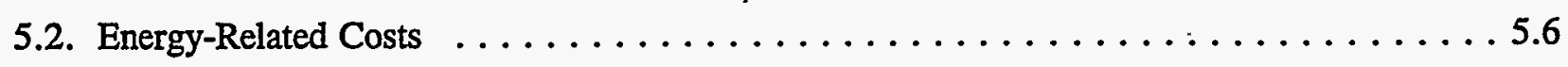

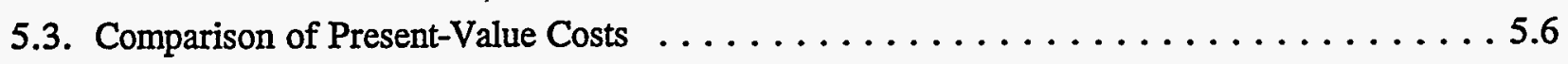




\subsection{Introduction}

The purpose of the New Technology Demonstration Program (formerly the Test Bed Demonstration Program) is to accelerate the deployment of advanced energy technologies through government and private-sector partnerships that install new technologies and evaluate their performance in the federal sector. Through the results of a new technology demonstration, federal agency decision makers have more "hands on" information with which to validate a decision to utilize that technology in their facilities. Energy saving technologies emerge regularly in the marketplace. This program seeks to identify those technologies, determine which have the broadest application for the federal sector, and then shorten the deployment time for those that prove beneficial to the federal market.

Beginning in 1989 activities were initiated to develop a demonstration program that could facilitate the introduction of new technologies into the federal sector. The first major program activity was to develop the overall concept and description of the program. Four concurrent activities were then undertaken, including development of the criteria for interagency and cooperative agreements. Another of those concurrent activities was to identify candidate technologies for new technology demonstrations. This was done through a series of meetings with government and industry representatives. A number of technologies were originally suggested and the scope of these options was narrowed through these discussions. Specific criteria associated with energy, cost, and environmental challenges in the federal sector were also identified.

Based on discussions and meetings with Department of Defense (DoD) officials, five technology alternatives were identified and ranked. The technology receiving the highest ranking was natural-gasengine-driven chillers. The reasons for this decision were the clean air aspects of the technology; potential energy savings; and potential cost savings. No limitation on equipment size was specified. Through selection of a target technology the groundwork for the first (pilot) new technology demonstration project was complete.

A solicitation of interested parties to participate in this first new technology demonstration project was made available in mid-1991 to utilities and manufacturers. The solicitation explained the purposes of the program and highlighted the benefits to be derived from such a public- and private-sector partnership. A search was undertaken to identify a federal site that was within the service area of the responding utilities, had a facility infrastructure that was broadly representative of the federal sector, and a building that was appropriate for the technology:

In early 1992, during the course of the search, the interest of some utilities and manufacturers changed and they could no longer consider participation. This left three manufacturers and three utilities still interested in participating in the first test demonstration. PECO Energy identified a federal site that had installed equipment from one of the three manufacturers that remained interested. The other two utilities also identified candidate sites, but these were found unsatisfactory. One was a postal facility where the priyate-sector building owner did not feel the subject equipment size was appropriate for the building. The other, a presidential library, would not have been ready for test initiation by the 
summer of 1992. Another possibility in Philadelphia was considered but found unsuitable due to the historic nature of the subject structure and its inability to accommodate the equipment. Although additional search efforts could have been undertaken to identify another federal site, the site proposed by PECO Energy was determined to be most appropriate to serve as the first project under the New Technology Demonstration Program. This decision was driven in large part by time, considering the desire to have the equipment installed and operational for evaluation during the summer of 1992 .

The site selected for the first FEMP new technology demonstration was the Naval Air Station in Willow Grove (NASWG), Pennsylvania. The building selected for application of the gas-engine-driven air-conditioning technology was a retail facility known to its customers as the Navy Exchange (NEX). The equipment installed was Thermo King (TK) natural-gas-engine-driven rooftop heating and air-conditioning equipment as submitted by Thermo King in their response to the solicitation. Two 15-ton units were installed on the roof to supply the heating and cooling to approximately $12,500 \mathrm{ft}^{2}$ of the $16,000-\mathrm{ft}^{2}$ structure. These units were already installed in the building, having been the first such sales in the federal sector. Other organizations responding to the solicitation and participating in the project were PECO Energy and the American Gas Cooling Center. Together with DOE these organizations were interested in forming a partnership to determine how the equipment would perform in the federal sector.

These organizations agreed to participate in the demonstration under the terms of a Cooperative Research and Development Agreement (CRADA) and a Joint Statement of Work (JSOW). The CRADA and JSOW documents formalize the partnership by which each organization sponsors and participates in the monitoring and evaluation of the performance of the Thermo King equipment. A key concept and portion of these documents addresses the in-kind services which each organization brought to the project. Rather than DOE supporting the entire project, each organization supported certain specific project activities. This resulted in the cost and value of the project being shared by DOE and the other four participants.

In 1992/93, two gas-engine-driven rooftop units were monitored and the favorable economics of the technology were demonstrated in the NASWG application. Then, in 1993, TK introduced a second gas-engine-driven ${ }^{(a)}$ cooling product in the form of a 15-ton condenser/compressor unit. The parties to the original CRADA agreed to extend the demonstration to include an application of the new product at NASWG.

The gas-engine-driven condenser unit was installed at the site in December 1993, and field monitoring instruments were installed in January 1994.

(a) The terms "gas-powered" and "gas-engine-driven" are used interchangeably in this report to refer the TK air-conditioning units. Note, however, that "gas-powered" equipment generally includes a variety of technologies, including gas-fired absorption machines and gas-fired desiccant cooling technologies. 
Beginning in early May 1994 operating data were logged by the DAS every 15 minutes and the logged data were downloaded daily to computer systems at PNNL for analysis. During the test period, and under the terms of the CRADA, Thermo King provided service and maintenance at no cost to NASWG.

The purpose of this report is to present the information gathered during the entire testing period at NASWG. The technology, the host facility, and the application-related equipment are described in Section 2.0. The system for monitoring equipment performance in the field is described in Section 3.0, and Section 4.0 presents the observations and analysis results for the monitoring period. Normal year performance is estimated from the measured performance results in Section 5.0, and a life-cycle cost analysis is presented. Section 6.0 concludes the site-specific analysis with general observations and recommendations derived from the activity at NASWG. References are.included in Séction 7.0. Appendix A summarizes the CRADA and joint statement of work development histories. Terms and abbreviations are defined in Appendix B. 


\subsection{Technology and Site Characteristics}

The gas-engine-driven cooling technology evaluated in this project represents the first extension of the Thermo King gas-engine-driven, direct-expansion cooling product line. The GTC-1 is a rooftop unit that was introduced in 1992 with the production of about ten 15-ton units. The GTC-2 is a . condensing unit, designed for split system applications, ${ }^{(a)}$ that was introduced in 1993. The condensing unit has broader application than the roof-top unit because it can serve multiple loads and because it can be used in applications where space or location constraints force the condenser and evaporator to be separated. Location constraints were the problem for the Willow Grove facility used in this demonstration: the building's roof structure could not support a large rooftop unit. Building 3 is a wood frame structure, built on a raised concrete floor deck, that has been extensively renovated with exterior insulation, new roofing and windows, new plumbing and wiring, and new suspended ceilings and interior partitions and finish. Building 3 had no air conditioning prior to the 1993 renovation.

\subsection{Facility Description}

Building 3 is a $15,000-\mathrm{ft}^{2}$ single-story frame structure built in 1942. The building layout-a main section with three wings extending to the southwest-is ideal for its current occupancy, which includes four distinct functions. The west-most wing is a day-care facility, the east-most wing is a youth programs facility, the central part of the main section contains a library, and the middle wing contains offices that are usually occupied Wednesday through Sunday and a large classroom used on reserve training weekends. Figure 2.1 shows the overall building layout, and Figure 2.2 shows a south elevation of the middle wing with the new condensing unit installed near the classroom entrance.

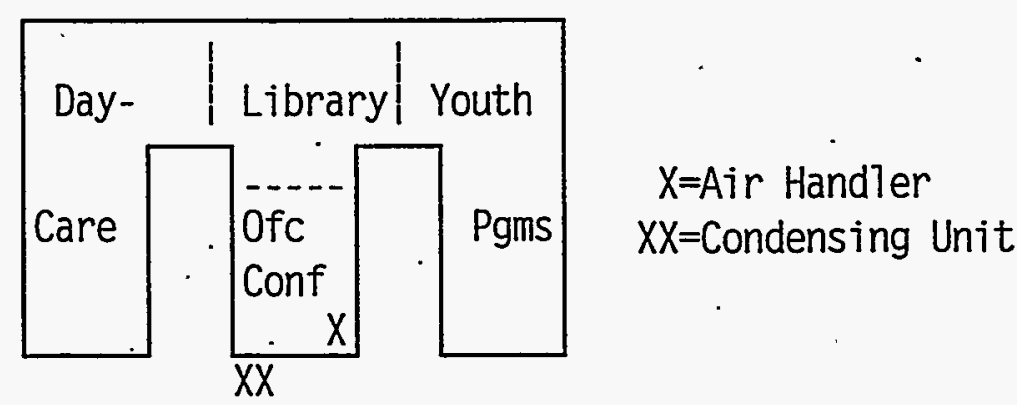

Figure 2.1. Floor Plan of Building $3^{\circ}$

(a) A "split system" is an air-conditioning system that consists of an outdoor condensing unit and an indoor evaporator coil. The term "condensing unit" is somewhat misleading because the main cost is in the compressor - the condensing coil just happens to be the most visible part. The gas-enginedriven condensing unit contains an engine-driven compressor in place of the motor-driven compressor of a conventional condensing unit and is about $25 \%$ larger in volume and weight. 


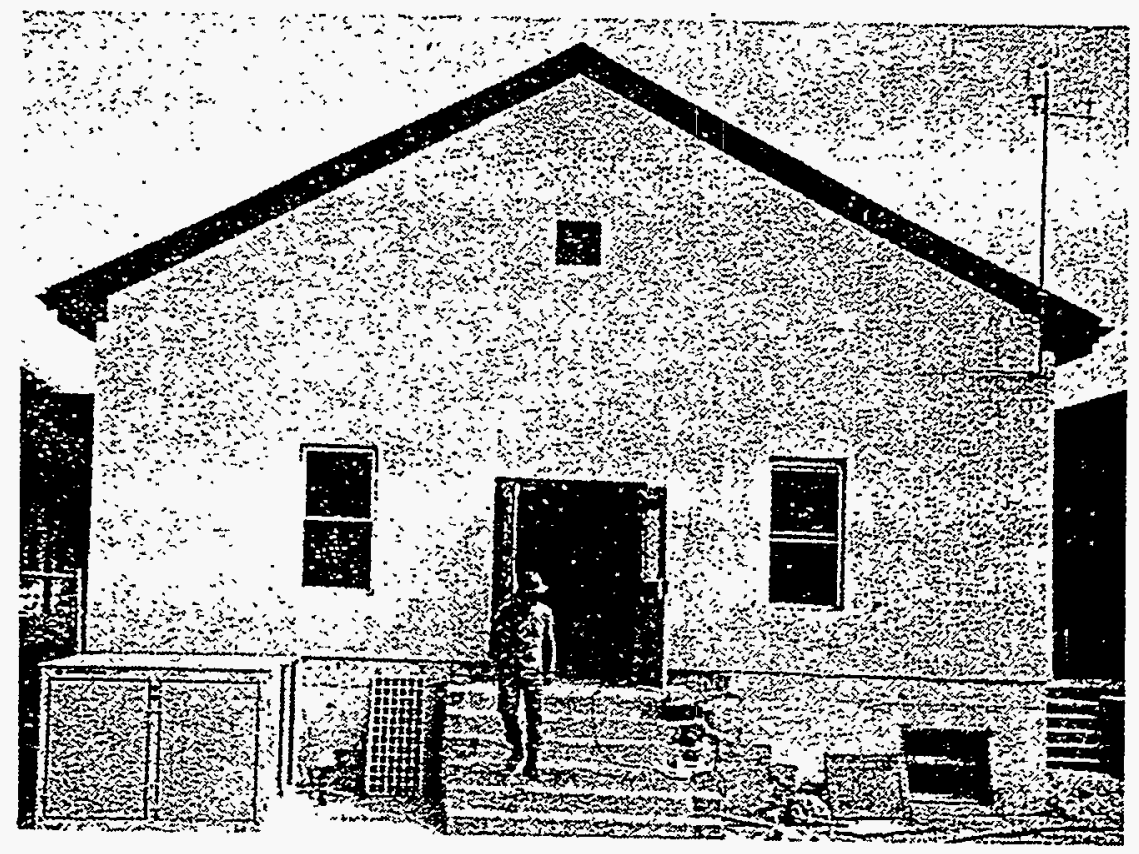

Figure 2.2. Condensing Unit and the Middle Wing of Building 3 from the South

The structure was insulated, during renovation, with exterior expanded styrene foam board and synthetic stucco. Air distribution ducts were installed in the attic and flex duct branches come down through the new ceiling plenum to registers located in the new suspended ceiling. The ceiling plenum is also used as a return air path to the air handler, which is located in a small mechanical closet in the south corner of the classroom. The three exposed walls of the central wing.have windows accounting for about $15 \%$ of the exterior wall area.

The portion of Building 3 served by the new condensing unit is occupied on most weekdays and training (usually alternate) weekends. The average number of weekday occupants is estimated to be 6 and the classroom has a capacity of about 30 . Lighting is provided by fluorescent fixtures in the suspended ceiling. The classroom fluorescent lights are supplemented by recessed incandescent fixtures around the ceiling perimeter. Heat is provided by perimeter hydronic finned tube.

\subsection{Air Handler and Distribution System}

The air handler is a fan-coil package of conventional design consisting of a filter/coil section followed by a fan/blower section. The unit weighs $500 \mathrm{lbm}$, has a $32 \times 60$ inch footprint and 72 inch height and is oriented for upflow operation in Building 3. 
Supply Fan. A belt-driven centrifugal blower provides a nominal supply airflow rate of $6000 \mathrm{cfm}$. A 208-volt, 3-phase, 3-hp, 1,750 rpm motor with an adjustable drive sheave powering the blower. The air-side design is typical of small air handlers in not incorporating a return fan, an economizer, or an exhaust air path.

Direct Expansion Coil. Refrigerant enters the enclosure via a 0.625 -inch liquid line and leaves via a 1.625-inch suction line. A 3-row coil with face area of $16.5 \mathrm{ft}^{2}$ and fin spacing of 13/inch carries the refrigerant in 0.375 -inch tubes. Two 7.5-ton thermostatic expansion valves (Y818-XVE-GA) regulate the refrigerant flow into the coil. The condensate pan drains through the floor and crawl space to the parking lot.

Filters. Six $20 \times 25 \times 1$ inch panel filters are arranged A-frame fashion in the return air plenum just upstream of the coil. The return air inlet measures $55 \times 30$ inches in cross-section. The air handler closet is open to the ceiling plenum in order to provide a return air path.

Air Distribution. The $30 \times 30$ inch supply air duct rises vertically from the blower outlet end of the air handler, up through the return air ceiling plenum and into the attic. The duct then runs north over the classroom, offices, and bathrooms, and terminates over the library. Ceiling diffusers are supplied from the main distribution duct by flex-duct branches that come down through the attic floor and ceiling plenum to the $2 \times 2$ foot diffuser panels that are supported in the suspended ceiling grid.

\subsection{Gas-Engine-Driven Condensing Unit}

The new technology is designed as a direct replacement for conventional single-zone, electricpowered condensing units. Each unit is factory assembled, charged with R-22 (an HCFC refrigerant), and requires single-point connections of electrical power, refrigerant liquid and suction lines, and natural gas. Maximum cooling capacity is 182,000 Btuh at ARI Standard 360 (ANSI/ARI 1986) rating conditions. A cutaway view of the unit, showing the main mechanical components, appears in Figure 2.3. 


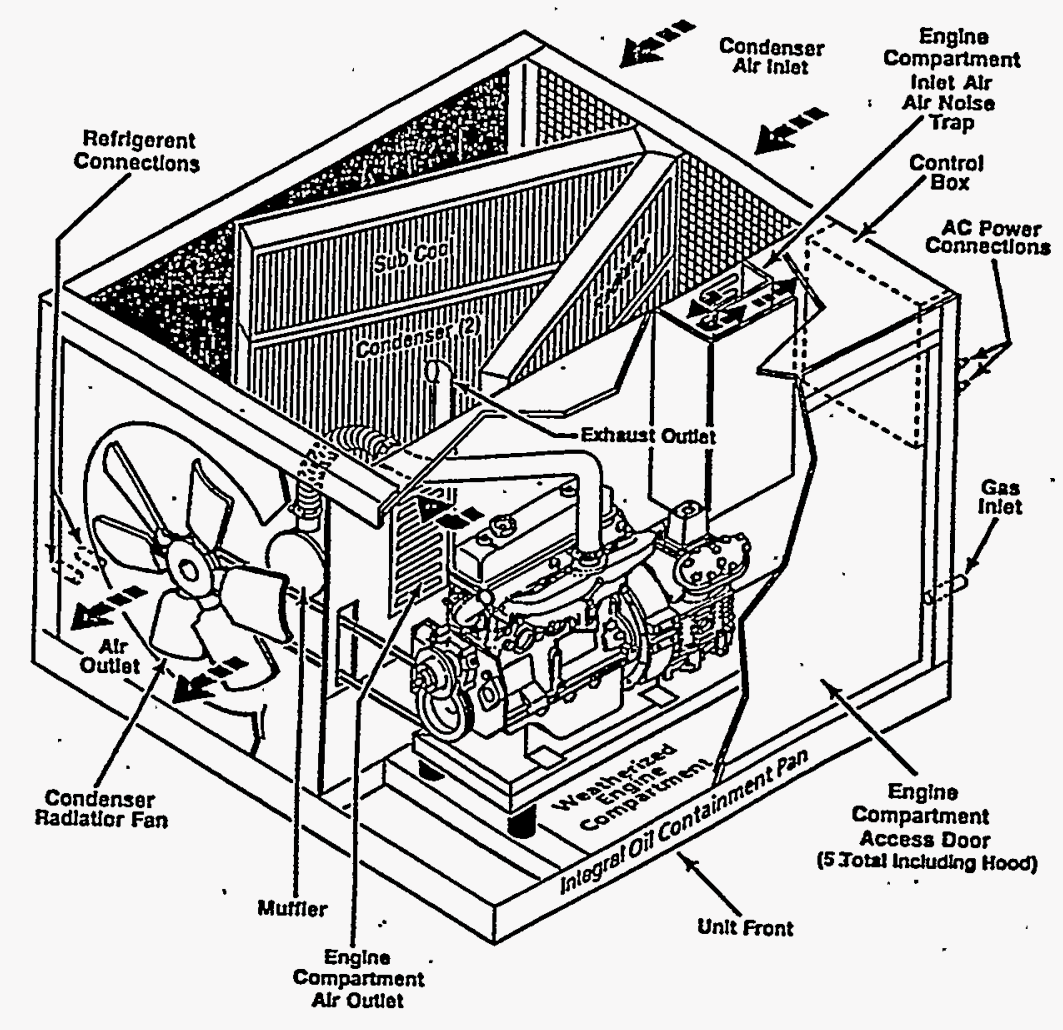

Figure 2.3. Cut-Away View of the Thermo King Condensing Unit

Cooling operation in four stages is effected by variable engine speed control as indicated in Table 2.1. The cooling stage parameters for the GTC-1 are also shown for comparison.

Table 2.1. Capacity and Related Operating Parameters

\begin{tabular}{|c|c|c|c|c|}
\hline \multirow{2}{*}{ Stage } & \multicolumn{2}{|c|}{ GTC-2 } & \multicolumn{2}{c|}{ GTC-1 } \\
\cline { 2 - 5 } & $\begin{array}{c}\text { Capacity } \\
\text { (kBtu/h) }\end{array}$ & $\begin{array}{c}\text { Engine Speed } \\
\text { (rpm) }\end{array}$ & $\begin{array}{c}\text { Capacity } \\
\text { (kBtu/h) }\end{array}$ & $\begin{array}{c}\text { Engine Speed } \\
\text { (rpm) }\end{array}$ \\
\hline C1 & 99 & 1200 & 28 & $1000^{(\mathbf{a})}$ \\
C2 & 124 & 1500 & 84 & 1000 \\
C3 & 149 & 1800 & 143 & 1500 \\
C4 & 182 & 2200 & 190 & 2400 \\
\hline
\end{tabular}

(a) With two of four compressor cylinders unloaded. 
Condenser. A 3-row coil with a face area of $24.4 \mathrm{ft}^{2}$, tube diameter of $3 / 8 \mathrm{in}$, and fin spacing of 14 per inch is provided to reject heat from the condensing refrigerant. A sub-cooling coil with a face area of $4.2 \mathrm{ft}^{2}$ cools the condensed (liquid) refrigerant enough below saturation point to prevent its reverting to the gaseous state in the liquid line. The engine-driven condenser fan is 42 inches in diameter and provides $16,000 \mathrm{cfm}$ of air flow with the engine running at $2,200 \mathrm{rpm}$.

Evaporator. The 6-row evaporator coil has a face area of $13 \mathrm{ft}^{2}$, tube diameter of $3 / 8 \mathrm{in}$, and fin spacing of 9 per inch. A 3-ton expansion valve is provided for the upper (75\%) section of the evaporator and a 3-ton expansion valve is provided for the lower (25\%) section of the evaporator. Both are external equalizer type with a superheat setting of $20 \pm 5^{\circ} \mathrm{F}$.

Compressor. The 4-cylinder V-configuration compressor displaces $30 \mathrm{in}^{3}{ }^{3}$, and cylinder unloading is provided on two cylinders. The unit holds a charge of approximately $40 \mathrm{lbm}$ of R-22, an HCFC refrigerant.

Engine. A 4-cylinder in-line engine displacing $163 \mathrm{in}^{3}$ produces $31 \mathrm{hp}$ at 2,400 rpm. A 40-gallon oil tank allows up to 2,000 operating hours between oil changes. Electronic ignition is provided to further reduce service requirements.

Maintenance. The condensing unit requires biannual preventive maintenance, which includes coil. cleaning and checking the refrigerant charge, i.e., identical to the maintenance required for the conventional electric-driven technology. Maintenance peculiar to the gas-engine-driven technology includes engine winterization at the end of each cooling season and an oil change every spring. Replacement or refacing of valves, seats, and guides is recommended by the manufacturer at 10,000 operating-hour intervals, and engine rebuilding is recommended at 20,000-operating-hour intervals. These rebuild intervals appear to be realistic based on natural-gas-fueled engine operating experiences of others (Mathews 1992).

Thermostat. A Honeywell T775A digital programmable thermostat is used to control the four cooling stages. The thermostat has four user-programmable setpoints and deadbands to determine the required cooling stage. The room temperature sensor can be internal or external, and multiple sensors can be used to provide a spatial average room temperature.

Additional details about the TK unit are presented in Appendix $\mathrm{C}$ as provided by Thermo King Corporation.

The engine and compressor of the unit installed at Building 3 are pictured in Figure 2.4. The engine is on the left and the compressor and control box are on the right. 


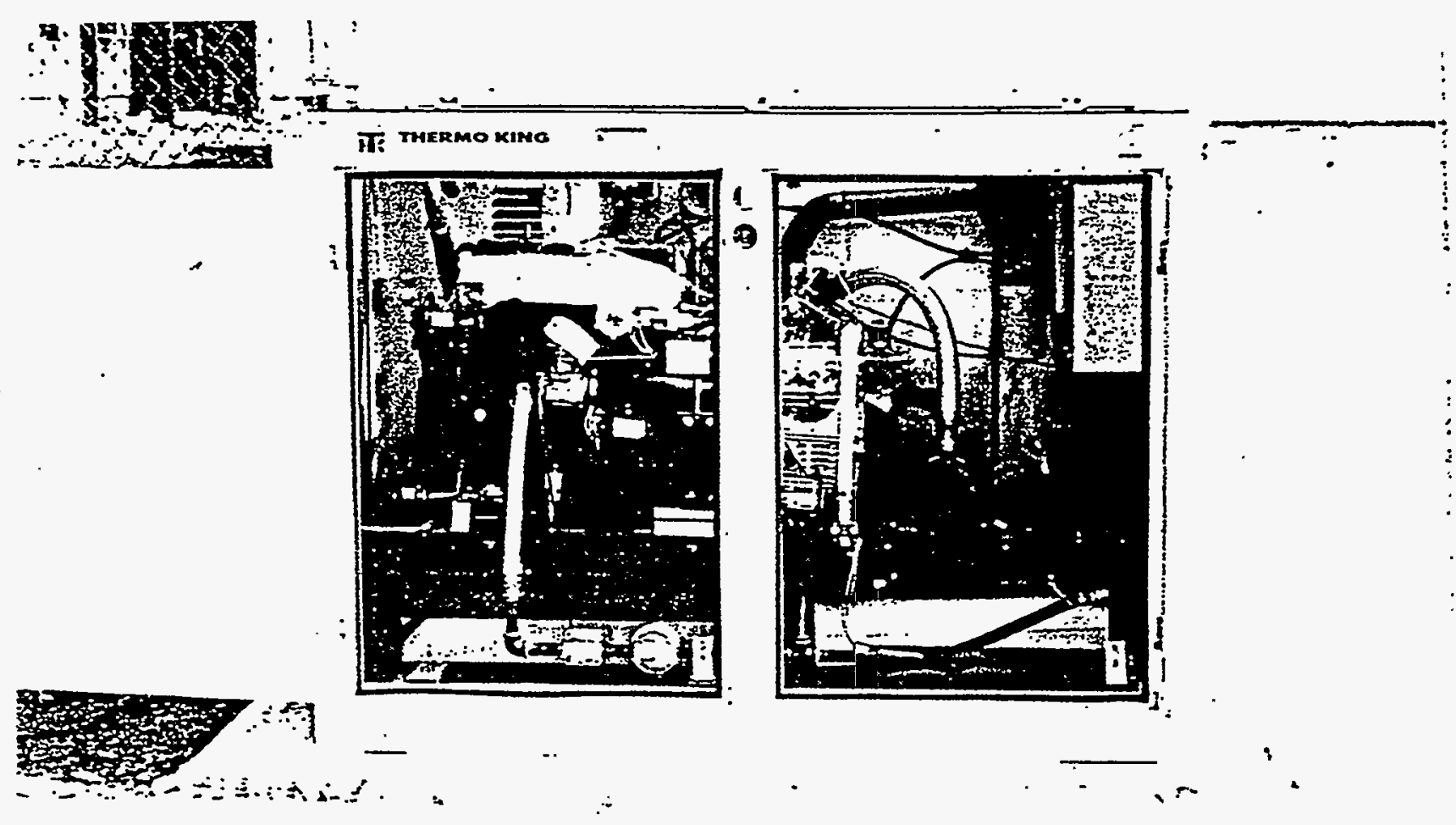

Figure 2.4. Thermo King Condensing Unit: View from the South

\subsection{Analysis that Supported Gas for Cooling}

The decision to use gas-engine-driven cooling was based on two earlier life-cycle cost (LCC) analyses. Steam and direct-fired absorption were considered, as well as gas-engine-driven and conventional electric cooling technologies by Falvey (1990). The gas-engine-driven and conventional electric-powered alternatives were again compared in an ex-poste analysis (Armstrong and Conover 1993) with the results summarized in Table 2.2. In both analyses the lowest LCC option was replacement with natural gas-engine-driven RTUs.

Table 2.2. Life-Cycle Cost Comparison of Gas and Electric-Powered Cooling of the Navy Exchange

\begin{tabular}{|l|c|c|c|}
\hline \multicolumn{1}{|c|}{ Option } & $\begin{array}{c}\text { Initial } \\
\text { Cost }\end{array}$ & $\begin{array}{c}\text { Present Value } \\
\text { Operating Cost }\end{array}$ & $\begin{array}{c}\text { Life-Cycle } \\
\text { Cost }\end{array}$ \\
\hline Electric-Powered RTUs & 51,330 & $\$ 182,696 \cdot$ & $\$ 234,026$ \\
\hline Natural Gas-fired RTUs & $\$ 77,972$ & $\$ 34,673$ & $\$ 112,646$ \\
\hline
\end{tabular}




\subsection{Technology Assessment Methodology}

The overall approach was to measure field performance of the TK 15-ton natural gas-engine-driven air-conditioning equipment, extrapolate the data to normal weather year conditions, and compare to normal year performance of current conventional technology on both an energy and life-cycle cost basis.

To measure field performance, the unit, air handler, and conditioned spaces were instrumented and a data acquisition system and phone line for remote data upload were installed as described in Section 3.0.

To assess performance, the average COP in each of four cooling stages was determined from measured air-side temperatures and condensate flows and fuel input rates as described in Sections 4.1 through 4.3.

To extrapolate performance to normal weather year conditions, a cooling degree-day base temperature and a building load coefficient ( $\mathrm{kBtu} /{ }^{\circ} \mathrm{F}$-day) were determined from the correlation between measured daily cooling plant input energy and daily mean temperature.

To estimate normal weather year performance of the conventional electric cooling technology, the hypothetical energy consumption during the monitoring period that would have resulted if the engine was replaced by an energy efficient motor was estimated. Normal year weather and performance estimates are developed in Sections 5.1 through 5.3.

The Code of Federal Regulations (10 CFR Part 436) requires that all energy improvements by justified by comparing the life-cycle costs of all reasonable alternatives. To compare life-cycle costs, the FEMP/NIST life-cycle cost program (NIST 1986) and fuel escalation data (NIST 1994) were used as described in Section 5.4. 


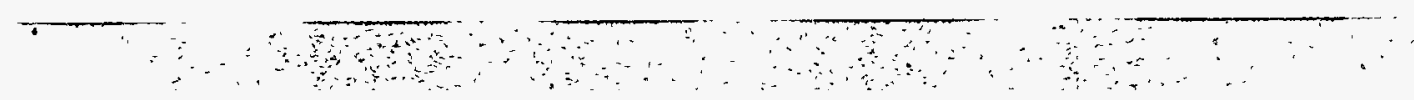




\subsection{Field Performance Monitoring}

To effectively assess. performance of the compressor/condenser unit, temperatures, flows, pressures, and other conditions in the equipment, building, and exterior environment were monitored.

\subsection{Data Acquisition System}

The data logger consists of a main unit, an analog extension module that provides additional analog channel capacity for thermocouples, thermopiles, and other low-level inputs, and a pulse/status input module. The capabilities of the data logger that are germane to this particular demonstration are summarized below.

The logger has six differential analog input channels, any of which can be configured as two singleended channels. The analog extension module provides an additional 32 differential input channels. The basic accuracy of the logger is $0.2 \%$ of full scale range (FSR) when operated between $-25^{\circ} \mathrm{C}$ and $+50^{\circ} \mathrm{C}$. Sampling takes $2.6 \mathrm{~ms}$ per channel in fast single-ended mode, $3.2 \mathrm{~ms}$ in fast differential mode, $8.6 \mathrm{~ms}$ in fast differential thermocouple mode, and $25.9 \mathrm{~ms}$ in $60 \mathrm{~Hz}$ rejection $(70 \mathrm{~dB})$ differential mode. Each channel can be configured to one of five input ranges: $\pm 2500 \mathrm{mV}, \pm 250 \mathrm{mV}$, $\pm 25 \mathrm{mV}$, and $\pm 7.5 \mathrm{mV}$. The analog input resistance is $20 \times 10^{10} \mathrm{ohm}$. The main unit has two eightbit, $2000 \mathrm{~Hz}$ pulse inputs. The extension module has 8 pulse/status inputs that are individually configurable for a variety of signals. The clock is accurate to \pm 1 minute per month.

The logger communicates remotely via an RS-232 serial port, a modem, and a dedicated phone line: Polling stations were set up at NASWG and PNNL, with PNNL being the primary site for uploading and archiving the data. The PNNL polling was performed nightly by a PC running a batch program that calls executable programs, in a predetermined sequence, for uploading data from the NASWG logger as well as from other types of loggers used in field monitoring projects. Figure 3.1 shows the data acquisition system installed in the closet that houses the air handler.

\subsection{Measurements for Field Performance Evaluation}

Most of the measurements are used to evaluate performance (e.g., efficiency as a function of conditions) and to diagnose operational problems with the system being monitored. Additional sensors provide redundant measures of performance and monitoring system diagnostics. In the case of the gaspowered condenser unit monitored at NASWG, the measurements can also be organized in terms of the unit's major subsystems: engine and compressor, refrigerant circuit, air circuit, controls, and building.

Engine/Compressor. The monitored conditions that affect engine performance are barometric pressure and ambient temperature. A fan-aspirated outside air temperature sensor was located on a 


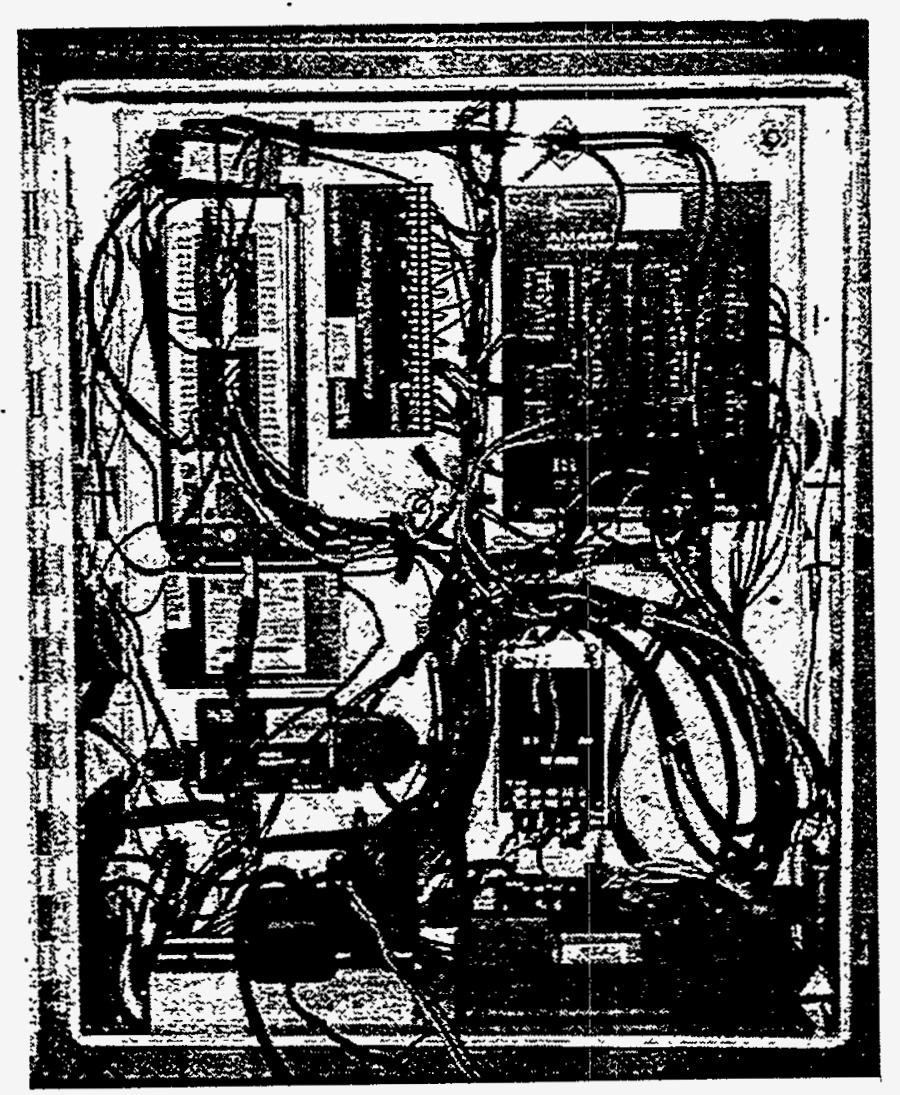

Figure 3.1. Data Acquisition System

mast attached to the southeast corner of Building 3 (visible in Figure 2.2). Engine performance is not measured directly, but the flow of natural gas to the engine.is measured to assess aggregate engine/ compressor performance. Compressor output is measured in terms of refrigerant mass flow rate and the pressures and temperatures of the refrigerant at the compressor's inlet and exhaust ports. Diagnostic points include manifold pressure, exhaust temperature and engine speed (rpm).

Refrigerant Loop. The cooling effect is measured on the refrigerant and air sides of the evaporator coil. Refrigerant heat rates involve sensible heating and cooling of the refrigerant in its liquid and vapor states as well as latent heat transfer associated with refrigerant boiling and condensation. The refrigerant mass flow rate is just upstream of the expansion valve where refrigerant is normally in a liquid state. The latent heat picked up by the refrigerant is determined from the evaporator pressure and the sensible heat from the temperature of the leaving refrigerant minus the saturation temperature. The latter is a function of evaporator.pressure. The latent heat rejected by the refrigerant is determined from the condenser pressure and the sensible heat from the superheating and subcooling temperatures measured, respectively, at the desuperheater inlet and the condenser outlet. 
Air-Side Measurements. A redundant measure of the cooling effect is obtained on the air side of the evaporator coil. The latent load is inferred from the flow of water, which condenses on the cold air-side surfaces of the coil, as it drains from the condensate pan through a tipping-bucket gauge. The sensible load is determined from the change in air temperature; the change is measured by a thermopile . connected across the coil; a second thermopile is connected across the supply air fan section of the air handler to measure heat added by the fan and motor. One-time air flow measurements were made at the return air inlet by a hot-wire anemometer. Each measurement was based on the average of 30 traverse points evenly distributed across the face of the return air opening with the unit in fan-only (no cooling) mode of operation. Four replications were made of each air flow measurement.

Conditioned Zone. Air temperatures in the conditioned zone were measured in each room served by the system. The locations are shown in Figure 3.2. The return air's humidity was measured at the air handler. The cooling load is also driven by outside temperature, solar radiation, and wind. These conditions were measured by instruments situated on a mast attached to the southeast corner of the monitored wing of Building 3. The weather instruments, visible in Figure 2.2, are about 8 feet above the eave and about 24 feet above grade.

Controls. The control signals for cooling stages 1 through 4 were monitored to allow disaggregation of the measured performance and conditions by mode of operation. Engine speed, on/off status, and number of starts were also monitored. The room thermostat sensor's output was not monitored.

The sensor locations in relation to the mechanical subsystems are shown schematically in Figures 3.3 and 3.4. The sensor characteristics are listed in Table 3.1. 


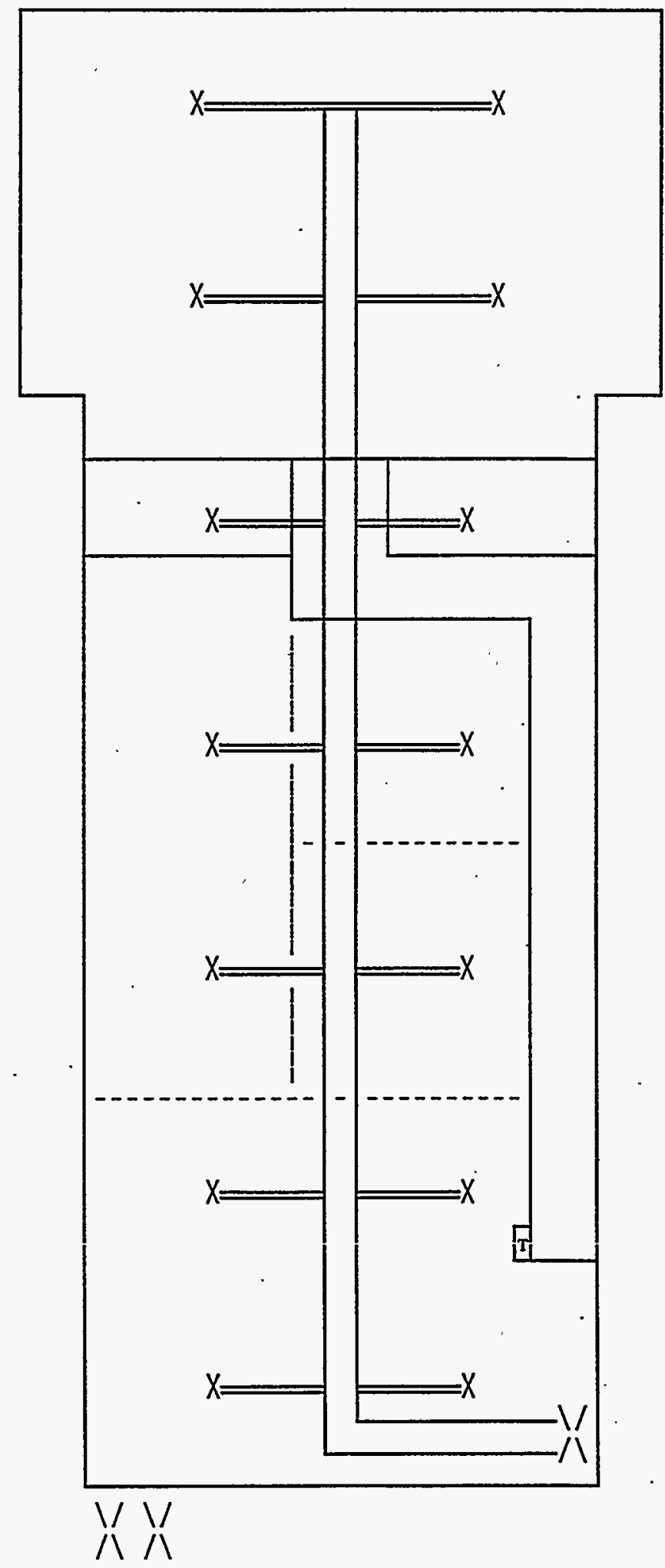

Figure 3.2. Location of Thermostat 6 in Relation to Rooms, TK Unit and Air Distribution System 


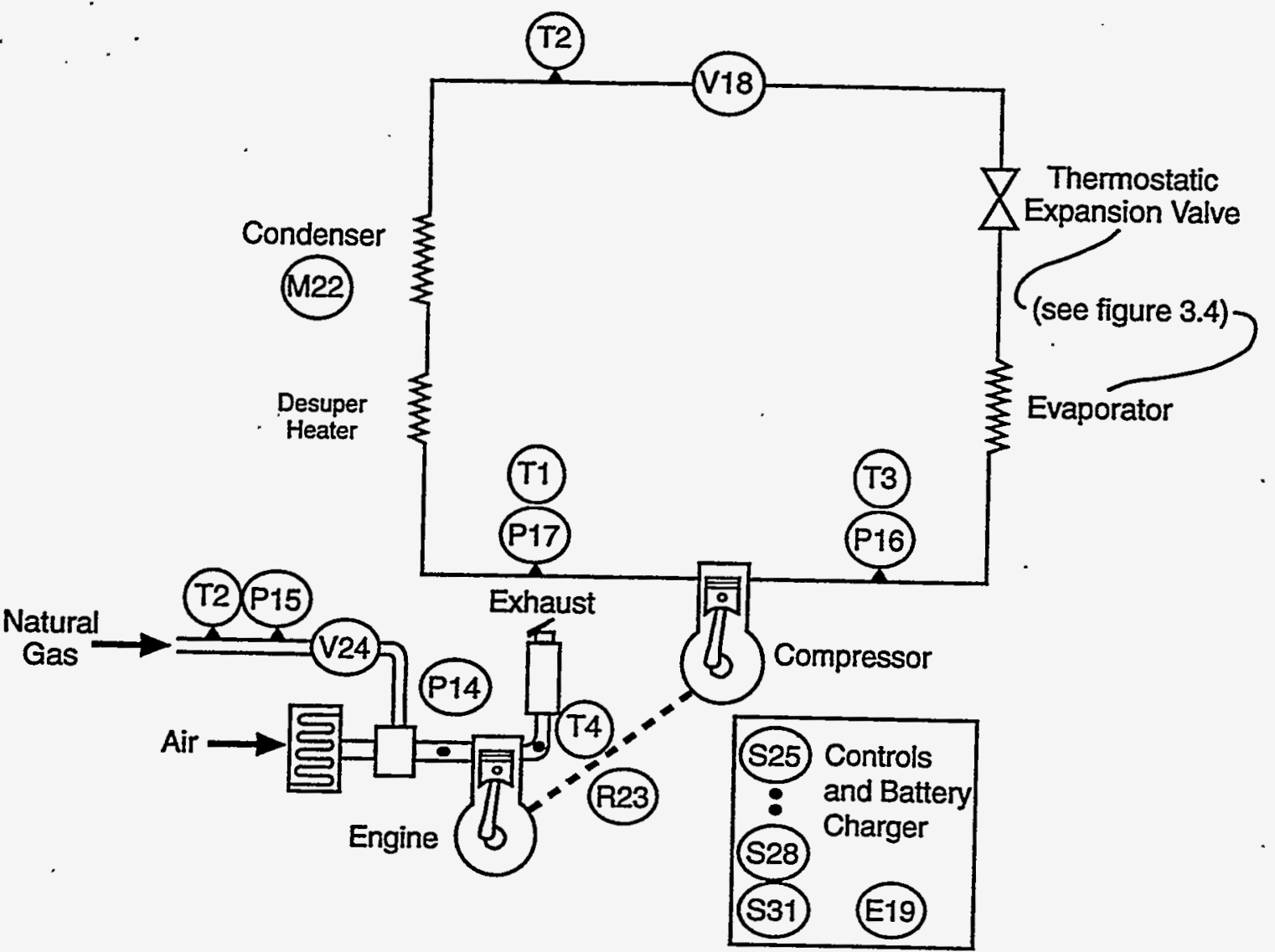

Figure 3.3. Sensor Locations in Zone and Air-Side Loop

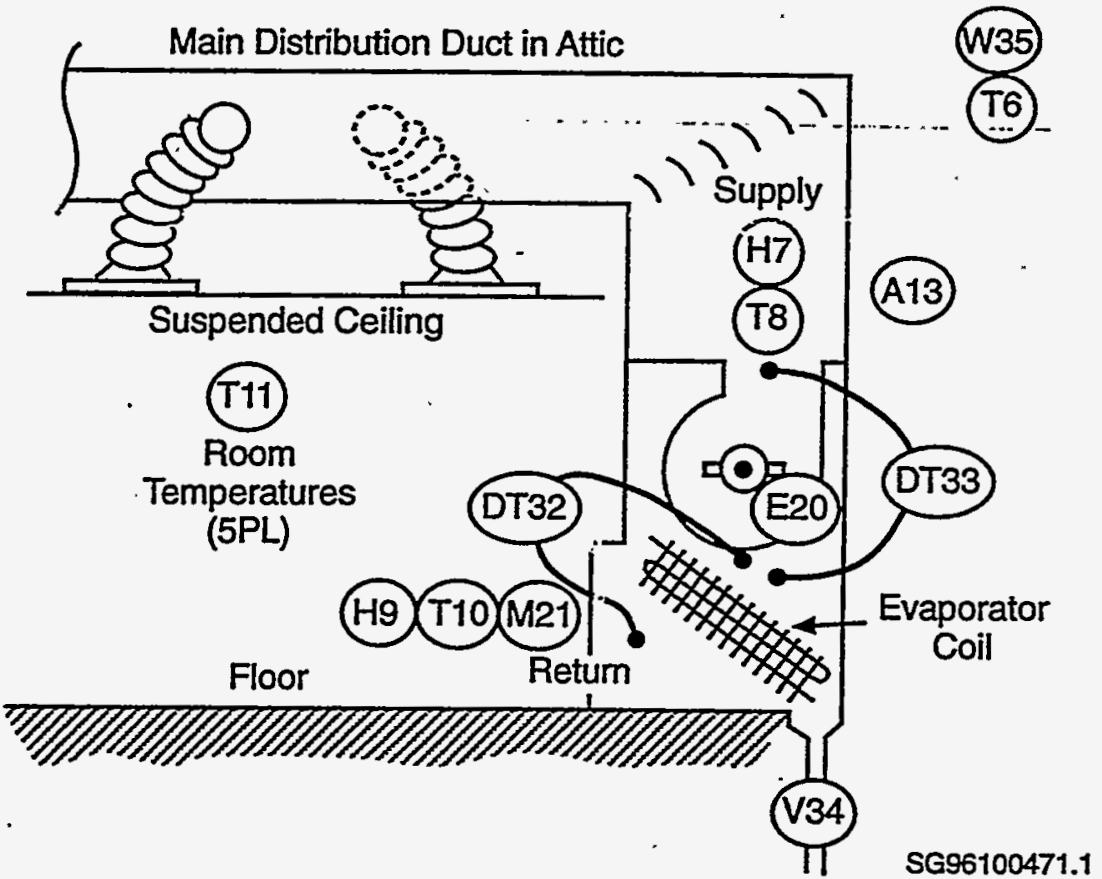

Figure 3.4. Sensor Locations in Refrigerant Loop 
Table 3.1. Sensor Specifications

\begin{tabular}{|c|c|c|c|c|c|c|c|c|}
\hline \multicolumn{2}{|c|}{ Point Description ${ }^{(\boldsymbol{)})}$} & \multirow{2}{*}{$\begin{array}{c}\begin{array}{l}\text { Input } \\
\text { Type }\end{array} \\
\text { DE }\end{array}$} & \multirow{2}{*}{\begin{tabular}{|r|}
$\begin{array}{r}\text { Sensor } \\
\text { Range }\end{array}$ \\
-200.470 \\
\end{tabular}} & \multirow{2}{*}{\begin{tabular}{|c|}
$\begin{array}{c}\text { Normal } \\
\text { Range }\end{array}$ \\
0.250 \\
\end{tabular}} & \multirow{2}{*}{\begin{tabular}{|l} 
Unit( $^{(c)}$ \\
${ }^{\circ} \mathrm{F}$
\end{tabular}} & \multirow{2}{*}{\begin{tabular}{|c|}
$\begin{array}{c}\text { Sensor } \\
\text { Type }\end{array}$ \\
type T \\
\end{tabular}} & \multirow{2}{*}{$\begin{array}{c}\begin{array}{c}\text { Sensor } \\
\text { Manufacturer }\end{array} \\
\text { Eustis }\end{array}$} & \multirow{2}{*}{\begin{tabular}{|c} 
Sensor Model \\
AFGDOTA12W803
\end{tabular}} \\
\hline T1 & Discharge & & & & & & & \\
\hline $\mathrm{T} 2$ & Subcool & $\mathrm{DE}$ & -200.470 & $\longdiv { 0 . 1 5 0 }$ & ${ }^{\circ} \mathrm{F}$ & type T & Eustis & AFGD0TA12W803 \\
\hline T3 & Suction & $\overline{D E}$ & -200.470 & 0.50 & ${ }^{\circ} \mathrm{F}$ & type T & Eustis & AFGD0TA12W803 \\
\hline$\overline{\mathrm{T} 4}$ & Engine exhaust & $\overline{\mathrm{DE}}$ & $-20 . .1000$ & $0 . .1000$ & $\circ \mathrm{F}$ & TC, type K & Omega Engineering & TJ36CASS-116U12 \\
\hline T5 & T.C. reference & $\mathrm{SE}$ & $-13 . .122$ & $-13 . .122$ & ${ }^{\circ} \mathrm{F}$ & Thermistor & Campbell Scientif & 10TCRT \\
\hline T6 & Outside air & $\mathrm{DE}$ & $-200 . .470$ & $-20 . .100$ & ${ }^{\circ} \mathrm{F}$ & $\begin{array}{l}\text { type T } \\
\text { fan/radshield }\end{array}$ & $\begin{array}{l}\text { CS Gordon } \\
\text { PNL shop }\end{array}$ & WT24-2-507-00 \\
\hline $\mathrm{H7}$ & Supply air & SE & $0 . .100$ & 0.100 & $\%$ RH & Polymer & Vaisala & HMD $30 \mathrm{YB}$ \\
\hline T8 & Supply air & $\mathrm{DE}$ & $-200 . .470$ & $50 . .140$ & ${ }^{\circ} \mathrm{F}$ & type T & CS Gordon & WT24-2-507-00 \\
\hline H9 & Return air & SE & $0 . .100$ & 0.100 & $\%$ RH & Polymer & Vaisala & HMD $30 \mathrm{YB}$ \\
\hline $\mathrm{T10}$ & Return air & $\mathrm{DE}$ & $-200 . .470$ & 60.80 & ${ }^{\circ} \mathrm{F}$ & type T & CS Gordon & WT24-2-507-00 \\
\hline T11 & Room air (5 PL) & $\mathrm{DE}$ & $-200 . .470$ & 60.80 & $\circ \mathrm{F}$ & type T & CS Gordon & WT24-2-507-00 \\
\hline T12 & Gas supply & $\mathrm{DE}$ & $-200 . .470$ & $40 . .70$ & of & type $T$ & Eustis & AFGD0TA12W803 \\
\hline $\mathrm{Al3}$ & Barometer & SE & 0.25 & 14.5..15 & psia & strain gage & Setra & C280E \\
\hline P14 & Intake vacuum & SE & 0.10 & $0 . .5$ & psig & strain gage & Setra & C239 \\
\hline P15 & Gas supply & SE & 0.10 & 4.5 .10 & in WC & strain gage & Setra & 264 \\
\hline P16 & Compressor suction & SE & 0.250 & 50.200 & psig & strain gage & Setra & C207 \\
\hline P17 & Compressor dischg & SE & 0.500 & 150.350 & psig & strain gage & Setra & C207 \\
\hline V18 & | Refrigerant flowrate & SE & 0.2 & 0.1 & $\mathrm{gpm}$ & ultrasonic & Controlotron & 991PMS-1 \\
\hline E19 & Controls/charger & SE & 0.1100 & 50.200 & $\mathrm{w}$ & Hall effect & FW Bell & PX-2221BL \\
\hline $\mathrm{E20}$ & Fan power & SE & 0.4400 & 0.4000 & w & Hall effect & FW Bell & PX-2221BL (2) \\
\hline M21 & Return Air & SE & 0.500 & $0 . .1024$ & sfpm & thermistor & CambridgeAcuSens & CAFS 1010-2-V \\
\hline MO22 & Condenser Air & SE & 0.800 & $0 . .1024$ & sfpm & thermistor & CambridgeAcuSens & CAFS 1010-2-V \\
\hline $\mathbf{R 2 3}$ & Engine RPM & $F$ & 0.5000 & 0.2200 & $\mathrm{rpm}$. & mag pickup & unknown ${ }^{(e)}$ & \\
\hline V24 & Gas ACFH & $\mathbf{P}$ & 0.500 & 0.300 & cfh & diaphragm & American & \\
\hline S25 & Cooling step 1 & $\mathbf{I N}$ & $1=0 N$ & $0 . .1$ & $x^{(\text {(o) }}$ & LED Relay & Stevens Engrg & RH2B-UL-AC24V \\
\hline S26 & Cooling step 2 & $\mathbf{N}$ & $1=0 N$ & 0.1 & $\mathrm{x}$ & LED Relay & Stevens Engrg & RH2B-UL-AC24V \\
\hline S27 & Cooling step 3 & $\mathbb{N} \mathbf{N}$ & $1=0 N$ & 0.1 & $\mathrm{x}$ & LED Relay & Stevens Engrg & RH2B-UL-AC24V \\
\hline $\mathbf{S} 28$ & Cooling step 4 & $\mathbb{I N}$ & $1=0 N$ & 0.1 & $\mathbf{x}$ & LED Relay & Stevens Engrg & RH2B-UL-AC24V \\
\hline \$31 & Engine enable & $\mathbf{N}$ & $1=0 \mathrm{~N}$. & $0 . .1$ & $x$ & LED Relay & Stevens Engrg & RH2B-UI_AC24V \\
\hline DT32 & Return-LATcoil & $\mathrm{DE}$ & $+1-200$ & $\mid-40 . .0$ & ${ }^{\circ} \mathrm{F}$ & TP, type T & C.S. Gordon & WT24-2-507-00 \\
\hline DT33 & | Supply-LATcoil & $\mathrm{DE}$ & $+1 / 200$ & 0.0 .5 & ${ }^{\circ} \mathrm{F}$ & TP, type T & C.S. Gordon & WT24-2-507-00 \\
\hline V34 & Condensate drain & $\mathbf{P}$ & 0.0 .5 & 0.02 & $\mathrm{gpm}$ & tip bucket & Peet Bros. & Self-emptying RG \\
\hline DT35 & Condenser air-side & $\mathrm{DE}$ & $+1-200$ & 0.25 & ${ }^{\circ} \mathrm{F}$ & TP, type T & C.S. Gordon & WT24-2-507-00 \\
\hline DT36. & Subcooler air-side & $\overline{D E}$ & $+/ 200$ & 0.20 & ${ }^{\circ} \mathrm{F}$ & TP, type T & C.S. Gordon & WT24-2-507-00 \\
\hline DT37 & Radiator air-side & $\mathrm{DE}$ & $+/ 200$ & 0.30 & ${ }^{\circ} \mathrm{F}$ & TP, type T & C.S. Gordon & WT24-2-507-00 \\
\hline W38 & Wind Speed & $\mathbf{P}$ & 0.100 & 0.80 & $\mathrm{mph}$ & 3-cup/ACgen & WeatherMeasure & W200 SD \\
\hline \multicolumn{9}{|c|}{ 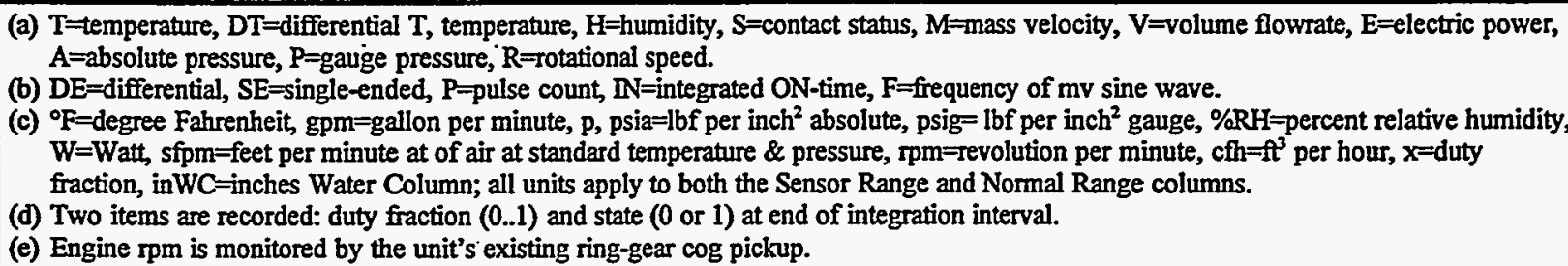 } \\
\hline
\end{tabular}




\subsection{Observed Performance and Operation}

The gas-powered air-conditioning unit was monitored from 5 May 1994 until the end of the 1994 cooling season. There were some minor operational-problems with both the monitoring system and the system being monitored. The interaction of these failures resulted in a relatively short period from which valid performance data could be drawn. However, sufficient data were obtained to develop a fairly complete and accurate picture of the technology's performance.

\subsection{Monitoring History}

The data logger was started 4 May 1994, two days before initial startup of the cooling unit. In May, operation was observed only on the 6 th and the 10 th. When hot weather arrived on 24 May, the unit did not start and the occupants called for service. The unit was serviced 30 June. The unit had lost charge some time after commissioning through a leak where one of the sensors, added for the NTDP evaluation, was connected to the refrigerant discharge line.

On 11. July a review of the data showed that something had caused loss of analog channel accuracy since 30 June, the day the chiller was repaired. A site visit was made 3 August and the data logger was repaired. The cooling system operated from 4-23 August. The unit stopped operating 24 August, when engine oil pressure was lost, and was not repaired until after the end of the cooling season.

In summary, data were collected continuously from 4 May to 9 November but the only time that proper chiller and data logger operation occurred simultaneously was the 20-day period from 4-23 August. Data used in the analysis were limited to this period, during which the system operated every day and a moderate range of daily load conditions was experienced.

The cooling load history is shown, in terms of the thermostat output, in Figure 4.1. The thermostat may call for cooling, at any given time, in one of four stages, designated C1 through C4, or it may call for no cooling. The notable feature of this particular history is the amount of cycling that occurs on all but two days. The expected behavior of a properly sized and operating system on a hot day would be an orderly progression such as "OFF, C1, C2, C3, C4, C3, C2, C1, OFF." On milder days the higher stages of operation would not occur and some cycling between adjacent stages might be expected. However, the cycling experienced at Building 3 is clearly excessive.

\subsection{Cooling Loads}

A model is needed to extrapolate the field evaluation data to a normal weather year. The easiest way to measure indictor of cooling load is input energy used to operate the compressor and condenser fan. The total rate of natural gas use is, therefore, the input energy stream of interest. The daily average gas input rates (based on 1,040 Btu/scf) are shown in Figure 4.2 along with the daily mean outdoor temperature history. The daily aggregations show that input load is correlated with outside temperature. 


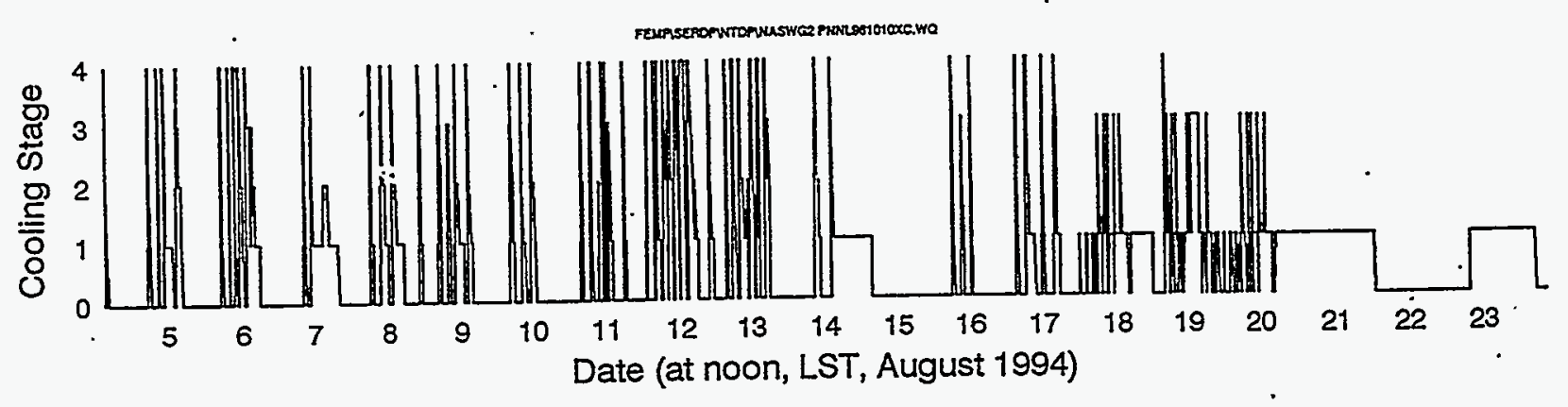

Figure 4.1. Cooling Stage as a Function of Time

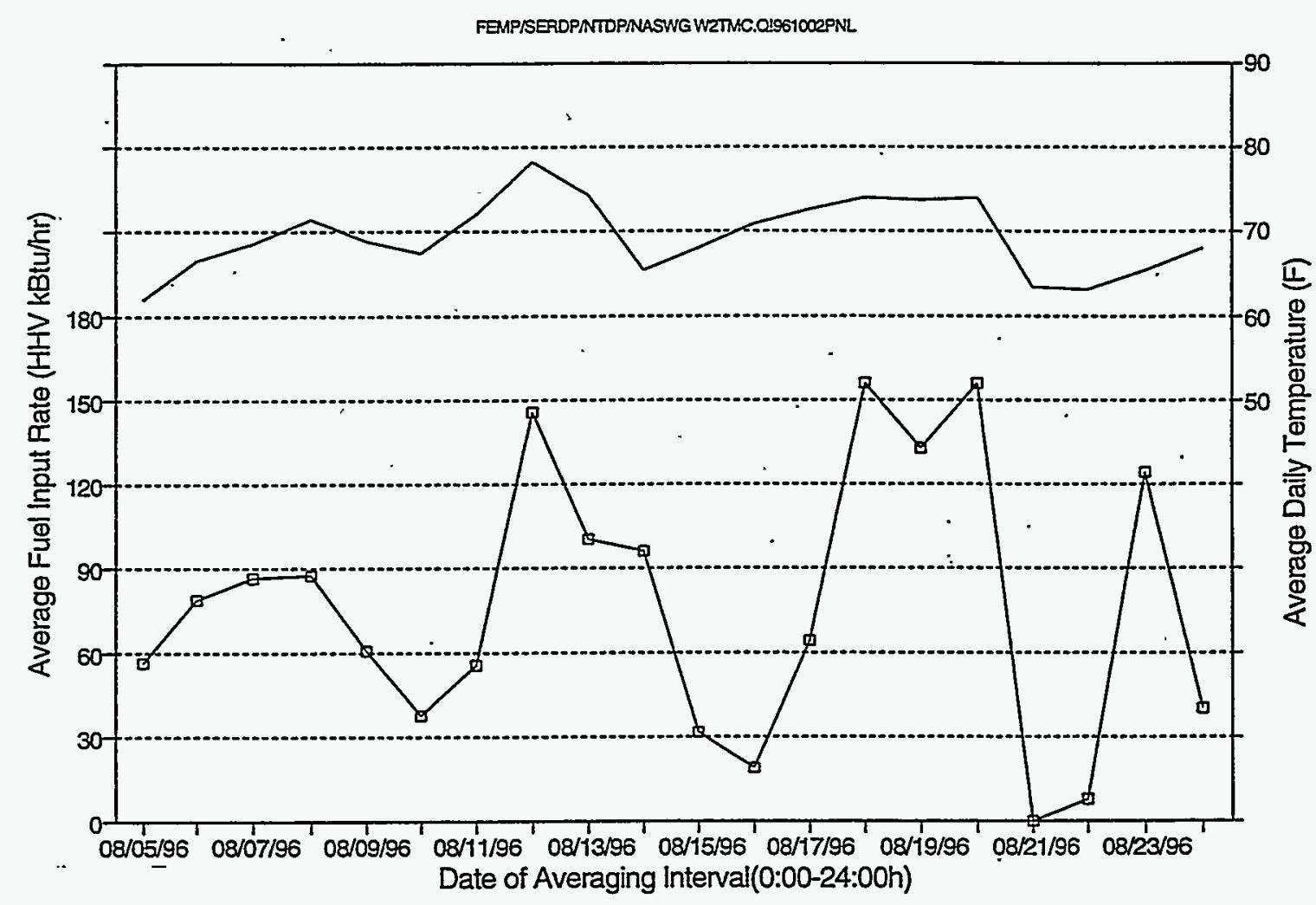

Figure 4.2. Daily Average Fuel Input and Outdoor Temperature as Functions of Time 
Figure 4.3 shows the daily gas loads as a function of ambient temperature. The amount of random error, while typical of a daily cooling load analysis, is too large for the small sample $(n=20)$ and limited range $\left(55^{\circ} \mathrm{F}\right.$ to $\left.75^{\circ} \mathrm{F}\right)$ to give a regression model that can used to estimate normal year loads with much confidence. Taking an alternate approach, we note, in Figure 4.4, that the daily aggregation points fall within the envelope of the much larger sample collected in a test of similar equipment at the same site in the 1992 and 1993 cooling seasons (Armstrong and Katipamula 1996). The model based on the previous evaluation, which indicated a load of $195 \mathrm{kBtu}$ per day per Fahrenheit degree above a mean daily temperature of $60^{\circ} \mathrm{F}$, will therefore be used for estimating annual performance and operating costs.

\subsection{Cooling Efficiency}

The coefficient of performance (COP) was computed from air-side sensible and latent loads and gas input energy rate. Note that the compressor and condenser and engine fan energy inputs are included in this definition but that the supply air (indoor) fan energy is not.

Short-Term COPs. Figure 4.5 shows the average COP during each period of continuous operation in each cooling stage. The COP is relatively constant in each cooling stage (C1 through $\mathrm{C4}$ ), ranging between 0.60 and 0.75 in $\mathrm{C} 1-3$. There was only one complete 15-minute monitoring interval when the unit operated continuously in $\mathrm{C4}$, and its COP in that interval was 0.54 . Also shown is the average daily load and overall daily average COP.

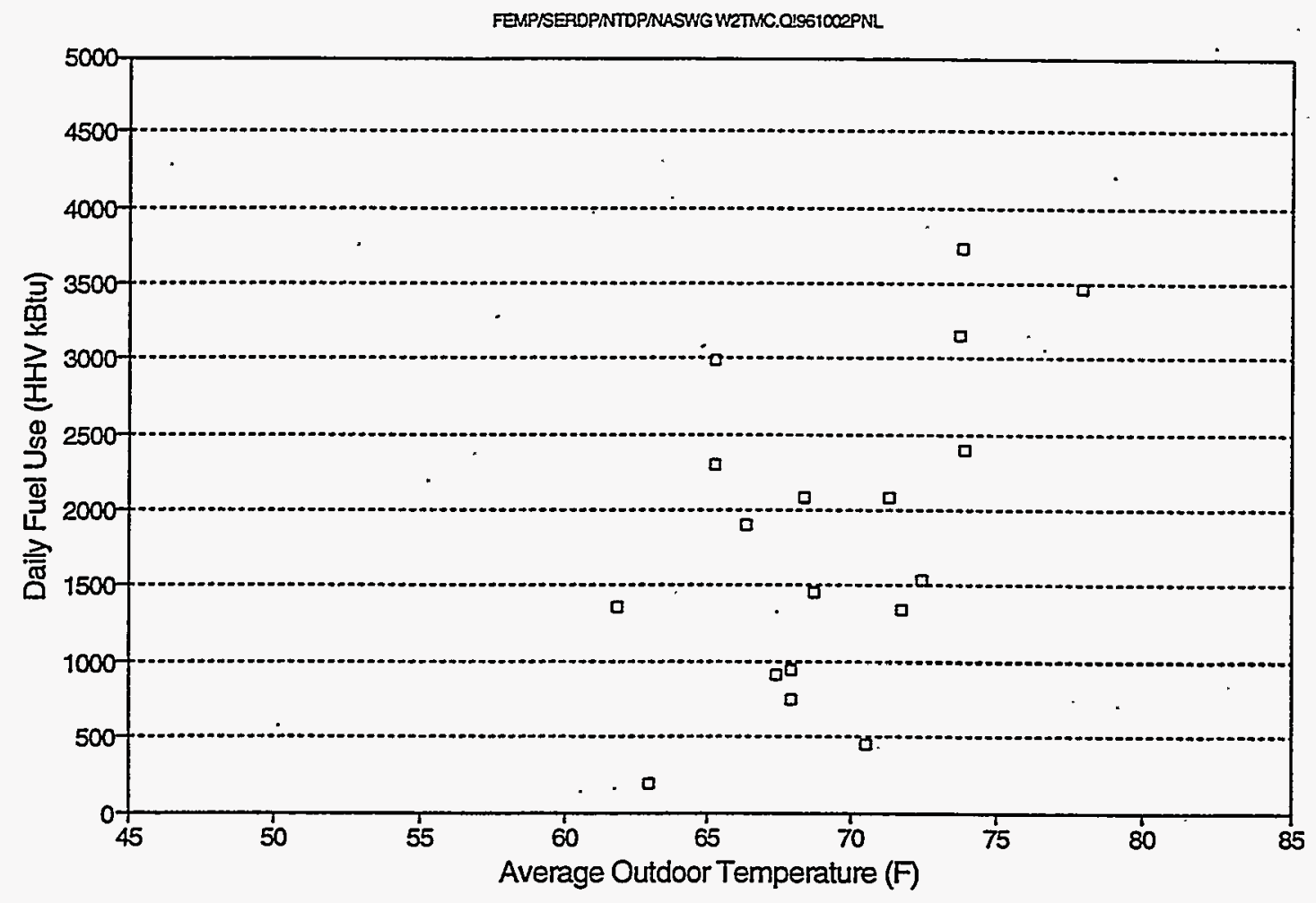

Figure 4.3. Relation Between Daily Gas Loads and Ambient Temperature 


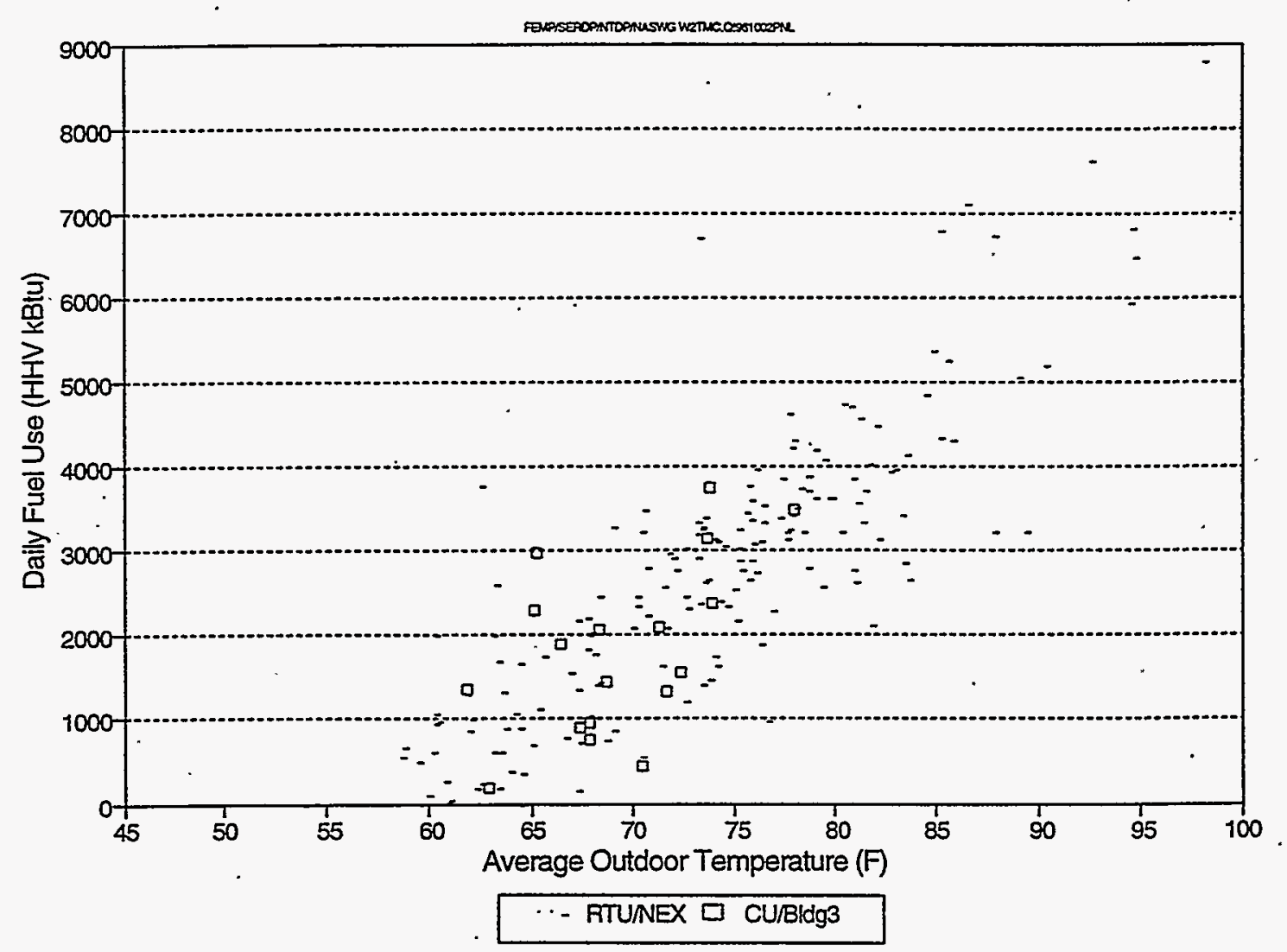

Figure 4.4. Daily Gas Loads for the Navy Exchange (NEX) and Building 3

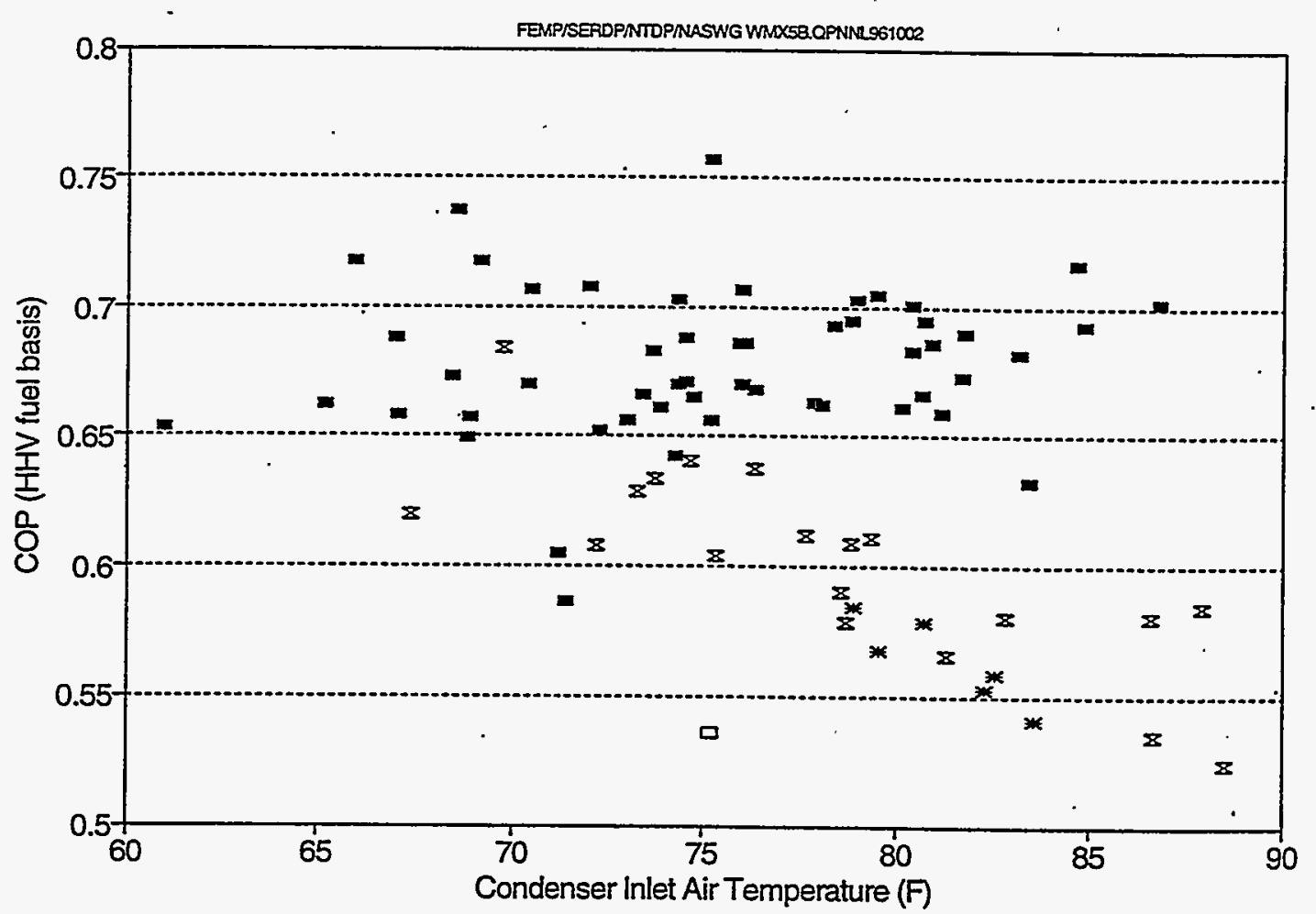

$$
\begin{array}{llllllllll}
\hline \text { - } & \mathrm{C} 1 & \mathrm{8} & \mathrm{C} 2 & * & \mathrm{C} 3 & \mathrm{C} & \mathrm{C} 4
\end{array}
$$

Figure 4.5. AHU-Temperature-Normalized COPs for All Observed Conditions 
The measured COPs are compared to the COPs quoted by the manufacturer (ThermoKing 1993, p. 21) in Table 4.1. The rated and observed COPs are in reasonable agreement except in cooling stage C1. Without shaft power or exhaust chemistry measurements, a thorough diagnosis of the observed performance in $\mathrm{C} 1$ is not possible. The most likely reasons are excess fuel-to-air ratio under lowspeed, light-load conditions or poor control of refrigerant flow. The latter could result from insufficient pressure across, or malfunction of, the thermostatic expansion valve. This would lead to insufficient or fluctuating evaporator superheat and, under certain conditions, to incomplete refrigerant vaporization in the evaporator coil and a significant fraction of cooling capacity appearing along the suction line or at the accumulator, rather than being imparted to the conditioned zone's supply air stream.

Table 4.1. Measured Versus Rated COPs

\begin{tabular}{|c|c|c|c|c|c|c|}
\hline \multirow[b]{3}{*}{ Stga } & \multicolumn{3}{|c|}{ GTC-2 } & \multicolumn{3}{|c|}{ GTC-1 } \\
\hline & \multirow{2}{*}{$\begin{array}{l}\text { Capacity } \\
(\mathbf{k B B t u} / \mathrm{h})\end{array}$} & \multicolumn{2}{|c|}{ COP } & \multirow{2}{*}{$\begin{array}{l}\text { Capacity } \\
\text { (kBtu/h) }\end{array}$} & \multicolumn{2}{|c|}{ COP } \\
\hline & & rated & observed & & rated & observed \\
\hline $\mathrm{C} 1$ & 99 & 0.80 & 0.65 & $28^{(2)}$ & $0.31^{(b)}$ & $0.54^{(\mathrm{c})}$ \\
\hline C2 & 124 & 0.66 & 0.66 & 84 & 0.90 & 0.89 \\
\hline C3 & 149 & 0.62 & 0.62 & 143 & 0.86 & 0.74 \\
\hline C4 & 182 & 0.56 & -0.54 & 190 & 0.65 & 0.56 \\
\hline
\end{tabular}

Seasonal COP. The test unit consumed 43 million Btu (MBtu) of fuel (based on the higher heating value of natural gas) and provided $26 \mathrm{MBtu}$ of cooling effect to Building 3 during the monitoring/analysis period.

The seasonal COP is, in simplest terms, the sum of the part-load COP and part-load operating time products divided by the total operating time. Because of its shortness and the limited range of conditions experienced during the monitoring period, the part-load operating time distributions for the system cannot be reliably estimated from this data. However, the similarity of the load distribution to the load distribution for the NEX, depicted in Figure 4.3, shows that the two load distributions are not significantly different. The NEX load distribution is therefore used to estimate seasonal performance in Section 5. 


\subsection{Cooling Operational Improvements}

A number of opportunities for improved operation were identified through analysis of the field performance data.

Staging Control. The thermostat settings have a significant effect on seasonal performance. It appears that a good strategy for the multistage gas-engine-driven cooling plant is to use a low setpoint (e.g., $70^{\circ} \mathrm{F}$ ) for the first stage and make the distances to successive stage setpoints fairly large, albeit progressively smaller (e.g., $75^{\circ} \mathrm{F}$ for stage $2,79^{\circ} \mathrm{F}$ for stage 3 , and $82^{\circ} \mathrm{F}$ for stage 4 ). Note that the setpoint for movement to a lower stage must be lower, by about $1^{\circ} \mathrm{F}$, than the corresponding setpoint in the upward progression (i.e., $81^{\circ} \mathrm{F}$ to return to stage 3 from stage $4,78^{\circ} \mathrm{F}$ to return to stage $2,74^{\circ} \mathrm{F}$ to return to stage 1 , and $69^{\circ} \mathrm{F}$ to stop cooling entirely).

Distribution Inefficiency. Many buildings are like Building 3 in the use of attic air distribution. In a well-insulated building with attic distribution, the cooling load to the conditioned space under given weather conditions when the fan is off can be significantly less than the cooling load under the same conditions with the fan on. This is caused by the conduction cooling load imposed on the attic ducts together with the outside air infiltration loads induced by fan operation. Measures that can help mitigate the problem of inefficient attic distribution include light roofing materials, attic ventilation, duct sealing, duct insulation, and a variety of conditioned space infiltration measures. The best solution, of course, is to avoid having any part of the distribution system outside of the conditioned space. Note that while the aforementioned efficiency measures are not as critical with the interior distribution system, they are still very beneficial.

A fan controlled to draw about $10 \mathrm{kcfm}$ into the attic of the conditioned wing when the attic temperature exceeds the outdoor by $3^{\circ} \mathrm{F}$ and $20 \mathrm{kcfm}$ when it exceeds the outdoor temperature by $6^{\circ} \mathrm{F}$ is probably the most cost-effective remedial measure for Building 3. The distribution system should also be checked for leaks. These improvements are likely to result in a load-plant capacity mismatch; i.e., the plant will be seriously over-sized. A straightforward remedy-and one likely to be welcomed by other Building 3 occupants-is to extend the conditioned space to the north and south of the library or to add a separate evaporator, air-handler, and distribution system in one of the other wings.

Control Instability. When a substantial thermal lag is associated with a well insulated space and an inefficient distribution system, we see the extreme cycling that occurs in Building 3 at the point in the diurnal cycle where the conditioned space first calls for cooling. If cycling persists after implementing the "wide-ratio" thermostat settings, attic ventilation measures, and conditioned-space extensions, replacement of the air-handler motors with two-speed $(1,150 / 1,750 \mathrm{rpm}, 0.9 / 3.0 \mathrm{hp})$ motors controlled to operate at low speed during occupied hours and in stage 1 cooling is recommended. A utility DSM program incentive may be available for this measure. Continuous fan operation at low speed uses relatively little energy and has the added benefits of air filtration and reducing temperature differences between zones. Constant operation of the fan during occupied hours also makes operation of the HVAC system less distracting and intrusive to occupants. 
Night Setback. The NEX thermostats used in the gas-engine-driven RTU demonstration had a 7day programmable occupancy schedule. This type of thermostat is needed to implement constant fan operation in occupied hours and provides the additional potential to disable cooling during unoccupied hours.

Preventive Maintenance. The checklist for spring maintenance should include-in addition to engine, fan, filter, condensate drain, and coil maintenance-the following checks: distribution system (obstructions and leaks) and building pressurization; TXV operation and refrigerant charge; thermostat setpoints and deadbands; engine speed setpoints and combustion-efficiency and $\mathrm{CO}$ tests at all four cooling stages.

\subsection{Technology Refinements}

Capacity modulation between $50 \%$ and $100 \%$ of gas engine-driven unit's rated capacity is provided for in the condensing unit's design. However, a 2:1 capacity control range is not enough to prevent a lot of on-off cycling in most cooling applications, even when the equipment is carefully sized to avoid costly excess capacity. Moreover, modulation to even moderately lower capacity fractions without substantial efficiency penalties is a challenge (Armstrong and Conover 1993). Under light loads the unit must cycle on and off (which wears out the engine), operate at low, inefficient engine speeds, or operate with some compressor cylinders unloaded. Efficiency is sacrificed with all three of the foregoing schemes. The design issues that have probably the greatest impact on seasonal performance and annual number of engine starts are the torque-speed match between the engine and compressor and the efficiency of operation over a wide speed (i.e., capacity) range.

Engine-Compressor Match. Based on its rated power and nominal fuel consumption in C4, the engine used in the test unit appears to be oversized. Furthermore, given its specific power rating of $0.245 \mathrm{hp} / \mathrm{cubic}$ inch, it is likely that with minor changes, the engine could be made to develop substantially more power. The engine might then be best suited for a 20 - or 25 -ton (240 or $300 \mathrm{kBh}$ ) machine. Such a machine could be modulated down to $30 \%$ of its rated capacity ( $15 \%$ with cylinder unloading). To do this, the compressor must be able to operate at higher speed efficiently. Some compressor design changes, or selection of a different compressor type (e.g., scroll or screw compressor) that is better suited to higher shaft speeds without sacrificing the wide range of shaft speed inherent in the reciprocating type, may be necessary. The objective, in any event, is to match the engine and compressor so that there is a wide (at least $2.5: 1$, better $3: 1$ ) range of useful operating speed. for this match to occur the engine must develop sufficient torque at the extreme high and low speeds, and there must not be a significant wear or efficiency penalties for either the engine or the compressor at the high extreme.

Capacity Control. Efficient operation of engine and compressor over a wide (3:1) speed range is important to achieve good annual efficiency. Designing or selecting the engine and compressor to achieve a good match in terms of their torque curves is a critical prerequisite. It is then up to the engine designer to obtain the highest possible fuel efficiency, without sacrificing engine longevity, over 
as wide a speed range as possible. Better control of fuel-air mixture and timing are possible paths for improvement in this area. Changes in valve timing ("cam grind") may also be beneficial. A gearbox between the engine and compressor is undesirable in terms of both cost and reliability.

The staging and cycling problems observed in the test indicate that the application of gas-enginedriven cooling equipment is not as simple as it is for conventional electric units. These problem are not peculiar to the subject technology but are common to many new energy efficiency technologies. This technology, in its current implementation, is sensitive to careless oversizing. Oversizing not only increases the first cost, which is already a barrier to broader use of this technology, but also increases long-term maintenance and energy costs. The manufacturer may have to offer better sizing guidance or design review services to improve the prospects for long-term market growth and industry acceptance of the technology. 


\section{0 Ánnual Performance and Life-Cycle Cost}

The economic analysis was performed in four steps. First, cooling loads were estimated for a normal weather year. Second, performance of a comparable electric chiller was estimated for the monitoring period. Third, input energy requirements of the gas-powered unit and the comparable electric-powered unit were extrapolated to a normal year cooling season. Fourth, and last, annual energy numbers and other pertinent cost and economic parameters were used to estimate life-cycle costs of the two alternatives.

\subsection{Base-Case Definition}

The decision to invest in a new technology cannot be made without evaluating at least the accepted standard existing technology. The conventional counterpart to the gas-engine-driven compressor/condenser unit is an electrically-driven unit of the same capacity and same general design.

To compare electric and gas technologies as equitably as possible, the comparable electric unit was assumed to be identical to the gas unit in all of its conventional parts-i.e., its compressor, condenser and controls-and is modeled as a TK unit with the engine replaced by a $30-\mathrm{hp}$ compressor motor and a 2-hp condenser fan motor. The single-speed premium energy-efficient motor efficiencies quoted by Nadel (1991) are assumed, optimistically, to prevail in all four cooling stages, and the engine efficiencies quoted by TK are used to convert natural gas input rates measured in the four cooling stages to corresponding shaft loads.

With the foregoing assumptions, the energy and demand requirements of the comparable electric unit can be evaluated for the monitoring period. To complete the life-cycle cost analysis, however, it is necessary to estimate the annual energy requirements of the gas-powered unit as well as the annual energy and demand requirements of the comparable electric unit. The analysis required to make this extrapolation is presented below.

\subsection{Normal Year Loads}

The cooling load is predominantly a sensible cooling load, linearly correlated with mean daily temperature. The balance point (temperature above which a cooling load exists) is about $60^{\circ} \mathrm{F}$. Base $65^{\circ} \mathrm{F}$ Cooling Degree Days (CDD) tabulated in NAVFAC P-88 (TM 5-785) are 946 CDD for NASWG. The corresponding numbers for nearby locations in Pennsylvania, New Jersey and Delaware are 1104 CDD for Philadelphia IAP, 1104 for Camden, 983 for McGuire AFB, NJ, 945 CDD for Wilmington $\mathrm{AP}$, and $608 \mathrm{CDD}$ for Wilkes Barre-Scranton. Long-term historical temperature distributions are also tabulated in NAVFAC P-88 (TM 5-785) for Newark IAP, McGuire AFB, Wilmington AP, and Wilkes Barre-Scranton, but not for NASWG, Philadelphia or Camden. The available data indicates annual base- 60 and base- 65 cooling load potentials as shown in Table 5.1. 
Table 5.1. Available Climate Data

\begin{tabular}{|c|c|c|c|}
\hline & $\begin{array}{c}\text { Base } 65^{\circ} \mathbf{F} \\
\text { CDD }^{(a)}\end{array}$ & $\begin{array}{c}\text { Base } 65^{\circ} \mathbf{F} \\
\text { CDD }^{(b)}\end{array}$ & $\begin{array}{c}\text { Base } 60^{\circ} \mathrm{F} \\
\mathrm{CDD}^{(\mathrm{b})}\end{array}$ \\
\hline Willow Grove NAS & 946 & $\mathrm{NA}$ & NA \\
\hline Philadelphia IAP & 1104 & NA & NA \\
\hline Camden & 1104 & NA & NA \\
\hline Newark IAP & 1024 & 1168 & 1835 \\
\hline McGuire AFB & 983 & 1076. & 1778 \\
\hline Wilmington AP & 992 & 1154 & 1822 \\
\hline Wilkes Barre-Scranton & 608 & 798 & 1336 \\
\hline \multicolumn{4}{|c|}{$\begin{array}{l}\text { (a) Based on mean of daily max/min temperatures, Chapter } 5.0 \text { of NAVFAC } \\
\text { P-89 (TM 5-785). } \\
\text { (b) Based on one-hour or three-hour temperature readings, Ch. } 3 \text { of NAVFAC } \\
\text { P-89 (TM 5-785). }\end{array}$} \\
\hline
\end{tabular}

From these data it is clear that Wilmington's climate is more (in terms of annual air-conditioning load) like that of Willow Grove than the climate of any of the other locations (except possibly distant McGuire AFB). The Wilmington, Delaware, climate was deemed sufficiently similar to be used as normal year weather without further adjustment.

Ambient temperatures at NASWG for the summer of 1994 are compared to normal-year Wilmington temperatures in Figure 5.1

The relation between daily gas use and average outdoor temperature showed the cooling balance point for Building 3 is about $60^{\circ} \mathrm{F}$, the same as the for the Navy Exchange (NEX). The relation appeared to be reasonably linear with a slope about half that of the NEX indicating that Building 3 requires about half the cooling capacity of the NEX. We therefore assume that Building 3 will use about half the cooling energy used by the NEX in a normal weather year. The Building 3 plant is therefore expected to consume $190 \mathrm{MBtu}$ of gas and provide $112 \mathrm{MBtu}$ of cooling in a normal cooling season. 


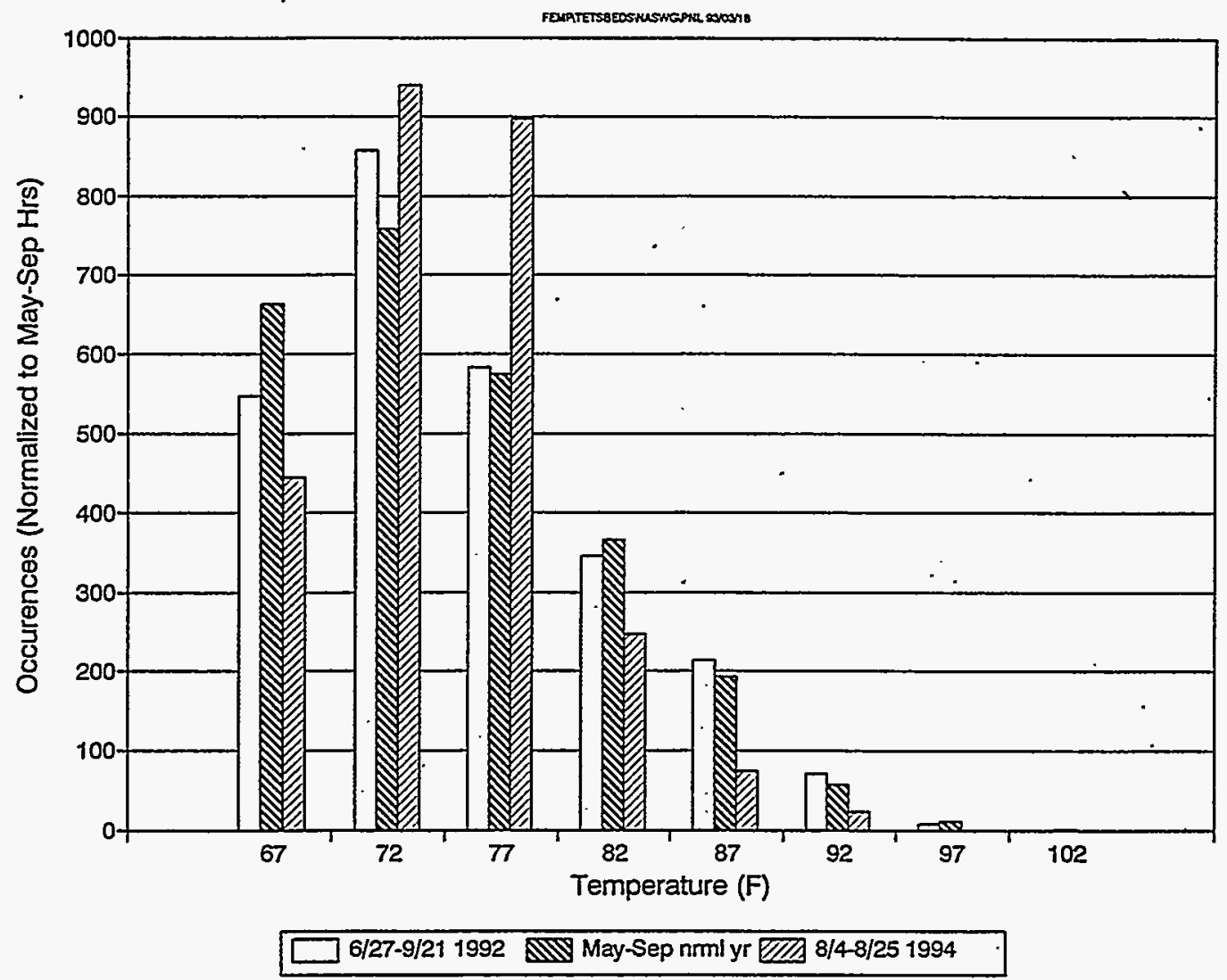

Figure 5.1. Comparison of Normal-Year and 1994 Ambient Temperature Distributions

\subsection{Energy Costs}

The annual operating cost for the base case (electric-powered unit) consists of electric energy, demand, and ratchet penalty costs. The cost of compressor motor maintenance is assumed to be negligible and the other maintenance costs (controls and refrigerant loop maintenance) are ignored since they will be the same for the gas- and electric-powered units. The PECO Energy rate schedule (PECO Energy 1991) that applies to NASWG charges $\$ 0.0299$ per $\mathrm{kWh}$ and $\$ 23.70$ per monthly peak demand $\mathrm{kW}$. The minimum monthly demand charge is $80 \%$ of the maximum over the preceding eleven months. The load peak for the electric-powered unit is assumed to coincide with the peak at the PECO Energy meter that measures all electrical energy supplied to NASWG.

The annual operating cost for the gas-powered unit is considered to consist of natural gas purchases plus annual engine service of $\$ 200 / y \dot{r}(P V=\$ 2780)$, plus the annual service cost of a conventional condensing unit of $\$ 100 / y r(P V=\$ 1390)$. The PECO Energy natural gas rate schedule that applies to NASWG charges $\$ 6.50 / \mathrm{kcf}$ for the first $200 \mathrm{kcf}$ purchased each month and $\$ 5.60$ per additional kcf.

The normal weather year energy requirements are shown, for the electric and natural-gas-powered alternatives, in Figure 5.2. The monthly electric and gas numbers are in almost constant proportion. because the electric motor and gas engine efficiencies are relatively insensitive to shaft speed and load. 
Monthly peak 15 -minute demand was assumed to be $100 \%$ of connected load for all months with at least one hour at, or over, $80^{\circ} \mathrm{F}$ and to decrease linearly with peak hourly temperature to $60^{\circ} \mathrm{F}$.

The corresponding monthly energy costs are shown in Figure 5.3. The electric cost is almost double the gas cost in July and the cost difference is even larger in the other months. The distribution of monthly energy costs for the electric-powered alternative are shown in Figure 5.4. The figure shows that demand charges account for more than half, ratchet charges account for over $30 \%$, while energy charges account for less than $10 \%$ of the electric unit's annual operating cost.

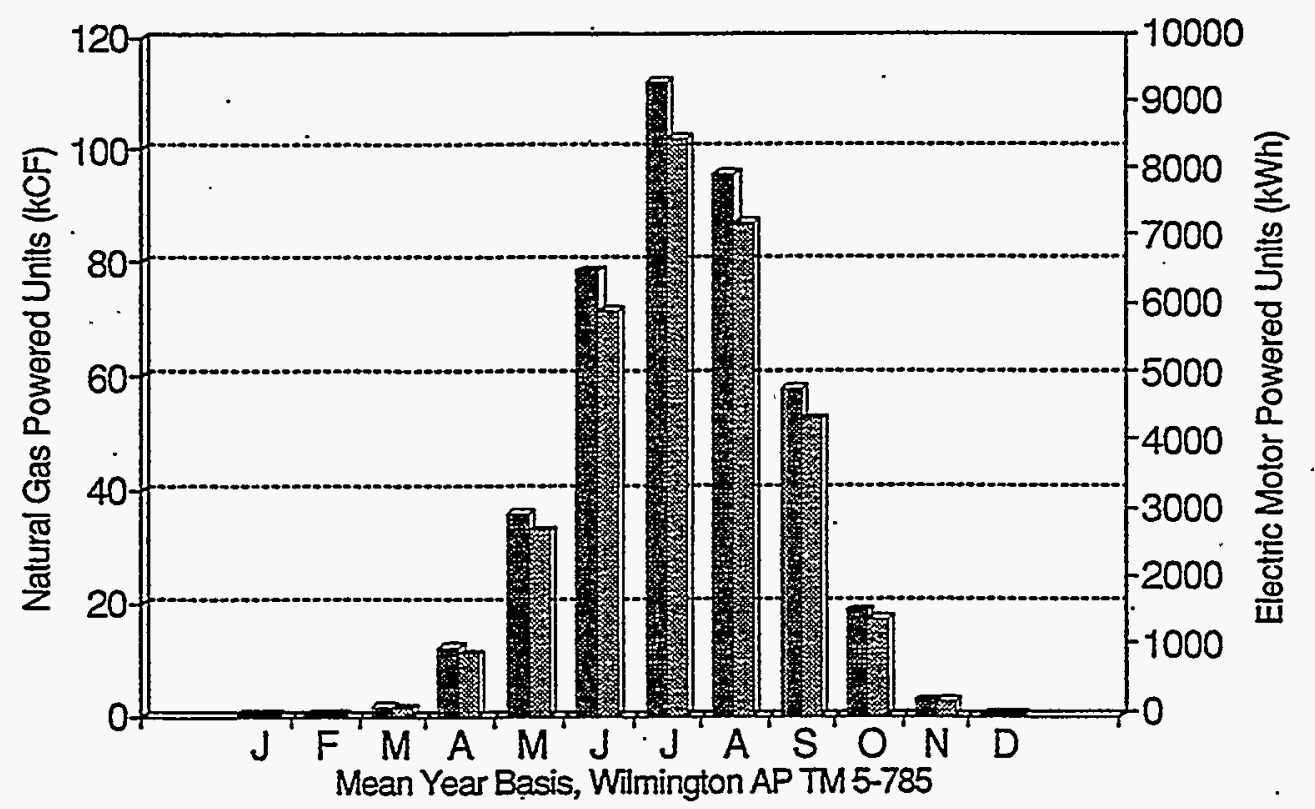

Electric Nat. Gas

Figure 5.2. Energy Requirements for Electric and Natural Gas Alternatives 


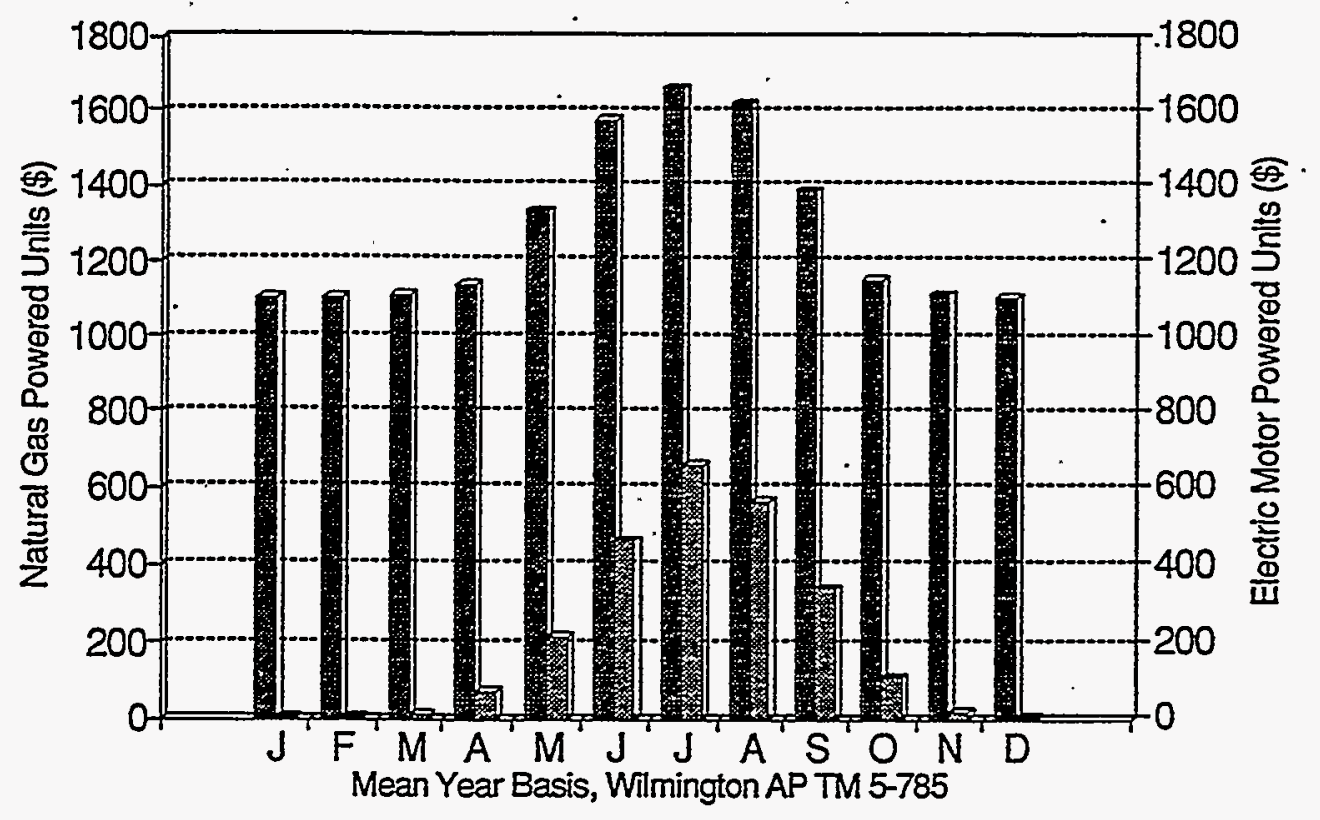

Electric Nat.Gas

Figure 5.3. Monthly Energy Costs for Electric and Natural Gas Alternatives

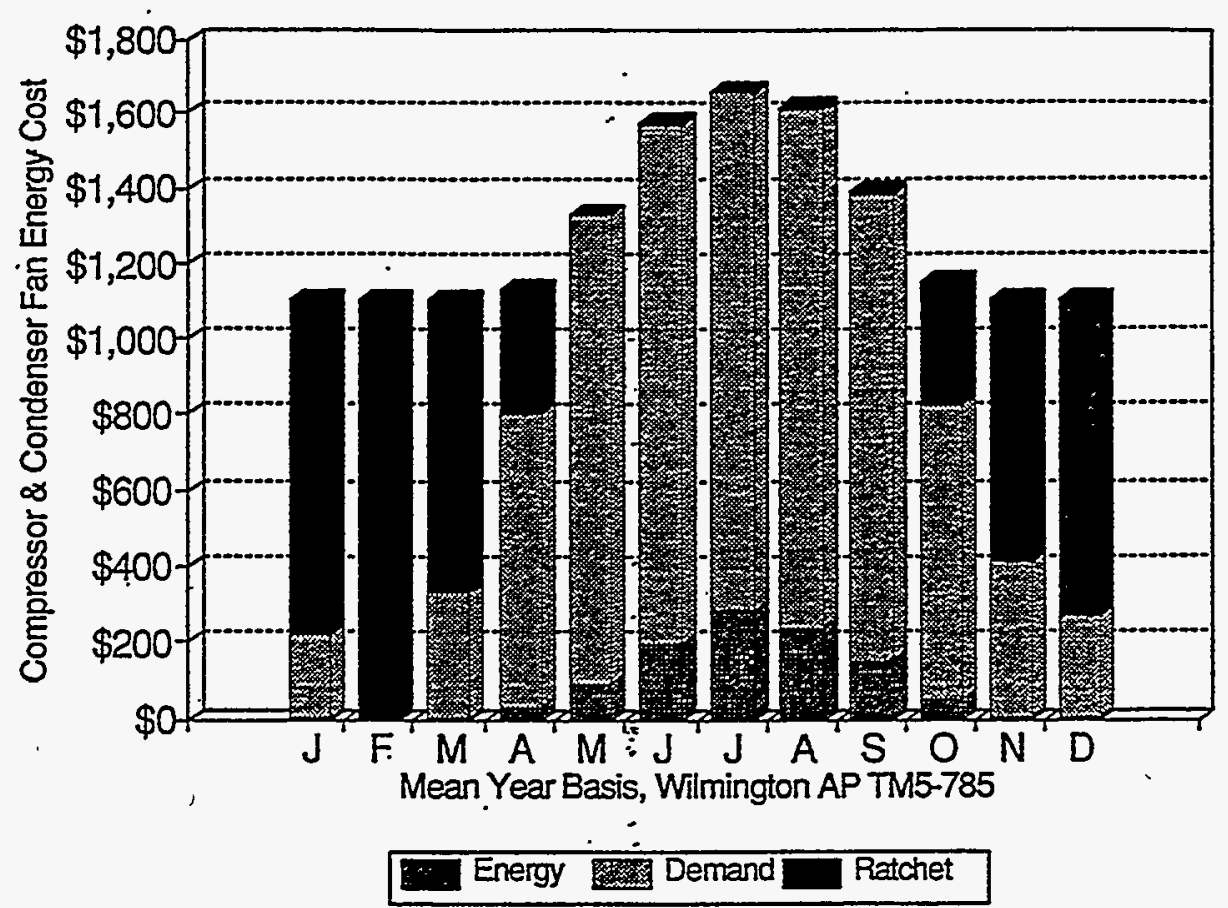

Figure 5.4. Distribution of Monthly Energy Costs for the Electric Alternative 


\subsection{Life-Cycle Cost Comparison}

A life-cycle cost analysis was performed using the FEMP analysis program BLCC (NIST). The financial parameters for the cost study are as follows:

Analysis Type: Federal Analysis-Energy Conservation Projects

Study Period: 15 Years (1994 Through 2008)

Discount Rate: $4.0 \%$ Real (exclusive of general inflation)

The energy-related costs for the electric- (base case) and gas-powered alternatives are shown in Table 5.2.

Table 5.2. Energy-Related Costs

\begin{tabular}{|l|c|c|c|c|}
\hline \multicolumn{1}{|c|}{ Energy Type } & Units/Year & $\begin{array}{c}\text { Price } \\
(\$ / \text { Unit) }\end{array}$ & $\begin{array}{c}\text { Demand } \\
\text { Cost }\end{array}$ & $\begin{array}{c}\text { Total P.V. } \\
\text { Cost }\end{array}$ \\
\hline Electricity & 17,309 & $\$ 0.030$ & $\$ 7,190$ & $\$ 91,348$ \\
\hline Natural Gas & 1,937 & $\$ 0.634$ & $\$ 0$ & $\$ 14,557$ \\
\hline
\end{tabular}

The present value costs for the two alternatives are shown in Table 5.3.

Table 5.3. Comparison of Present-Value Costs

\begin{tabular}{|c|c|c|c|}
\hline & $\begin{array}{l}\text { Base Case: } \\
\text { WGNAS_E }\end{array}$ & $\begin{array}{l}\text { Alternative: } \\
\text { WGNAS_NG }\end{array}$ & $\begin{array}{c}\text { Savings From } \\
\text { Alternative }\end{array}$ \\
\hline $\begin{array}{l}\text { Initial Investment Item(s): cash } \\
\text { requirements as of occupancy }\end{array}$ & $\$ 7,505$ & $\$ 19,595$ & $-\$ 12,090$ \\
\hline Subtotal & $\$ 7,505$ & $\$ 19,595$ & $-\$ 12,090$ \\
\hline $\begin{array}{l}\text { Future Cost Item(s): annual and non- } \\
\text { annual recurring costs energy expenditures }\end{array}$ & $\begin{array}{r}\$ 1,390 \\
\$ 91,348\end{array}$ & $\begin{array}{r}\$ 4,170 \\
\$ 14,557\end{array}$ & $\begin{array}{r}-\$ 2,780 \\
\$ 76,791\end{array}$ \\
\hline Subtotal & $\$ 91,348$ & $\$ 17,337$ & $\$ 74,011$ \\
\hline Total P.V. Life-Cycle Cost & $\$ 98,853$ & $\$ 36,932$ & $\$ 61,921$ \\
\hline
\end{tabular}


The net savings for the gas-powered alternative is the difference between the present value of noninvestment savings, $\$ 74,011$, and the increased total investment of $\$ 12,090$. This gives a net savings, expressed as a present value, of $\$ 61,921$ for the gas-powered alternative. The net savings to investment ratio is 5.12 .

One consideration in the decision to procure the subject technology is the first cost of the equipment versus operating costs. Since many facilities fund capital improvements from one budget and operation, service, and maintenance from another, the long-term savings have no practical benefit. In the above case for NASWG the long-term operating expense reduction of $\$ 148,023$ would not be considered, or even attainable, if a procurement decision based on lowest first cost were made. Note that the increased first cost is paid back in less than two years.

Some utilities offer rebate programs and financing assistance that can help address the first cost issue. For instance, the PECO Energy Demand Side Management Program Plan proposes incentives for gas cooling of $\$ 300 / \mathrm{kW}$, or about $\$ 450 /$ ton, cooling capacity. This incentive, had it been in effect at the time of installation, would have resulted in about $\$ 6,750$ being available to NASWG to offset the additional $\$ 12,090$ for the Thermo King equipment. Where such demand side management or incen- . tive programs exist, financial support for the additional first cost can usually be found. 


\subsection{Conclusions and Recommendations}

Based on the results of the NASWG demonstration, certain conclusions about the equipment performance can be drawn and then applied to the entire federal sector. In addition, recommendations for application of the equipment at other federal sites can be provided. Section 6.1 describes the savings potential at NASWG. The savings potential in the federal sector is estimated in Section 6.2. Conditions that should be considered in implementing this technology at other federal sites are presented in Section 6.3.

\subsection{Savings Potential at NASWG}

The annual energy cost is $\$ 1,225 /$ yr to operate the compressors and condenser fans in the TK unit. This is based on the building loads and equipment performance measured during the 3-week monitoring period during the summer of 1994 and weather data normalized to the full cooling season in a normal year as described in Section 4.0. The annual energy costs to operate the compressor and condenser fan in a comparable electric-powered unit would be $\$ 520 / y r$ in energy charges and $\$ 7,190 / y r$ in demand and ratchet charges. Maintenance of the TK unit is expected to cost $\$ 200 / \mathrm{yr}^{(2)}$ more than the maintenance of a comparable electric-powered unit.

The TK unit will use about the same amount of source energy ${ }^{(b)}$ as a comparable electric-powered unit. The only real differences between the electric- and gas-powered units result from the operating characteristics of the electric motor or natural gas engine as a source of compressor shaft power. The service (level of comfort) provided by the two types of units is indistinguishable. ${ }^{(c)}$

(a) The estimate is based on engine maintenance only because refrigeration subsystem and air-side maintenance activities are the same as for electric motor driven units. According to GTC-1 Installation, Operation and Maintenance Manual, publication \#TK 40267-1, 1/93, page 11, one engine maintenance call per year is required for complete tune-up, renewal of filters, 40 quart oil change and engine winterization.

(b) Source energy is defined as total energy that must be supplied to the source power plant or .

- regional gas transmission system to provide a specified end-use service. This definition considers transmission, distribution, and generation losses but does not consider extraction, processing and transmission losses outside the region of interest.

(c) The noise level of the units was not considered objectionable by the NASWG. No incremental effect of ozone depletion would be found since the TK unit uses R-22, an HCFC refrigerant which is common to electric rooftop equipment as well. A short-term reduction in fossil fuel emissions may result from replacement of electric power as the energy source by natural gas; however, in the long term central plant emissions are expected to be as low, per electric cooling ton-hr delivered, as the per-ton-hr emissions resulting from gas-powered air conditioners. 
The net savings for the gas-powered unit is the difference between the present value of non-investment savings, $\$ 74,011$, and the increased total investment of $\$ 12,090$. This gives a net savings, expressed as a present value, of $\$ 61,921$ for the gas-powered alternative over a 15 -year life cycle. The savings-to-investment ratio is $\mathbf{5 . 1 2}$.

\subsection{Savings Potential in the Federal Sector}

Estimates of the aggregate cost-effective fuel-switchable capacity and present value of the resulting decrease in annual energy costs can be made given certain assumptions. The mix of existing cooling equipment and fraction for which replacement by the new technology is feasible must be assumed because the only numbers available for most federal sites are aggregate installed capacities. The annual energy consumption per unit installed capacity must also be estimated from available climate data. The quotient of annual full-load-equivalent operating time (FLE) and SEER gives one such estimate. A database of FLE (and other characteristics data) for 240 U.S. military installations has been compiled by Nemeth $(1993,1995)$. In this compilation FLE is estimated for a particular site by:

\section{4 [hr/day] x CDD [ ${ }^{\circ} \mathrm{F}$-day/yr $]$}

where

$$
\mathrm{FLE}[\mathrm{hr} / \mathrm{yr}]=\frac{}{\mathrm{T}_{\mathrm{CE}}-\mathrm{T}_{\mathrm{CI}}\left[{ }^{\circ} \mathrm{F}\right]}
$$

$\mathrm{CDD}=$ cooling degree days with respect to a base temperature of $65^{\circ} \mathrm{F}$,

$\mathrm{T}_{\mathrm{CE}}=$ exterior design temperature, and

$\mathrm{T}_{\mathrm{CI}}=$ interior design temperature.

The sites where the new technology is cost-effective may be identified by computing the net present value per unit capacity:

$$
\mathrm{NPV}=\mathrm{C}_{\mathrm{E}}-\mathrm{C}_{\mathrm{G}}+\mathrm{R}+\mathrm{PW}\left(\mathrm{P}_{\mathrm{Emmc}^{-}}-\mathrm{P}_{\mathrm{Gmac}_{\operatorname{mac}}}+\mathrm{FLE}\left(\mathrm{P}_{\mathrm{E}} / \mathrm{SEER}_{\mathrm{E}^{-}}-\mathrm{P}_{\mathrm{G}} / \mathrm{SEER}_{\mathrm{G}}\right)+\mathrm{CFLE} \mathrm{P}_{\mathrm{Dmd}_{\mathrm{d}}} / \mathrm{FLEER}_{\mathrm{E}}\right)
$$
where

$C_{E}, C_{G}=$ first cost per unit capacity of conventional electric- and alternative gas-engine-driven units, $\mathrm{R}=$ utility rebate,

$\mathrm{P}_{\mathrm{Emtac}_{\text {mat }}}, \mathrm{P}_{\mathrm{Gmac}}=$ annualized maintenance costs, per unit capacity, of electric and gas units

$\mathrm{PW}(\mathrm{x})_{i}$ : = present worth of annually recurring cost $\mathrm{x}$ over a 15 -year period at $4 \%$ real discount rate,

FLE = full-load-equivalent operating time per year,

$P_{E}, P_{G}=$ energy prices, adjusted for difference between fuel escalation and general inflation rates,

$\mathrm{SEER}_{\mathrm{E}}, \mathrm{SEER}_{\mathrm{G}}=$ electric and gas equipment seasonal energy efficiencies,

CFLE $=$ equivalent number of demand billing period coincident-full-load events per year,

$\mathrm{P}_{\mathrm{Dmd}}=$ electric demand price (per summer demand billing period)

FLEER $_{E}=$ full-load energy efficiency of conventional electric-driven equipment. 
Note that the first cost to the owner may be modified by utility incentives in some cases. However, this effect is not considered here because of the large number of, and frequent changes in, utility incentive programs. The effect of ratchet demand rates is also not considered because the ratchet parameters are not included in the database. Savings at sites where the per unit NPV is positive are evaluated by multiplying by the installed capacity of equipment eligible for replacement by the new technology. The site NPVs are summed to obtain total savings across all sites.

The results of this analysis indicate that the new technology is life-cycle cost-effective at 10 of the 240 military sites. These sites represent about $6 \%$ of the cooling capacity reported for all sites and over $5 \%$ of the aggregate annual cooling load, as estimated by the above formulas, for all sites.

Assuming that gas-engine-driven cooling equipment with performance and price characteristics similar to the 15-ton rooftop units is made available in a range of sizes ( 2 to 2,000 tons) and configurations (chillers, split systems, package units), the aggregate potential NPV is over $\$ 100$ million and the fuel switch results in about $396,000 \mathrm{MWh} / \mathrm{yr}$ of electric energy use being displaced by $5,628,000 \mathrm{MBtu} / \mathrm{yr}$ of natural gas consumption. These numbers can be extrapolated to the entire stock of federally owned buildings if it is assumed that the distributions of building type, installed cooling capacity, climate, and utility rates for the entire federal sector are well represented by Nemeth's 240 military sites. For the entire federally owned building stock, the potential NPV and energy savings would be about twice as large.

\subsection{Conditions for Implementation}

In the analysis of the retrofit economics for other sites, it is important to determine-by simulation or by monitoring existing equipment with simple run-hour clocks ${ }^{(a)}$ and logs-the distribution of part-load hours for a typical cooling season. This is imperative where the gas-powered alternative is expected to be only marginally attractive or where there is reason to believe that the existing equipment is significantly oversized or undersized. A feasibility study can then be completed using the normal year energy analysis developed and presented in Section 5.2 of this report.

A preliminary sense of the technology's feasibility can be gained using an analysis similar to the federal sector potential analysis described in the previous section. By defining an end-use specific blended electric rate, the analysis can be generalized to include typical demand ratchet rate structures. To avoid confusion with the site-wide blended rate we will refer to this end-use-specific blended rate as the marginal electric cooling rate, $\mathrm{P}_{\mathrm{MEC}}$.

(a) A run-hour clock connected to each cooling stage control line will give a good indication of part load distribution. The readings should be logged at least weekly. A daily log of the readings, together with daily outdoor maximum and minimum temperature, will facilitate extrapolation of the part-load distribution to a normal-weather year. 
This rate is defined as follows:

$$
P_{M E C}=P_{E}+P_{E, D m d} \frac{\text { CFLE }}{\text { FLE }} \frac{\text { SEER }_{E}}{\text { FLEER }_{E}}
$$

The reduction in annual demand and ratchet charges effected by the switch from electric- to gaspowered cooling equipment can also be estimated using a simple approximation (Sohn 1992) in which cooling season demand charges are given by

and the ratchet penalty is given by

$$
\mathrm{N}_{\mathrm{CSM}} \mathbf{P}_{\mathrm{Dmd}}
$$

where

$$
F_{\text {sachet }}\left(12-\mathrm{N}_{\text {CSM }}\right) \dot{P}_{\text {Dmd }}
$$

$\left.\mathrm{N}_{\text {CSM }}={ }_{L} \mathrm{~N}_{\text {CSD }} / 30.67+1\right\lrcorner$ is the number of cooling season months,

$\mathrm{N}_{\text {CSD }}=$ number of cooling season days from the REEP database or, if reliable load-specific data is available, from local experience,

$\left\lfloor x_{\perp}\right\rfloor$ is the integer part of $x$, and

$F_{\text {ratrbet }}$ is the ratchet penalty ( 0.5 to 0.9 for most capacity-short utilities, 0 in most other cases).

With the foregoing parameters it is possible to estimate NPV based on three variables (FLE, $P_{0}$, $P_{M E C}$ ) representing climate and gas and electric rates. It is also possible to determine the value of any one parameter that is needed to make the new technology cost-effective given the other two. This relationship is presented in Figure 6.1.

The sites used in the Section 6.2 analysis are also shown in Figure 6.1 to give an indication of how a rate change or rebate will affect the technology's federal-sector potential. Two points are shown for each site where gas is available. (Thirty-five of the 240 sites do not have gas, and the database therefore gives a gas price of 0 ; these sites are not represented in the figure.) Each " $\square$ " on the plot indicates the existing marginal electric cooling cost at a site. Vertically aligned with each " $\square$ " is an " $\mathrm{x}$ " indicating the marginal electrical cost that is needed to make the new technology cost-effective at. the site. In most cases the " $x$ " is above its corresponding " $\square$ " and the vertical separation is the increase in $P_{M E C}$ needed to justify a change to gas-powered cooling equipment. In the 10 cases with a positive site NPV, the " $x$ "s are below their corresponding " $\square$ "s.

Note that one representative value of FLE was used for each site in the Section 6.2 analysis. Different buildings at a given site will, in reality, exhibit different annual FLE runtime characteristics, so a site for which the preliminary analysis shows the cooling technology to be "not quite" cost effective is likely to have a number of buildings where the technology is, in fact, cost effective. Building or zone-specific feasibility analyses, e.g., the FEDS program, should be performed in such cases.

In addition to the strictly economic conditions, one must consider practical constraints on the technology. Foremost among these is the need for a well-organized maintenance provider. The maintenance requirements of the technology are not burdensome, but the possible consequences of maintenance errors or omissions are more serious than for comparable electric-driven cooling 


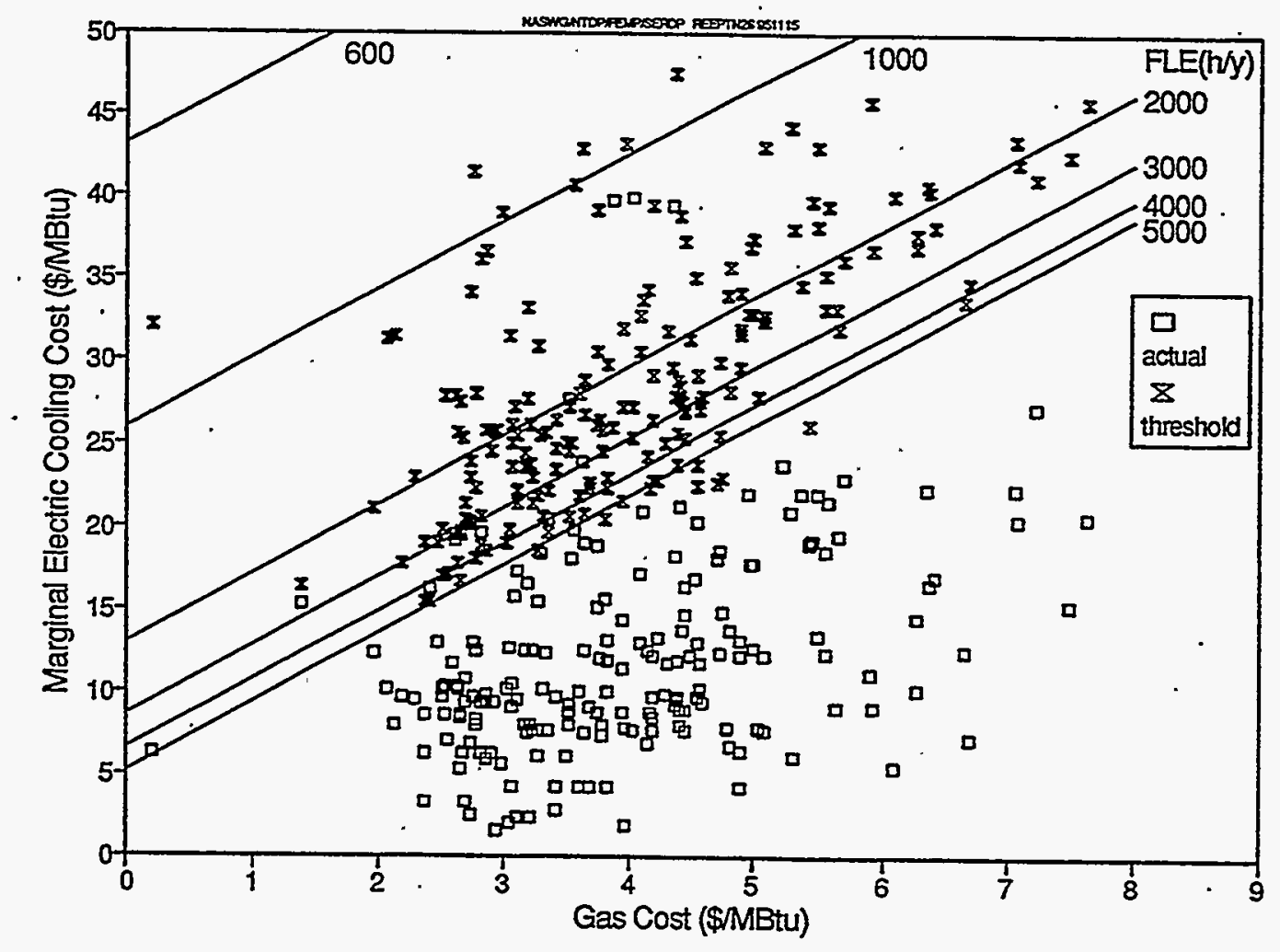

Figure 6.1. LCC-Effectiveness Thresholds for the Gas-Cooling Technology Based on the REEP Data for 240 Military Sites

equipment. Noise and vibration must also be considered because both are considerably greater than those of comparable electric-driven equipment.

The location of the equipment in relation to air intakes must be considered because of the high carbon dioxide and water vapor content of the engine exhaust stream. The heat rejection load must be considered in densely populated or temperature-sensitive areas. The new technology's heat rejection load is about $50 \%$ greater than that of comparable electric-driven technologies. Lastly, a responsible building occupant should be assigned to act as the point of contact for thermal comfort issues. This person should be briefed on the nature of the equipment, importance of correct and consistent thermostat schedule, and the need to promptly report unsatisfactory or unusual system behavior.

In summary, the new technology is generally cost-effective at sites where marginal electricity cost (per MBtu at the meter) is more than four times the marginal gas cost (per MBtu at the meter) and annual full-load-equivalent (AFLE) cooling hours exceed 2,000. This rule-of-thumb was derived from the analysis of sites with marginal gas prices of $\$ 2.20$ to $\$ 7.30$ per MBtu. Applications with fewer AFLE cooling hours will be cost effective at correspondingly higher electric-to-gas price ratios. 



\subsection{References}

AGAL, 1990. Combustion Analysis of TK Units in $C A, N M, M N \& O H$. American Gas Association Laboratory, Cleveland, Ohio.

ANSI/ARI. 1986. Commercial and Industrial Unitary Air-Conditioning Equipment, ANSU/ARI 36086, Air-conditioning and Refrigeration Institute, Arlington, Virginia.

Armstrong, P. R., and D. R. Conover. May 1993. Performance and Evaluation of Gas Engine Driven Rooftop Air Conditioning Equipment at the Willow Grove (PA) Naval Air Station, Interim Report - 1992 Cooling Season. PNL-8677, Pacific Northwest Laboratory, Richland, Washington.

Armstrong, P. R., and S. Katipamula. September 1996. Performance and Evaluation of Gas-EngineDriven Rooftop Air-Conditioning Equipment at the Willow Grove Naval Air Station - Final Report.

PNNL-11366, Pacific Northwest National Laboratory, Richland, Washington.

ASHRAE, 1991, "A Guide for Analyzing and Reporting Energy Use and Characteristics of Commercial Buildings," prepared for PNL under contract 001011-A-A2, May 1991.

ASHRAE, 1987, "An Assessment of the Energy Audit Process in Commercial Buildings," SP-56, December 1987.

ASHRAE, 1989, Handbook of Fundamentals. American Society of Heating, Refrigeration and AirConditioning Engineers, Atlanta, Georgia.

Balcomb, J. D., et al., Passive Solar Design Handbook, Volume II, DOE/CS-0127/2 (January 1980).

EOGC, 1994. Hercules G 1600 Emissions Potential: Ohio EPA Exempt Source Filing, East Ohio Gas Company, eog/mdr 5-16-94.

Falvey, T. P. Natural Gas Cooling at NAS WLGRO. Phase Two--Building 605, Base Exchange, Public Works Services Directorate, Northern Division, Naval Facilities Engineering Command, Philadelphia, Pennsylvania (May 1990).

Mathews, W. F. 1992. "Chill out with another opinion of engine-driven chillers," letter to the editor, Engineered Systems, November/December 1992.

NAVFAC P-89, Engineering Weather Data (áka USAF TM-785) 1978, Washington, D.C.

Nemeth, R. J., D. E. Fornier, and L. A. Edgar. 1993. Renewables and Energy Efficiency Planning (and accompanying database), U.S. Army Construction Engineering Research Laboratory, Champaign, Illinois. 
Nemeth, R. J., D. E. Fornier, and L. A. Edgar. 1995. Renewable and Energy Efficiency Planning-REEP Database, version 2.6, U.S. Army Construction Engineering Research Laboratory, Champaign, Illinois.

NIST, Comprehensive Guide for Least-Cost Energy Decisions, National Institute of Standards and Technology, NBS Special Publication 709, 1987, USDOC, Gaithersburg, Maryland.

NIST, Life-Cycle Costing Manual, National Institute of Standards and Technology, NBS Handbook 135, 1987, USDOC, Gaithersburg, Maryland.

NIST, Energy Prices and Discount Factors for Life-Cycle Cost Analysis 1993, National Institute of Standards and Technology, NIST Interagency Report 85-3273-8 (Annual Supplement to Handbook 135), 1993, USDOC, Gaithersburg, Maryland.

NIST, $A$ User's Guide to the Federal Building Life-Cycle Cost (FBLCC) Computer Program, National Institute of Standards and Technology, NBS Technical Note 1222, 1986, USDOC, Gaithersburg, Maryland.

Philadelphia Electric Company, Demand Side Management Program Plan, February 28, 1991, Before the Pennsylvania Public Utilities Commission, Docket No. I-900005.

Sohn, C. W., and J. H. Kim. 1992. STOFEAS: A CERL Computer Program for Estimating the Economic Feasibility of Storage Cooling Systems. USACERL Report FE-93/12, December 1992.

SWRI, 1988. Natural Gas Engine Performance Tests, Southwest Research for GRI.

TM-785 (see NAVFAC P-89).

\subsection{Site Data}

Building characteristics data provided by Jim Edmond in ASHRAE (1991) format.

Daily maximum/minimum temperatures from NASWG site weather station for 6/92 through 10/92.

Thermo King, 1990. Specification, Thermo-King Corp. (draft-no publication \#).

Thermo King, 1991. Thermo-King GTC-1, Thermo-King Corp. publication \#TK 30058-2 (4-91).

Thermo King, 1993. GTC-2. Installation, Operation and Maintenance Manual, Thermo-King Corp. publication (2-93). 


\section{Appendix A}

Summary of Activity Leading to the Cooperative R\&D Agreement (CRADA) and the Joint Statement of Work (JSOW) 


\section{Appendix A}

\section{Summary of Activity Leading to the Cooperative R\&D Agreement (CRADA) and the Joint Statement of Work (JSOW)}

The federal government is the largest single energy consumer in the United States with consumption estimated to be nearly 1.5 quads $\left(1\right.$ quad $\left.=10^{15} \mathrm{Btu}\right)$ and cost valued at nearly $\$ 10$ billion annually. The Federal Energy Management Program (FEMP) supports efforts to reduce energy use and associated expenditures within the federal sector. One such effort, the New Technology Demonstration Program (formerly the Test Bed Demonstration Program), seeks to evaluate new energy saving U.S. technologies and secure their more timely adoption by the federal government.

Each year the federal government purchases equipment and products through a procurement process that may not readily recognize or accommodate new technologies. In addition, new technologies are rarely purchased and installed until they have been proven through private-sector use. This results in unnecessary federal energy use and operating cost between the time that the technology is commercially available and when it has been "proven" to, and recognized by, federal decision makers.

The New Technology Demonstration Program aims to demonstrate the field performance of selected technologies implemented within the Federal sector and transfer that information to federal decision makers. These "hands on" data provide the federal decision maker with the information needed to justify procurement of the technology in a more timely fashion. This leads to accelerated energy savings and associated environmental benefits. In addition, because the program is limited to U.S. technologies, the U.S. position in the global marketplace may be enhanced.

The program works by using available FEMP resources as leverage to secure public and private interest in jointly evaluating the performance of a new technology. Through a Cooperative Research and Development Agreement (CRADA) a partnership can be created that allows federal and non-federal interests to jointly sponsor such efforts. These partnerships usually involve the manufacturer of the selected technology, a federal site, the utility serving the site, a technology-related research institute, a trade association, and other interested parties. All participants perform certain activities, at their own cost, within the larger program to install and evaluate the technology. This creates a cooperative atmosphere and affords information sharing and economies of scale that might not occur otherwise. 
Recent initiatives within the federal government have focused on the use of natural gas for both economic and environmental reasons. It is therefore fitting that the technology selected for evaluation in the first new technology demonstration, and the subject of this report, is natural gas engine driven cooling equipment.

The project began with the solicitation of interested parties willing to participate in the installation and evaluation of gas cooling technologies. Responses to the solicitation were received from manufacturers and utilities and communications were initiated to explore potential demonstration arrangements. In addition a search was undertaken to identify a suitable federal site within the service areas of those responding utilities. During the last half of 1991 and in early 1992 the plans of many of the respondents changed, leaving one manufacturer and three utilities still interested in participating in the project.

The equipment offered by the one manufacturer, Thermo King Corporation, was a 15-ton natural gas engine driven rooftop air-conditioning unit. The unit is air cooled and serves a single zone for both heating and cooling. It is factory assembled with R-22 (an HCFC refrigerant) and requires single point connections of electrical power and natural gas. The unit's cooling capacity is 190,000 Btuh at ARI Standard 360 rating conditions. The unit's heating capacity is 216,000 Btuh output at 265,000 Btuh input. Variable engine speed and cylinder unloading allow for cooling operation in 4 stages.

All three utilities still interested in participating in the project were asked in early 1992 to help identify a federal site and building that would be suitable for installation and evaluation of the cooling equipment. Numerous buildings were suggested, including historical buildings associated with Independence National Historic Park in Philadelphia, the James E. Carter Library in Atlanta, and postal service facilities in Baltimore. PECO Energy, one of the three interested utilities, located a naval facility within its service area that had recently (fall 1991) installed two of the Thermo King units. This provided an opportunity to more quickly implement the first demonstration, which became critical with the 1992 cooling season approaching. Efforts were initiated to formalize a CRADA among the participating organizations for a demonstration project at the Naval Air Station, Willow Grove, Pennsylvania (NASWG).

A site visit was made to the Naval Air Station at Willow Grove Pennsylvania where two units were installed to serve a retail facility. Discussions were also conducted with other interested parties who had responded to the solicitation. These included the American Gas Cooling Center, PECO Energy, and the Thermo King Corporation. Based on an evaluation of the building, utility costs, and past building performance, it was determined that the installation offered a good opportunity to evaluate the performance of the subject technology.

A CRADA, which included a joint statement of work, was developed and forwarded to all parties for review and evaluation. Subsequent to signing the agreement, work was initiated on planning the evaluation methodology and installing the data acquisition system that would monitor and report on 
equipment and building operation, and climatic conditions. As part of the agreement the American Gas Association Laboratories, who had performed similar efforts on the equipment at other non-federal installations, was tasked to design the data acquisition system on behalf of PECO Energy and AGCC. At the beginning of the 1992 cooling season the data acquisition system was installed and commissioned. Data on the operation of the units were secured during the 1992 cooling season and testing was continued during 1993 to observe heating season performance.

An addendum to the CRADA was signed by the participants in June 1993 to continue monitoring through the 1993 cooling season in order to test control improvements proposed in the May 1993 interim report (Armstrong and Conover 1993). These improvements involved coordinating the operation of the two RTUs and required installation of a duct with a backdraft damper to connect the two distribution systems. NASWG was tasked, in the joint statement of work, to install the duct and damper but the work was never completed.

A second addendum to the CRADA was signed by the participants in July 1993 to install and monitor the new gas-engine-driven cooling product, a 15-ton split system, in the 1993 and 1994 cooling seasons. The installation was not completed until November of 1993 and it was too cold by then to operate the system. The system was therefore started in May 1993 and monitored for one cooling season. 



\section{Appendix B}

Glossary of Terms and Abbreviations 



\section{Appendix B}

\section{Glossary of Terms and Abbreviations}

AGA

AGCC

AGAL

AP

balance point

BLCC

Btu

Btuh

Btu/scf

CBECS

CDD

CDD base
American Gas Association

American Gas Cooling Center

American Gas Association Laboratory

airport weather station

mean daily temperature above which a daily cooling load is observed; the $x$ intercept of the best linear fit to the daily cooling load versus mean daily temperature plot

the FEMP/DOC/NIST computer program for calculating Building Life-Cycle Costs of alternative investments that affect energy use; the program uses the energy escalation and cost of money rates specified in Federal regulations

British thermal unit

Btu per hour

heat content of a cubic foot of gaseous fuel at standard conditions

Commercial Building Energy Consumption Survey-a survey conducted by DOE's Energy Information Agency and the title under which the survey results are reported

cooling degree days -the sum of all positive values of $\left(T-T_{\text {base }}\right)$ in the month, year, or other period of interest, where $T$ is the mean daily temperature and $\mathrm{T}_{\text {base }}$ is the cooling degree-day base (see CDD base)

the outdoor temperature (usually mean daily) above which cooling is required to maintain a specified maximum indoor temperature; although $65 \mathrm{~F}$ is often assumed, the true CDD base temperature varies with building and occupancy characteristics (see also CDD)

\section{B.1}


$\operatorname{cfm}$

condenser

condenser unit

COP

CRADA

$\mathrm{C} 1, \mathrm{C} 2, \dot{\mathrm{C}} 3, \mathrm{C} 4$

DAS

degree-day

degree-day base

demand charge

discharge

DoD

DOC

DX cubic foot per minute

a heat exchanger in which a refrigerant is condensed by rejecting heat to another fluid, such as ambient air or cooling tower water, which has a lower temperature than the saturation temperature of the refrigerant.

a piece of air conditioning equipment containing a refrigerant condenser and, usually, a compressor and controls. Also known as a condensing unit or a condenser/compressor unit, the condenser unit, except in the case of watercooled units, is usually installed outdoors on a roof or pad (see also split system)

coefficient of performance-the ratio of cooling effect to input energy required to deliver the effect

\section{Cooperative Research and Development Agreement}

cooling stage designations where $\mathrm{C} 1$ refers to the lowest cooling rate and $\mathrm{C} 4$ to the highest cooling rate (nominal capacity) of the machine

data acquisition system

a measure of the temperature distribution of a climate obtained by taking the time integral of the difference between outdoor temperature and base temperature whenever that difference is positive (CDD) or negative (HDD)

the reference temperature (usually a building's heating or cooling balance temperature, often assumed to be $65^{\circ} \mathrm{F}$ ) used in a degree day calculation

a charge based on the utility customer's peak 15-minute electric load during the billing month

pertaining to the compressor outlet port or to refrigerant conditions at the compressor outlet port

Department of Defence

Department of Commerce

direct expansion-a common method of space cooling in which the refrigerant expands inside the tubes of a heat exchanger, the outside surfaces of which are directly exposed to the air stream 
evaporator

FEMP

HCFC

HDD

HDD base

HHV

hp

HVAC

IAP

IC engine

IPLV

JSOW

kef

kWh a heat exchanger in which a refrigerant is boiled, thus extracting heat from another fluid, such as air, water or brine

Federal Energy Management Program-the umbrella program under which the Test Bed Demonstration Program operates

hydrogenated chloroflourocarbon-a refrigerant that has low impact (compared to the non-hydrogenated CFC compounds) on the earth's atmospheric ozone, but which will eventually be replaced by refrigerants with even lower impact

heating degree days-the sum of all positive values of $\left(\mathrm{T}_{\text {base }}-\mathrm{T}\right)$ in the month, year, or other period of interest, where $T$ is the mean daily temperature and $\mathrm{T}_{\text {base }}$ is the heating degree-day base (see HDD base)

the outdoor temperature (usually mean daily) below which heating is required to maintain a specified minimum indoor temperature; although $65 \mathrm{~F}$ is often assumed, the true HDD base temperature varies with building and occupancy characteristics (see also HDD)

higher heating value-includes the latent heat of water vapor produced in the combustion of a fuel

horsepower-a measure of shaft (output) power and, in the case of motors, of electrical (input) power

heating, ventilating and air conditioning

international airport weather station

internal combustion engine

integrated part-load value-a seasonal average COP or efficiency or total energy use obtained by convolution (integral of the product) of an HVAC unit's part-load COP, efficiency, or input power function with the load distribution function

joint statement of work

thousand cubic feet

kilowatt-hour 
life-cycle cost-the total cost to own and operate a building (or other tangible property)-including cost of money, periodic and aperiodic maintenance and equipment replacement costs, energy escalation rates and salvage valueexpressed (usually) as a present value or annualized value

lbf pound force-a measure of force, in the English system, equal to the force required to accelerate one pound mass at $32.2 \mathrm{ft} / \mathrm{s}^{2}$

$\mathrm{lbm}$ pound mass-a measure of mass (not weight) in the English system

MBtu

million British thermal units

multi-zone RTU a rooftop HVAC unit that provides variable supply air flow rates to a distribution system that has dampers or other means of controlling flow independently to two or more zones

NAS

Naval Air Station

NASWG

NAVFAC

Naval Air Station at Willow Grove, Pennsylvania

Naval Facilities Engineering Command

net present value (NPV)

net savings to investment ratio

the difference between the PVLCC of the base case and the PVLCC. of a given alternative divided by the initial cost of the alternative

NIST

National Institute for Science and Technology-a DOC laboratory and developer of the FEMP life-cycle cost methodology and computer program

NTDP New Technology Demonstration Program

PECO Energy

The electric and gas utility serving the Philadelphia, Pennsylvania, area (formerly Philadelphia Electric Company)

PNNL

Pacific Northwest National Laboratory

PV

present value

PVLCC

present value life-cycle coṣt 
ratchet charge

source energy

split systen

subcool

suction

superheat

TK

ton

Trico Inc. a monthly charge based on the utility customer's highest monthly demand in the preceding 12 months

the amount of energy input to a power plant (electricity) or energy input to a regional gas transmission system (natural gas) required to provide a given amount of energy at the customer's meter

a heat pump or direct-expansion air conditioner in which the evaporator coil and condenser coils are in separate equipment cabinets. The condenser is usually included in the the outdoor cabinet with the condenser (see also condenser unit)

to cool a liquid (e.g., refrigerant) below its saturation temperature

.pertaining to the compressor inlet port or to refrigerant conditions at the compressor inlet port

to heat a gas (e.g., refrigerant) above its saturation temperature

Thermo-King Corporation-developer and manufacturer of the gas IC engine driven air-conditioning units demonstrated in this project

measure of refrigeration capacity equal to 12,000 Btuh

TK spin-off company that currently markets the gas engine cooling technology evaluated in this report 



\section{Appendix C}

\section{Thermo King GTC-2 Specification}

\section{5-Ton Natural Gas Powered \\ Air Conditioning Unit}

February 1, 1993

Revision 1 



\section{INDEX/SUMMARY}

\section{SECTION}

1.0 DESCRIPTION - GENERAİ

2.0 DESCRIPTION - TECHNICAI

3.0 CONTROL SYSTEM DESCRIPTION

4.0 INSTRUMENTATION

5.0 MISCELLANEOUS DATA

6.0 COOLING CONTROL SEQUENCE

7.0 APPLICATION CONSIDERATIONS
PAGE

1

$1-2$

$2-4$

4

$5-7$

8-9

10-13

\section{DRAWINGS}

Electrical Schematic

Unit Drawing Unit Dimensional Drawing

$\frac{14-15}{16}$

Corner Loading Diagram

Rigging Diagram

17

Forklift Detail Diagram

$-18$

19

20

COP vs A/C Capacity Chart

21

Refrigerant Piping Diagram.

22 



\subsection{DESCRIPTION}

\subsection{General Description:}

The Thermo King GTC-2 is a 15 ton air cooled, remote condensing unit that uses a natural gas powered engine to drive a reciprocating compressor. The system is suitable for connection to indoor or outdoor installations of new or existing industry standard evaporator coil(s), air handler(s) or chiller barrel(s).

Each GTC-2 unit is factory wired, piped and tested prior to shipment. The unit requires connection of electrical power, natural gas, refrigerant lines and a temperature control interface. All necessary fluids are included with the unit. See Page 16 for a unit outline drawing.

\subsection{Capacity Rating:}

The unit cooling capacity at $2200 \mathrm{rpm}$ is $182,000 \mathrm{Btu} / \mathrm{Hr}$ (15.2 tons) at 95 degrees ambient temperature and 50 degrees suction temperature.

The unit is rated in accordance with ARI Standard 365. See section 5.5 for additional performance information.

\subsection{Physical Data:}

\subsubsection{Unit Dimensions: $85.1^{\prime \prime} \times 85.6^{\prime \prime} \times 56.6^{\prime \prime}(\mathrm{L} \times \mathrm{W} \times \mathrm{H})$}

1.3.2 Unit Weight: 2200 pounds (including fluids)

\section{2:0 TECHNICALLDESCRIPTION}

\subsection{Cabinet Construction:}

The base frame is constructed of welded 12 gauge mild steel with 14 gauge galvaneal frame members. Exterior panels are $.050^{\prime \prime}$ thick aluminum. All exterior cabinet components are chemically cleaned and painted with a high solids polyester baked enamel for maximum corrosion protection. The engine compartment is insulated to minimize noise emissions. Lifting lugs are factory installed for rigging and the unit can . be moved with a forklitt.

\subsection{Engine/Compressor:}

2.2.1 Engine: The compressor drive engine is an industrial duty natural gas fueled engine. See Page 5 for engine specifications. Starting and ignition systems are 12 volt dc. The unit is supplied with a starting battery.

2.2.2 Compressor: The compressor is a Thermo King Model X430; 4 cylinder, 30 cu./in., industrial duty, reciprocating, open drive type. The compressor includes a positive displacement oil pump, suction and discharge line service valves, suction strainer, oil level sight glass and crankcase heater. 
2.2.3 Engine/Compressor Coupling: The engine/compressor are directly coupled using a Thermo King two plate design. The compressor is flange mounted to the engine flywheel housing.

2.2.4 Vibration Isolation: "The engine/compressor assembly is isolated from the unit frame using an elastomeric mounting system. Further isolation is achieved using braided wire line isolators for the refrigerant and engine fuel connections.

\subsection{Refrigeration Components:}

2.3.1 The refrigerant circuit is piped, tested, dehydrated and factory charged with 40 pounds of refrigerant HCFC-22.

2.3.2 Coils: (Condenser/Radiator/Subcooler) The coils are fabricated from 3/8" O.D:, $0.016^{\prime \prime}$ wall seamiess copper tubing and mechanically bonded to corrugated $0.008^{\prime \prime}$ aluminum fins. Each coil is factory leak tested to 400 PSIG.

2.3.3 Condenser/Subcooler/Radiator Fan: The fan is a propeller type and is belt driven off the engine. The drive system includes a spring loaded idler pulley for belt tensioning.

2.3.4 Refrigeration Circuit Components: Refrigeration circuit components include suction and discharge service valves, wire braided discharge and suction line isolators, receiver tank, suction accumulator, sight glass, liquid line filter/drier, manual liquid line shutoff valve, spring type high pressure relief valve, replaceable core suction filter and a compressor bypass oil filter. All copper . refrigeration lines are vinyl coated for corrosion protection.

\subsection{CONTROL SYSTEM}

\subsection{General:-}

The unit is factory equipped with refrigeration and engine safety/operating controls which require 230 or 460 volt single phase electrical power. The maximum current draw is five amps at 230 volts.

\subsection{Engine Controls:}

\subsubsection{Engine Operating Controls:}

3.2.1.1 Engine On/Off Switch: Enables or disables the fuel shutoff solenoid and starter.

3.2.1.2 Auto/Thermostat/Thermostat By-Pass, Auto/Start, Auto/Run Switch: In the auto position, engine operation is controlled by the field supplied thermostat. When switch is placed in the by-pass position, the engine will automatically start and run. 
3.2.1.3 Manual Start Switch: The engine starter can be operated by enabling the manual - start switch on the unit.

3.2.1.4 Starter Control: The unit is equipped with an automatic start module that . functions off of the external cooling signal.

3.2.1.5 Electronic Governor: A solid state controller and actuator provide precise regulation of engine speed. The operating speeds are 1200,1500, 1800 and $2200 \mathrm{rpm}$.

3.2.1.6 Battery Charging Control: The unit is equipped with a regulated battery charging system to recharge and maintain the 12 volt dc starting battery.

\subsubsection{Engine Safety Controls:}

3.2.2.1 Oil Pressure Switch: The engine is protected from lubrication failure by a low oil pressure switch.

3.2.2.2 Coolant Temperature Switch: The engine is protected from overheating by a high coolant temperature switch.

3.2.2.3 Engine Overspeed Module: A solid state electronic device is provided to stop the engine if excessive speed is sensed.

\subsubsection{Engine Gas Train:}

The engine gas train is supplied complete with the unit. Components include an electric fuel solenoid valve, carburetor inlet pressure regulator and a natural gas carburetor with an integral zero governor (positive fuel shut off when engine isnot running).

\subsection{Refrigeration Controls/Safeties:}

\subsubsection{Refrigerant High Pressure:}

The compressor circuit has a manual reset high refrigerant pressure lockout .. switch.

3.3.2 Refrigerant Low Pressure:

The compressor circuit has a manual reset low refrigerant pressure lockout switch.

3.3.3 Low Ambient Compressor Lockout:

The control circuit has an auto reset outdoor ambient temperature switch to prevent compressor operation below $45^{\circ} \mathrm{F}$.

3.3.4 High Pressure Relief:

A spring loaded relief valve is provided to prevent unsafe build up of refrigerant pressure. 


\subsubsection{Compressor Low Oil Pressure:}

The compressor circuit has a manual reset lockout switch for low lubricating oil pressure.

\subsubsection{Crankcase Heater:}

A line voltage compressor crankcase heater is energized during the off cycle to provide protection against refrigerant migration.

\subsection{Temperature Controls:}

The GTC-2 control system has four stages of cooling. Each stage is activated by the field supplied thermostat/controller. The thermostat/controller provides the necessary signals to the GTC-2 based on the cooling requirements of the controlled space. See the detailed control sequence on Page 8.

\subsection{INSTRUMENTATION}

\subsection{Engine Hourmeter:}

The control panel mounted hourmeter is a solid state type with LCD readout. It records the number of hours of engine/compressor operation.

\subsection{Engine Oil Pressure Gauge:}

Analog type; mounted by engine/compressor compartment access doors.

\subsection{Engine Coolant Temperature Gauge:}

Analog type; mounted by engine/compressor compartment access doors. 
(5)

\subsection{MISCELLANEOUS DATA}

\subsection{Hercules G1600 Natural Gas Engine:}

The Hercules G1600 is a spark ignition, carbureted natural gas engine that has the following features:

Fuel

Number of cylinders

Cylinder arrangement

Bore

Stroke

Displacement

Rated horsepower

Operating speeds

Ignition (electronic)

Spark plugs

Plug gap

Valve lash:

Intake (cold and hot)

Exhaust (cold and hot)

Firing order

Compression ratio

Lubrication system

Oil pressure (regulated)

Oil change interval

Oil çarsacity

Oil type

Oil pump

Oil filters

Engine serial number

Engine rotation

Carburetor

Carburetor regulator

Air filter

Cooling system coolant

Unit inlet gas pressure

Oil pressure switch

Coolant temperature switch

Crankcase breather
Natural gas

4

No. 1 at pulley end

4.0 in.

3.25 in.

$163 \mathrm{cu}$. in.

31.0 BHP @ 24,00 RPM

2200 RPM

1800 RPM

1500 RPM

1200 RPM

Solid state distributorless

Champion RJ88P

.013-.016"

0.015 in.

$0.015 \mathrm{in}$.

$1-3-4-2$

7.5:1

Dry sump

37-40 PSIG at $2200 \mathrm{rpm}$ with the engine at operating temp.

Consult Thermo King Maintenance Manual 40 guests withi ieniote zant.

Consult Thermo King Maintenance Manual Gear type - positive pressure

Full flow type - TK P/N 11-7079

By-pass type - TK P/N 11-5703

Right rear side viewed from pulley end .

Clockwise (viewed from pulley end)

IMPCO Model 100

Maxitrol full flow type

TK P/N 11-5978, dry element type

$50 / 50$ water ethylene glycol.

$4.5^{n}-12^{n}$ Water column - size piping for a maximum of $350,000 \mathrm{BTU} / \mathrm{Hr}$.

Normally closed, opens at $15 \pm 3$ PSIG

Normally open, open at minimum $190^{\circ} \mathrm{F}$, closed at $225+5^{\circ} \mathrm{F}$

Open type PCV system 


\subsection{Refrigeration Components:}

Compressor:

Max. operating speed

Oil charge

Oil type (150 SUS)

Refrigerant

Refrigerant charge

High pressure cutout (HCFC-22)

Opens

Closes

Low pressure cutout

Opens

Closes

Oil pump pressure operating range

Compressor drive

High pressure relief opens

(spring loaded)

Low ambient lockout

\subsection{Condenser/Radiator Fan:}

Air flow

Fan diameter

Number of blades

Fan drive

\subsection{Air Coil Data:}

Condenser Coil:

Net face area

Tube diameter

Number of rows

Fins per inch

Subcool Coil:

Net face area

Tube diameter

Number of rows

Fins per inch

Radiator Coil:

Net face area

Tube diameter

Number of rows

Fins per inch
Thermo King Model X430, $30 \mathrm{cu}$. inch

2200 RPM

$134 \mathrm{oz}$.

TK P/N 67-404 synthetic

HCFC-22

40 lbs. from factory, system requirements will vary with the application

400 PSIG

325 PSIG

30 PSIG

50 PSIG

$15-45$ PSIG

Direct drive 6 pin rubber bushing coupling

450 PSIG

$45^{\circ} \mathrm{F}$ cutout

$55^{\circ} \mathrm{F}$ cutin

16,000 CFM (maximum)

42 inches

6

Belt driven off engine

24.44 sq. $\mathrm{ft}$.

$3 / 8$ inch

3

14

4.20 sq. ft.

$3 / 8$ inch

3

14

4.20 sq. ft.

$3 / 8$ inch

3

14 


\subsection{Capacity Data (Btu/Hr):}

Suct. Temp.

$\left({ }^{\circ} \mathrm{F}\right)$

1200 RPM, Compressor $100 \%$ Loaded

\begin{tabular}{|c|c|c|c|c|c|c|}
\hline 50 & 125,000 & 119,000 & 112,000 & 106,000 & 99,000 & 93,000 \\
\hline 40 & 107,000 & 101,000 & 95,000 & 88,000 & 82,000 & 76,000 \\
\hline & 55 & 65 & $75)$ & 85 & 95 & 105 \\
\hline \multicolumn{7}{|c|}{ Ambient Temp., ( $\left.{ }^{\circ} \mathrm{F}\right)$} \\
\hline
\end{tabular}

Suct. Temp.

$\left({ }^{\circ} \mathrm{F}\right)$ 1500 RPM

\begin{tabular}{|c|c|c|c|c|c|c|}
\hline 50 & 156,000 & 148,000 & 140,000 & 132,000 & 124,000 & 116,000 \\
\hline 40 & 134,000 & 126,000 & 118,000 & 111,000 & 103,000 & 95,000 \\
\hline \multicolumn{8}{|c|}{ Ambient Temp., $\left({ }^{\circ} \mathrm{F}\right)$} & 85 & 95 & 105 \\
\hline
\end{tabular}

Suct. Temp.

$\left({ }^{\circ} \mathrm{F}\right)$
\begin{tabular}{|c|c|c|c|c|c|c|}
\hline 50 & 188,000 & 178,000 & 168,000 & 159,000 & 149,000 & 140,000 \\
\hline 40 & 161,000 & 152,000 & 142,000 & 133,000 & 123,000 & 114,000 \\
\hline & 55 & 65 & 75 & 85 & 95 & 105 \\
\hline
\end{tabular}

Ambient Temp., ( $\left.{ }^{\circ} \mathrm{F}\right)$

Suct. Temp.

$\left.{ }^{\circ} \mathrm{F}\right)$ 2200 RPM

\begin{tabular}{|c|c|c|c|c|c|c|}
\hline$\left({ }^{\circ} \mathrm{F}\right)$ \\
\hline 50 & 230,000 & 218,000 & 206,000 & 194,000 & 182,000 & 171,000 \\
\hline 40 & 197,000 & 185,000 & 174,000 & 162,000 & 151,000 & 140,000 \\
\hline & 55 & 65 & 75 & 85 & 95 & 105 \\
\hline
\end{tabular}

Ambient Temp., $\left({ }^{\circ} \mathrm{F}\right)^{-}$ 


\subsection{COOLING CONTROL SEQUENCE}

\subsection{Control Sequence:}

The unit is supplied with a terminal strip for four stages of cooling and a 24 volt ac power feed for the field supplied thermostat/controller power and cooling contacts.

To initiate cooling, the external thermostat/controller first stage cool contacts close and energize the "YI" terminal in the GTC-2 control box. A solid state autostart control then energizes the 12 volt dc starter motor which initiates engine cranking. When sufficient engine intake manifold vacuum is developed, proving engine cranking, a manifold vacuum pressure switch closes and energizes the engine fuel valve. The starter motor cranking is terminated by the autostart module after the engine has reached approximately $650 \mathrm{rpm}$ as sensed by a magnetic sensor mounted next to the flywheel gear teeth (which transmits engine rpm to the autostart control). The electronic governor will be disabled and the compressor unloader enabled during the starting cycle and for 30 seconds after cranking is terminated. This insures that the engine has reached idle speed before engine speed control is given to the external thermostat/controller. During the start cycle, the throttle position is controlled by the carburetor's mechanical idle stop. While the engine is cranking, the engine safety circuit (which includes the low oil pressure and high water coolant temperature switches) is disabled to prevent nuisance tripping. The safety circuit is enabled once the engine starts.

A second time delay relay will hold the engine at $1200 \mathrm{rpm}$ for four minutes to allow proper engine warm-up. After the warm-up period, the engine speed controi is fully passed to the external thermostat/controller. The second, thrro and fourih stages are enabled (depending on denand) by the external thermostat/controller which energizes the "Y2", "Y3" and "Y4" terminals respectively. The engine rpm will increase to 1500,1800 and 2200 rpm respectively. Unit stage down is the reverse of the above. The engine can be cycled between any speed as required once the start and warm-up cycles are complete (for instance the engine can be accelerated from 1200 to $2200 \mathrm{rpm}$ ). The engine cool-down cycle will start with the termination of the external signal to the "Y1" terminal. This keeps the engine running for 4 minutes to insure proper engine cool-down. After the time delay has been satisfied, the engine will be cycled off. If during the cool-down cycle the external controller re-enables the cooling by energizing terminals "Yl", "Y2", "Y3" or "Y4", the cool-down timer will be reset and engine control will revert back to the external controller/thermostat. 
6.2 Engine Operating, Safety and Limit Controls: -

If the engine control switch is turned off or a safety limit, operating limit or ac power failure occurs, the cool-down cycle is bypassed and the engine cycles off immediately When the fault is corrected, or the engine control turned on, the normal start and run sequence is enabled.

The engine autostart module will lock out the starting circuit after 30 seconds if the engine does not start. The module can be reset and the start sequence reinitiated by de-energizing all cooling contacts for 6 seconds and then re-applying power to cooling contact "Y1". When the unit is reset, the standard start cycle is initiated. .

Engine limit controls include:

1. high coolant temperature cutout switch

2. Low lubricating oil pressure cutout switch

3. overspeed switch

All are manual reset. If an engine fault condition occurs, the normal shut-off cycle is bypassed and the engine shuts off immediately.

\subsection{Compressor Operating, Safetv and Limit Controls:}

Compressor limit controls include:

1. high discharge pressure cut-out switch

2. low suction pressure cut-out switch

3. low lubricating oil pressure cut-out switch

-All are manual reset. Duning off cycle operation, a line voltage compressor crankcase heater is energized. If a compressor fault condition occurs, the normal shut of cycic is bypessed and the engine struts wown immeưiately.

\subsection{Unit Status/Alarm Outputs:}

The GTC-2 unit is supplied with electrical quick connect terminals to provide 24 volt ac outputs of the unit's operational status. An interface relay panel is required to access this information. Contact Thermo King Corporation for more details. 


\subsection{APPLICATION CONSTERATIONS}

\subsection{General:}

The Thermo King GTC-2 units are gas engine driven, reciprocating compressor, remote condenser units (HCFC-22 refrigerant). Refrigeration performance and system design are very similar to electrically powered, reciprocating compressor, condensing units. They are suitable for new or retrofit installations using single or multiple indoor/outdoor industry standard evaporator coil(s), air handler(s) or chiller barrel(s). The following are general application guidelines. Contact Thermo King Corporation Gas A/C Application Engineering for specific application recommendations and/or additional information.

\subsection{Evaporator Coil Sizing and Circuiting:}

Refer to the unit capacity data on Page 7 for performance information. For new applications, the use of ARI listed evaporator coil(s) and air handler(s) rated for the GTC's capacity are recommended to insure satisfactory low side capacity. For retrofit or specialized applications consult a professional HVAC design engineer and/or Thermo King Corporation Gas A/C Application Engineering.

When selecting an evaporator coil or sizing an air handler for comfort cooling applications, some general HVAC industry guidelines are:

Evaporator Face Area - Good design practice for comfort cooling applications is to select the coil's face area so the face velocity is between 300 and 550 feet per minute (fpm). Applications over $600 \mathrm{fpm}$ will result in excessive condensate water carryover from the coil.

Evaporator Coil Circuiting - It is recommended that at full load the evaporator refrigerant pressure drop is 3.5 to $6.0 \mathrm{psi}$. This will aid oil return to the compressor during lightly loaded (low engine speed/low suction. pressure) conditions.

Expansion Valve Selection - Thermal expansion valves (TXV's) of the 'balanced port' design (Sporlan 'OVE' or Alco 'TRAE' are examples) are recommended to insure good performance over the machine's capacity range. Use of capillary tube systems will void the factory compressor warranty. In single TXV applications, a $10 \%$ bleed port is recommended to help equalize system pressures when the unit cycles off. This will minimize engine starter torque requirements. 
Conditioned Air Requirements - General comfort cooling systems are sized for $400 \mathrm{~cm} / \mathrm{ton} \pm 10 \%$. Special applications may require significantly higher or lower air flows.

Suction Temperatures - Full load (max. engine speed) design suction temperatures should not exceed $50^{\circ} \mathrm{F}$ (84.0 psig). Applications requiring suction temperatures below $35^{\circ} \mathrm{F}$ (61.5 psig) are permitted, but should be referred to Thermo King Corporation

\subsection{System Design Considerations:}

Follow accepted industry guideines when designing and sizing system refrigeration piping. The Thermo King GTC has ainigh capacity turndown, so proper sizing of the suction line plumbing for adequate oil return is very important.

Systems utilizing multiple evaporators and chiller barrels are, in general, permitted, but it is highly recommended that a HVAC design professional be consulted to insure proper system design, load matching and control system. integration. Each evaporator or chiller barrel in these applications should be isolated by a solenoid valve.

The unit controls are very flexible and are suitable for a variety of comfort or process cooling applications, but proper control system integration is very important (refer to Page 8 for the unit control sequence for additional information). The engine speed settings can be modified to maximize application performance, but require TK Corporation approval. Refer any special applications requirements or questions to Thermo King Corporation Gas A/C Application Engineering.

The X430 compressor has one step of unioading $(50 \%)$. The staniard control sequence uses the unloader only during the engine starting mode. If continuous operation of the unloader is required, the application must be approved bv Thermo King Corporation

Use of a single or recycling compressor pump down cycles are not permitted.

Makeup air applications require written Thermo King Corporation approval to maintain unit warranty.

Thermo King does not guarantee the suitability of the GTC remote condenser in any application. It is the responsibility of the system designer(s) and installer(s) to insure that the system design and installation allows for proper unit performance and maximum reliability.

The above recommendations are not applicable for all applications and represent generally accepted HVAC industry practices. For further information contact Thermo King Gas A/C Application Engineering. 


\subsection{Unit Placement:}

Proper operation of the GTC-2 condensing unit requires that sufficient space be allowed around the unit to allow free flow of ambient air through the unit. See Page 27 which illustrates the air pattern through the unit and minimum allowable service and operating clearances. Applications that either restrict condenser air or cause condenser air recirculation will decrease both unit capacity and efficiency and lead to operational problems.

The GTC-2 engine driven fan draws air into and discharges air out the condenser coil in a horizontal direction. The fan discharge grille allows for changing the direction of air discharge from the unit (see Page 23 ). The discharge grille is shipped from the factory in the updraft position.

Pages 24 to 26 show application diagrams which illustrate a variety of unit placement options, their limitations, associated design considerations and unit locations to avoid.

Contact your local Thermo King dealer or Thermo King Corporation Gas A/C Application Engineering Department for assistance with unit location requirements.

\subsection{Unit Mounting:}

' The GTC-2 unit can be mounted without a base or foundation if the unit location is level and can support the unit weight. The unit is suitable for both rooftop or ground mounting and can be installed on combustible flooring or Class A, B or C roofing material. It is suggested that the unit is placed on a support of a minimum ten inches in height. This is to aid in draining the engine lubricating oil during maintenañce. Follow all applicable local codes when installing the unit.

Contact Thermo King for curbing information. See Pages 28 to 30 for curbing information and details regarding unit installation and mounting. In general the unit base is strong enough to require support of the unit on two opposing sides only. Contact your local Thermo King dealer or Thermo King Corporation Gas A/C Application Engineering Department for assistance with unit location requirements.

\subsection{Vibration Isolation and Sound Emissions:}

The GTC-2 engine/compressor is isolated from the unit base to, minimize vibration transmission and structural sound transmission into the building. In general, extra isolation such as spring loaded curbing is not required. The unit refiigeration and gas piping are also isolated from the engine. In general, flexible connectors on the external gas piping and refrigerant lines are not required. 
The GTC-2 unit is designed to minimize noise levels, but unit placement will affect radiated sound. See Page 27 for details. Place the unit with the condenser fan away from an acoustically sensitive area. Contact your local Thermo King dealer or Thermo King Corporation Gas A/C Application Engineering Department for assistance.

\subsection{Unit Servicing:}

Following the unit minimum spacing recommendations on Page 27 will allow sufficient clearances for normal maintenance and servicing of components.

The GTC-2 engine compartment is designed to contain any possible leak of engine lubricating oil. Some roofing materials may break down if subjected to lubricating oils. It is recommended that oil resistant roofing material be used in the areas adjacent to the engine compartment. See the unit installation, operation and maintenance (IOM) manual for additional information and precautions. 


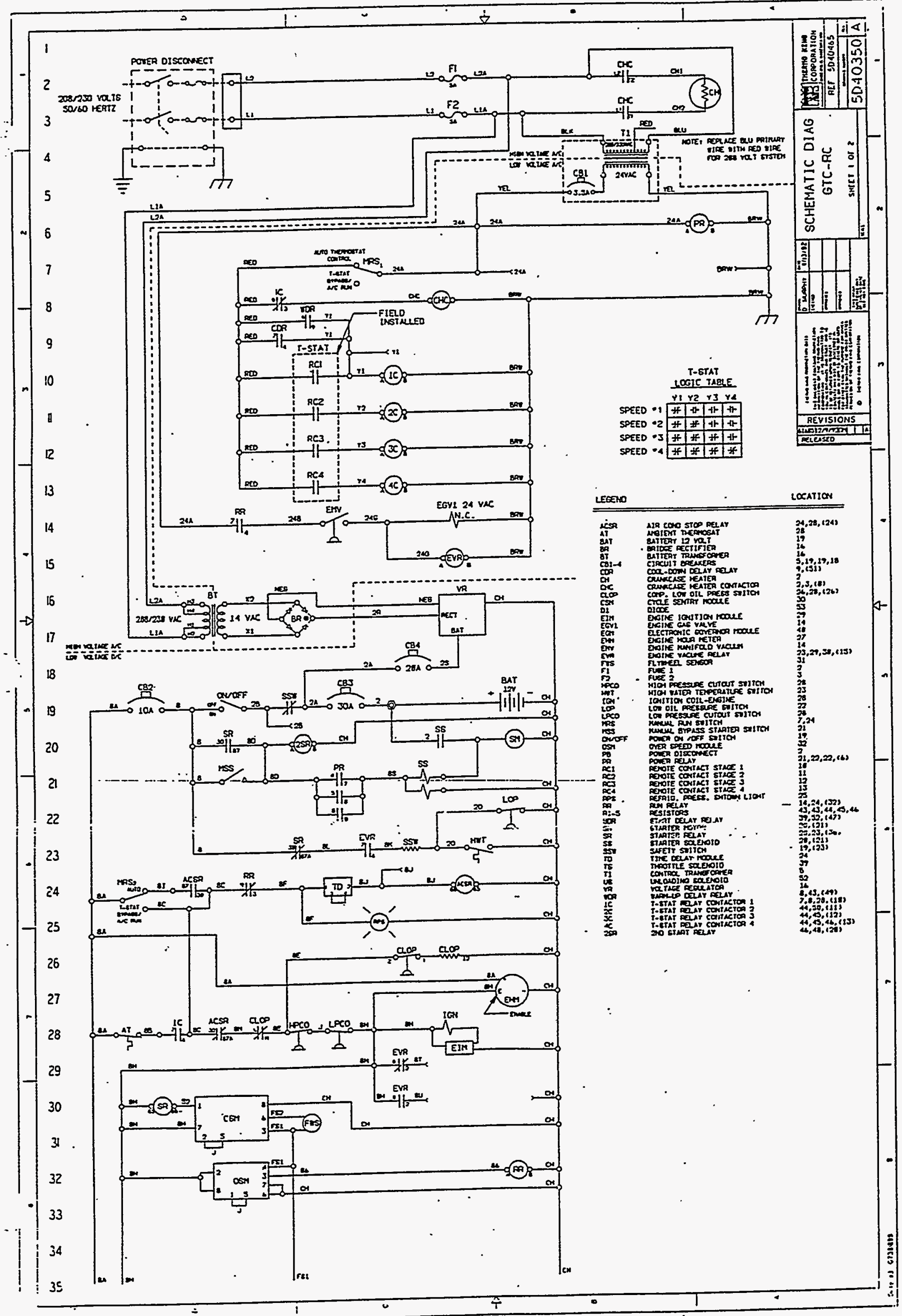




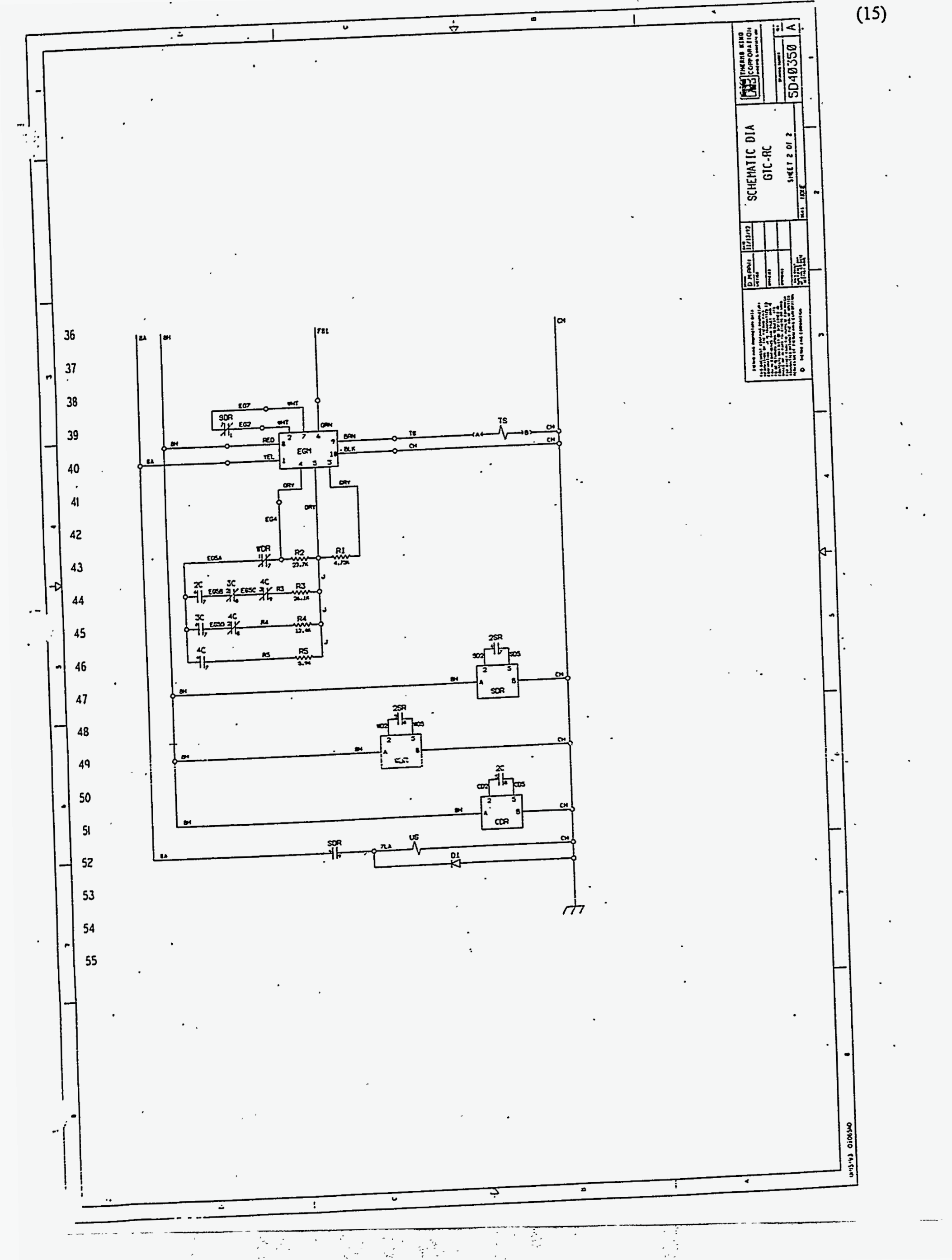




\section{GTC-2. GAS ENGINE CONDENSING UNIT}

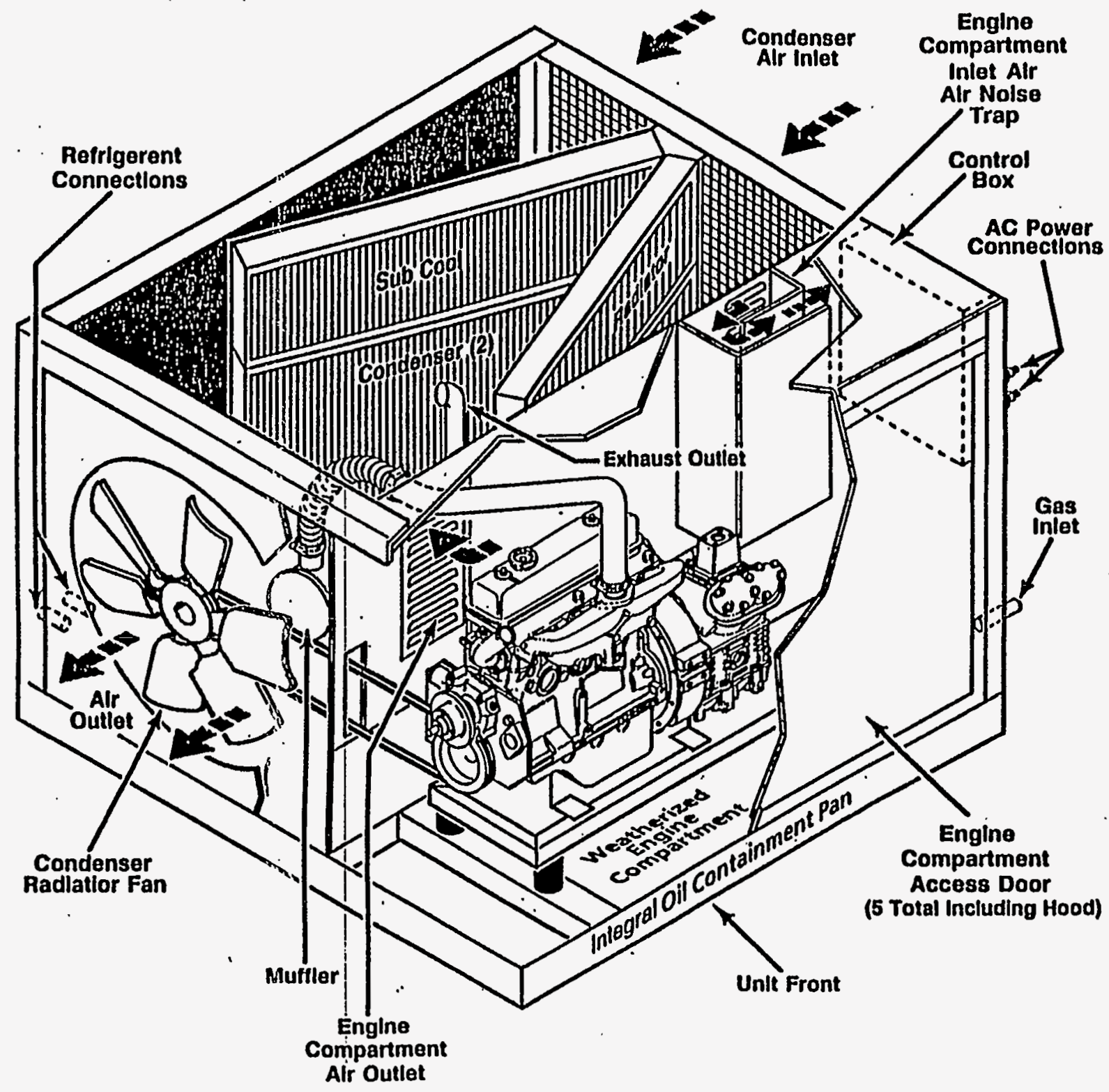




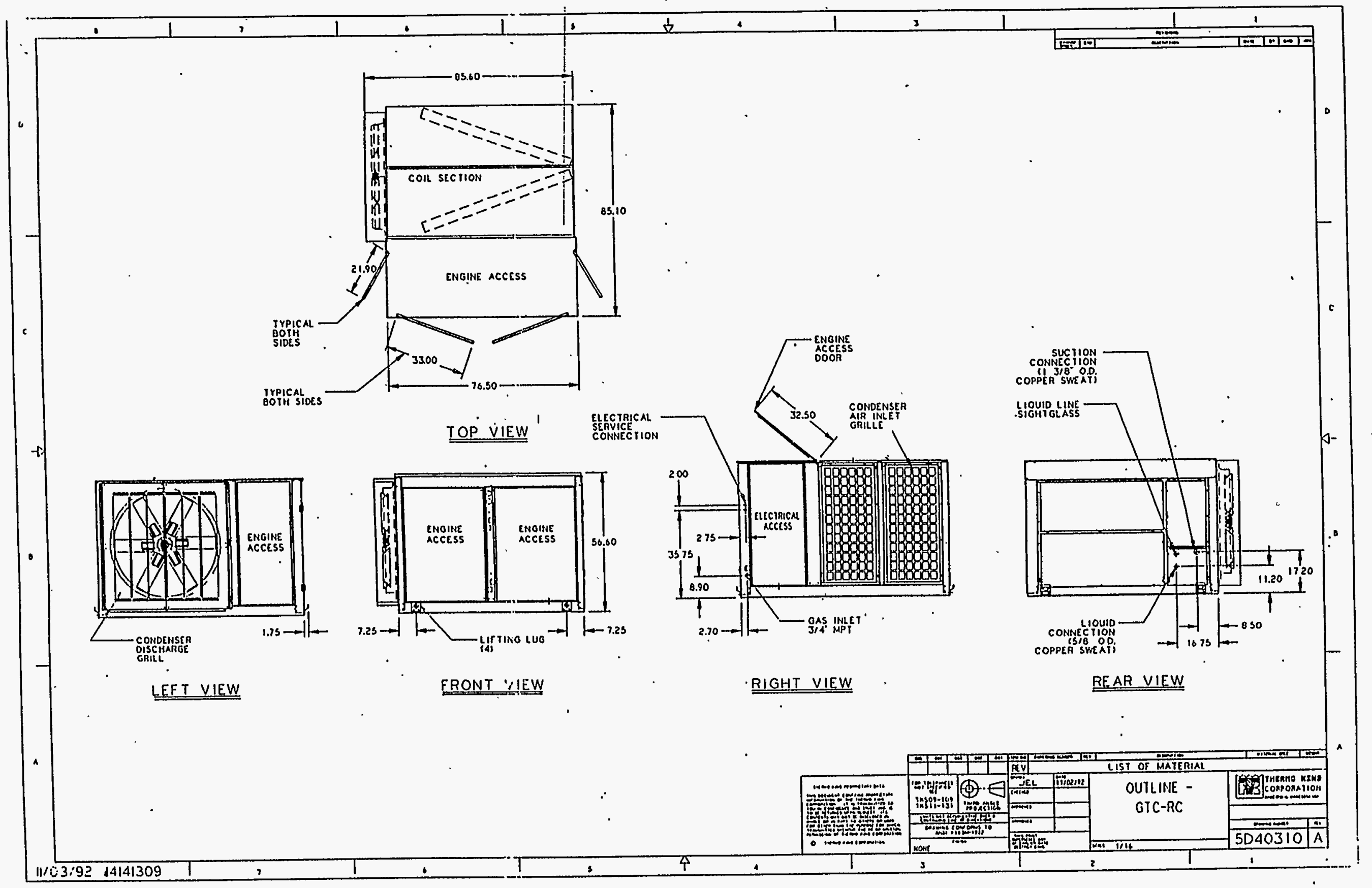




\section{GTC-2 CORNER LOADING}

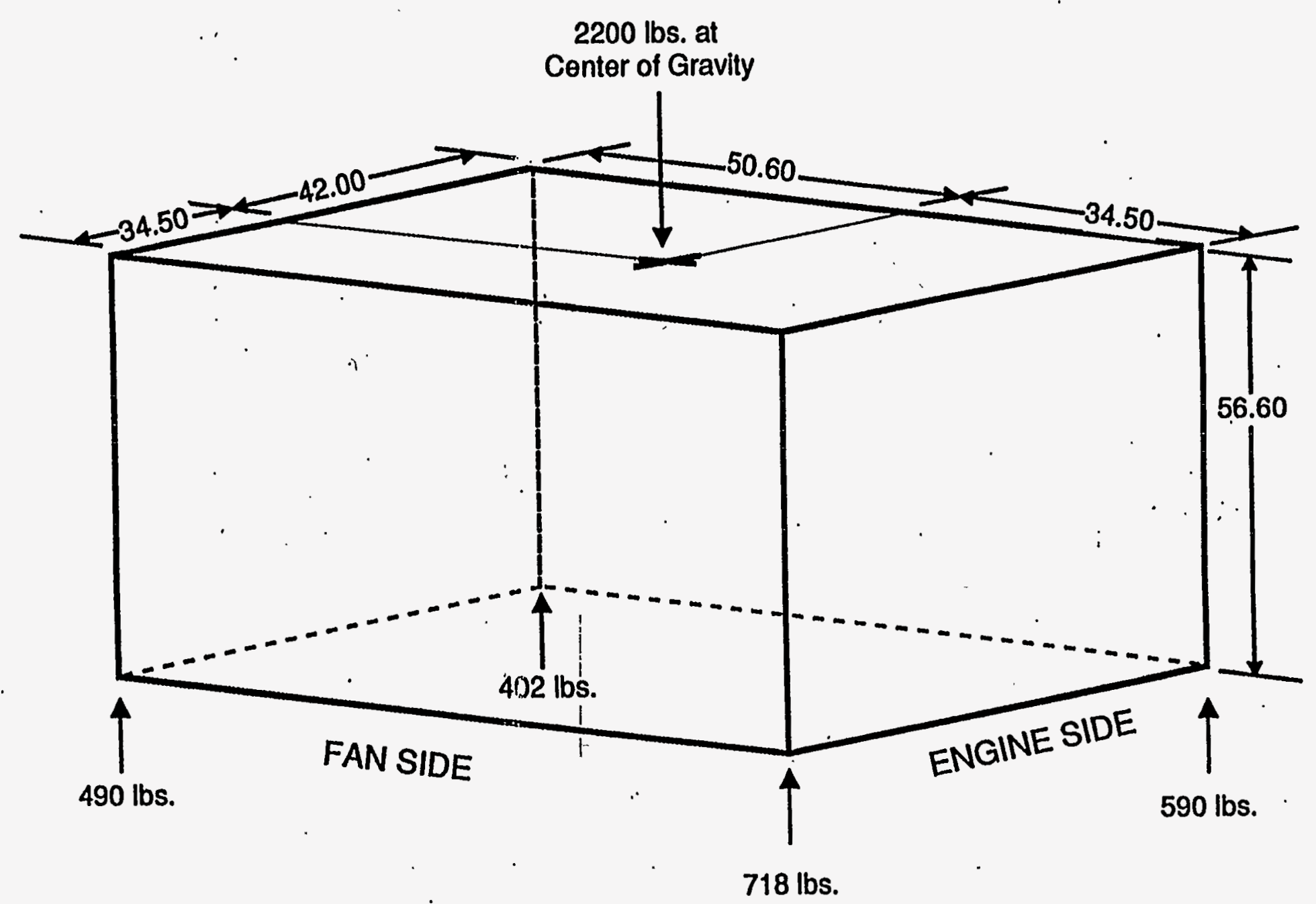

NOTE: Thermo King GTC-2 Corner Welghts (with flulds) 


\section{[T] $\mathbb{C}-2$

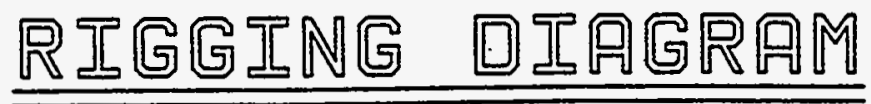

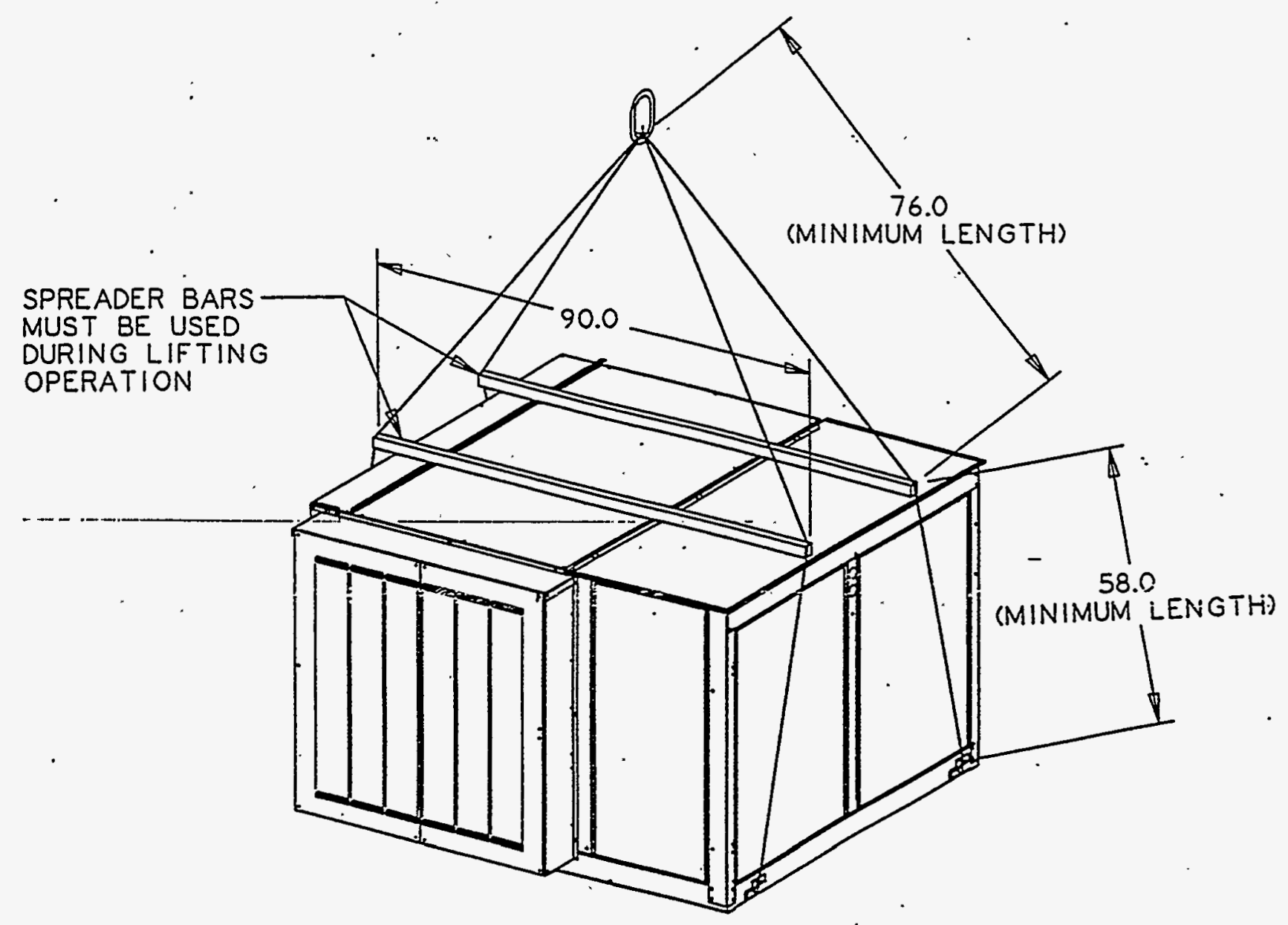


FQRRLIET DETIIL
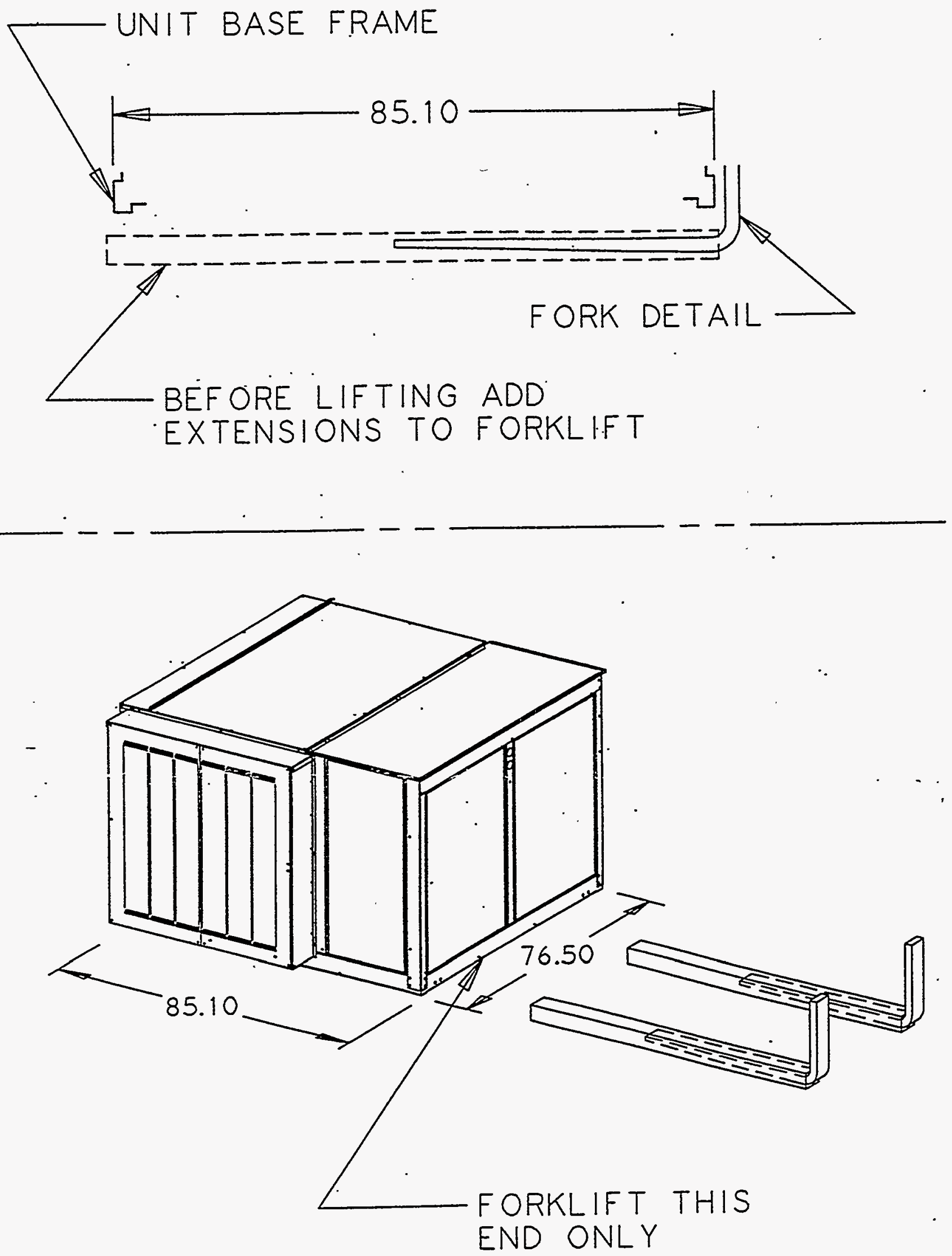


\section{GTC - 2 COP VS. AIR CONDITIONING CAPACITY}

\begin{tabular}{|c|c|c|c|}
\hline $\begin{array}{c}\text { COOLING CAPACITY (1) } \\
\text { BTU/HR }\end{array}$ & $\begin{array}{c}\text { ENGINE/COMPRESSOR } \\
\text { RPM }\end{array}$ & $\begin{array}{c}\text { FUEL CONSUMPTION }{ }^{(2)} \\
\mathrm{MBTU}^{2} / \mathrm{HR}^{3} \\
\left(\mathrm{FT}^{3} / \mathrm{HR}\right) \\
\end{array}$ & $\begin{array}{c}\text { THERMAL }{ }^{(4)} \\
\text { COP }\end{array}$ \\
\hline 182,000 & 2,200 & $\begin{array}{l}325.0 \\
(313)\end{array}$ & 0.56 \\
\hline 149,000 & 1,800 & $\begin{array}{l}240.0 \\
(231) \\
\end{array}$ & 0.62 \\
\hline 124,000 & 1,500 . & $\begin{array}{l}189.3 \\
(182)\end{array}$ & 0.66 \\
\hline 99,000 & 1,200 & $\begin{array}{r}123.3 \\
(118) \\
\end{array}$ & 0.80 \\
\hline \multicolumn{3}{|c|}{ COP IPLV ${ }^{(5)}$} & .74 \\
\hline
\end{tabular}

(1) Rated @ $95^{\circ} \mathrm{F}$ ambient temperature, $50^{\circ} \mathrm{F}$ suction temperature, $10^{\circ} \mathrm{F}$ liquid subcooling, $15^{\circ} \mathrm{F}$ sat. suction super heat.

(2) $1040 \mathrm{BTU} / \mathrm{FT}^{3} \mathrm{HHV}$ natural gas assumed

(3) Includes condenser/radiator fan HP

(4) Thermal $\mathrm{COP}=$ net cooling cap./gas input

(5) IPLV = integrated part load value 


\section{GTC-2 REFRIGERANT PIPING DIAGRAM}

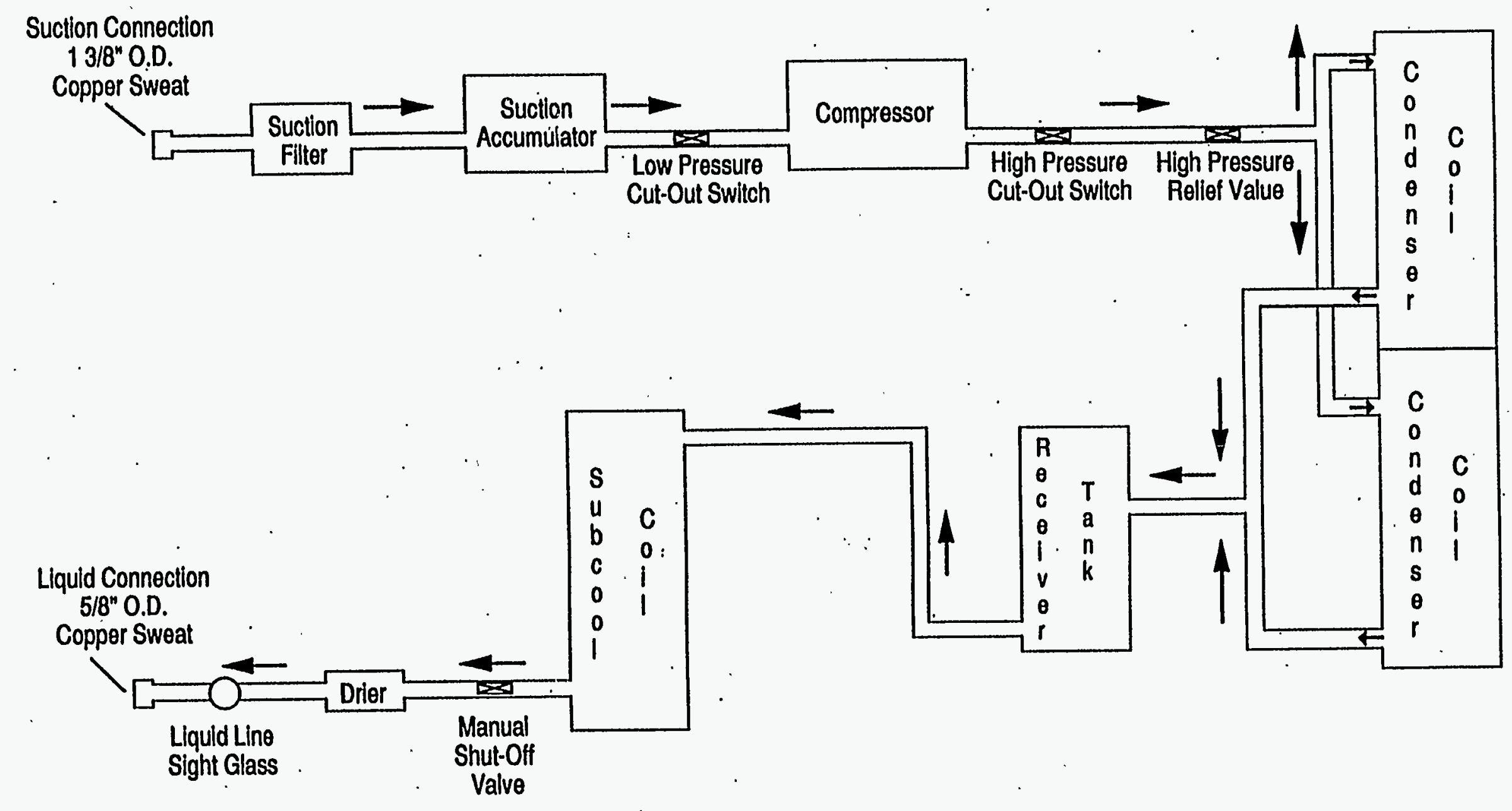

